IZA DP No. 5381

Where Have All the Young Girls Gone? Identification of Sex Selection in India

Sonia Bhalotra

Tom Cochrane

December 2010 


\title{
Where Have All the Young Girls Gone? Identification of Sex Selection in India
}

\author{
Sonia Bhalotra \\ University of Bristol (Economics and CMPO), \\ University of Oxford (CSAE and QEH), CHE (York), CHILD and IZA \\ Tom Cochrane \\ Cambridge Economic Policy Associates, London
}

\section{Discussion Paper No. 5381 \\ December 2010}

\author{
IZA \\ P.O. Box 7240 \\ 53072 Bonn \\ Germany \\ Phone: +49-228-3894-0 \\ Fax: +49-228-3894-180 \\ E-mail: iza@iza.org
}

\begin{abstract}
Any opinions expressed here are those of the author(s) and not those of IZA. Research published in this series may include views on policy, but the institute itself takes no institutional policy positions.

The Institute for the Study of Labor (IZA) in Bonn is a local and virtual international research center and a place of communication between science, politics and business. IZA is an independent nonprofit organization supported by Deutsche Post Foundation. The center is associated with the University of Bonn and offers a stimulating research environment through its international network, workshops and conferences, data service, project support, research visits and doctoral program. IZA engages in (i) original and internationally competitive research in all fields of labor economics, (ii) development of policy concepts, and (iii) dissemination of research results and concepts to the interested public.
\end{abstract}

IZA Discussion Papers often represent preliminary work and are circulated to encourage discussion. Citation of such a paper should account for its provisional character. A revised version may be available directly from the author. 


\section{ABSTRACT \\ Where Have All the Young Girls Gone? Identification of Sex Selection in India*}

This paper presents the first estimates of the causal effect of facilities for prenatal sex diagnosis on the sex ratio at birth in India. It conducts a triple difference analysis across cohort, birth order and sex of previous births. Treated births are those that occur after prenatal sex detection becomes available at birth order two or more in families that have not yet had their desired number of sons (or daughters). The three implied control groups are births that occur pre-ultrasound, births of first order and births that occur after the family has achieved its desired sex mix of births. We identify a significant divergence between the treated and control groups. We consider alternative hypotheses and conduct an array of robustness checks to show that the divergence of the sex ratio of the treated group from the normal biological range that characterizes the control groups is on account of female foeticide. We estimate that as many as 0.48 million girls p.a. were selectively aborted during 1995-2005, which is more than the number of girls born in the UK each year. The estimates suggest that Indian families desire two boys and a girl; previous studies often assume that the desire is for at least one boy. The incentive to conduct sex selection is increasing in birth order and family socioeconomic status, both consistent with stronger incentives to sex-select as fertility approaches its target.

JEL Classification: J13, J16, I18, I38, H40

Keywords: sex selection, abortion, sex ratio, son preference, prenatal sex diagnosis, ultrasound, gender, India, triple difference estimator, differences in differences

Corresponding author:

Sonia Bhalotra

Department of Economics

University of Bristol

8 Woodland Road

Bristol BS8 1TN

United Kingdom

E-mail: s.bhalotra@bristol.ac.uk

\footnotetext{
* We have benefited from presentations at the Reproductive Health Unit of the World Health Organisation (Geneva, July 2009), the Indian Statistical Institute (Delhi, December 2009), the Department for International Development (London, March 2010), CMPO (Bristol May 2010), the European Society of Population Economics conference (Essen, June 2010), the American Society of Health Economics conference (Cornell, June 2010), a CAGE workshop on the Indian Economy at Warwick (July 2010), the Econometrics seminar at Tilburg University (July 2010), the CMPO workshop on Sex Selection and Parental Investments at Bristol and an invited seminar at Aix-Marseille. We received helpful comments from Doug Almond, Prashant Bharadwaj, Avi Ebenstein, James Fenske, Fiona Steele and Frank Windmeijer. The first author acknowledges ESRC-DFID research award RES167-25-0236 which financed Tom's summer internship at Bristol.
} 


\title{
Where have all the young girls gone? \\ On the rising trend in sex selection in India
}

\author{
Sonia Bhalotra and Tom Cochrane
}

\section{Introduction}

For centuries, son preference in India has been expressed in female infanticide (Dickemann 1979) and excess mortality amongst girls and women associated with their endemic neglect (Sen 1990, 1992, Klasen 1994, Mishra et al. 2004, O ster 2009). Male-biased sex ratios were noted, for example, in the first census in 1871 (Visaria 1967). Decades of development have not rectified this imbalance, indeed the all-age population sex ratio (males: females) has drifted upwards through the twentieth century (Bhaskar and Gupta 2007). A more recent phenomenon, which motivates this work, is that the sex ratio at birth has risen sharply since the 1981 census, even as the all-age sex ratio has stabilised. ${ }^{2}$ It is generating an unprecedented demographic squeeze with likely consequences for the prevalence of prostitution and sexually transmitted infections, crime and violence, labour markets and old-age care (Samuelson 1985, Angrist 2002, Hesketh and Zing 2006, Edlund et al. 2007, Ebenstein and Jennings 2009).

We provide the first estimates of the causal effect of the arrival and diffusion of prenatal sex determination techniques (nenceforth, PSD T) on the sex ratio at birth and so the first reliable estimates of the scale of female foeticide. The latter has been fiercely debated following a recent Lancet publication (Jha et al. 2006; see section 1.1). Foeticide is not directly observed. Recent survey data record self reported use of ultrasound and abortion services but reported usage is likely to be understated and, in any case, does not provide a measure of foeticide because both PSDT and abortion services may be accessed for purposes other than sex selection. O ur strategy is to exploit exogenous variation in the arrival and spread of PSDT but, so as to rule out the force of correlated trends, we interact variation in availability of sex diagnosis across cohorts with variation across families in the incentive to conduct sex selection by sex of previous births and birth order. We begin with the premise that families seldom attempt sex selection for first births (this is defended in section 6). Randomness of the sex of the first birth creates a natural

\footnotetext{
${ }^{2}$ In 1971 there were 964 girls for every 1000 boys at birth, which is in the "normal" range. This diminished at an increasing rate over the next three decades, falling to 927 in 2001 (census data). The allage sex ratio in 1971 was more unfavourable, at 932. This fluctuated over the period, returning to 933 in 2001. So the female disadvantage at birth intensified even as the survival of females across the age distribution improved.
} 
experiment in which some families are subject to the "treatment" of having a firstborn girl. This raises their incentive to abort a female foetus relative to untreated families (families with a firstborn son). This incentive grows stronger with parity (birth order) especially as parity approaches the desired number of births (Das Gupta and Bhat 1997, Ebenstein 2010). In this way variation in birth order amongst post-ultrasound cohorts born into families that have not yet realized their desired sex mix of births captures treatment intensity.

Any omitted variables associated with competing explanations would have to exhibit the very specific pattern suggested by the multiple differences that we employ. The focus on differential trends in the sex ratio eliminates hypotheses that predict a male bias in the sex ratio in levels, for example, the prevalence of hepatitis-B (O ster 2005, although see O ster forthcoming, Bhaskar forthcoming) and the tendency for girl births to be under-reported in son-preferring societies (Visaria 1967, Bhat 2006). At the same time, alternative hypotheses that predict trends in the sex ratio would have to also predict systematic differences in the trend by previous sibling sex and birth order in order to bias our estimates. A relevant trend is in the direct impact of ultrasound scans which are increasingly available as an element of prenatal care and used to detect genetic abnormalities or pregnancy problems. Prenatal care and, related, improvements in maternal health witnessed in this period (Bhat 2002) will tend to favour male over female foetal survival because the male foetus is relatively sensitive to prenatal inputs (Waldron 1983, Stinson 1985, Lazarus 2002). Indeed, this has been proposed as a potential explanation of the increasing maleness of the sex ratio at birth in India (Jayaraj and Subramaniam 2004). It is clearly pertinent to identify whether the trend in the sex ratio is a result of more boys surviving to birth or of more girls being killed before birth. Improved maternal health and prenatal care are increasingly recognised as essential if neglected legs of development, producing long term gains to health, cognitive attainment and earnings (Almond 2006, Black et al. 2007, Almond and Mazumder 2009, Bhalotra and Rawlings 2010). In contrast, widespread female foeticide raises a host of difficult ethical and policy issues concerning medical science and ethics, the legalization of abortion and tensions in the status of women and girls in the process of economic development. O ther trends that may alter the incentive to sex select include dowry inflation (Anderson 2003) and the recent appearance of state programmes providing financial incentives to families with girls (Sinha and Yoong 2009). All of these trends are captured by the main effect of time in the estimated model which is flexibly modeled with year dummies and state specific trends. In sum, our empirical strategy identifies sex selective abortion from the coefficient on a triple interaction while allowing alternative hypotheses to exert their influence through the main effects in the model. Previous studies, whether set in India or elsewhere, have tended to investigate either 
trends in the average sex ratio or cross-sectional differences in the sex ratio, the latter often by either the sex of previous births or birth order. Previous studies analysing trends tend to use data restricted to post-ultrasound cohorts, making it difficult to identify the impact of ultrasound; see section 1.1, where we also delineate other innovations in this paper.

We use nationally representative microdata on more than 0.5 million births that belong to pre and post PNDT cohorts in the period 1972-2005. The data contain the complete birth histories of more than 0.2 million mothers. Simple mn-parametric plots of the data provide compelling evidence of sex selection, which persists in parametric estimates that control for the play of alternative drivers of the sex ratio. A significant negative trend in the probability that a birth is a girl emerges for post-ultrasound cohorts at birth order two in families with a first-born girl. The divergence of this trend from the relatively stable sex ratio of pre-ultrasound cohorts, first births and families with a first-born boy is larger at birth orders three and four and increases with time in line with exogenous changes in the aggregate supply of PSDT. A generalization of the specification of previous sex composition suggests that Indian families desire two sons and one daughter. Previous work often implicitly assumes that families want one son, consistent with a vast literature documenting reasons such as that parents live with sons in their old-age, Hindu rituals require that the son lights the parent's funeral pyre, and primogeniture. It is less well known that Indian families often want two sons, possibly to cover for the risk of the one dying or exhibiting filial non-allegiance. The deviations of the sex ratio from the biologically normal level amongst "treated" families are large. For example, relative to pre-ultrasound births in 19721984 and to families with only boys at each birth order, the estimated girl deficit in 1995-2005 in families with no boys is 3.1, 4.9 and 4.8 percentage points (henoforth ppt) at orders two, three and four respectively. In families with one boy it is $2.2 \mathrm{ppt}$ and $3.1 \mathrm{ppt}$ at orders three and four respectively. Based upon a comprehensive examination of first to fourth order births, we estimate that as many as 0.48 million girls per annum were selectively aborted during 1995-2005. This is 3.0\% of potential second to fourth order births in India and $6.2 \%$ of potential female births. It is more than the number of girls born in the UK each year (which is about 0.35 million). The scale of the problem is enormous because some 27 million babies are born in India each year. This is more than the number born in all of Sub-Saharan Africa (which has higher fertility but a smaller population) and more than the number born in China (which has lower fertility and a larger population).

The estimates are subject to an array of specification checks. The assumption that sex selection is not conducted amongst first births is closely examined, we investigate selection on unobservables and allow heterogeneity in treatment effects. The estimates allow for unobserved 
heterogeneity (across mothers) in the sex of their births and are extended to allow state dependence (within mothers) in child sex. We construct a placebo test that exploits the timing of the processes of sex detection, abortion, re-conception and birth. On the grounds that it is the sex composition of surviving siblings that will influence the decision to sex select for the index birth, detailed information on the age at death of all births in the sample is used to adjust previous sibling sex for survival up until conception of the index birth. Self-reported use of ultrasound scans for recent births is exploited in a further check. The baseline estimates are, in general, very robust. There is evidence of heterogeneity in the treatment effects although this appears to be uncorrelated with the treatment, indicating that the simple linear model delivers a consistent asymptotically normal estimate of the average treatment effects (Wooldridge 2002: $68)$.

For a given sex history of births, substantially more sex selection was conducted postultrasound by families with wealth (top 20\%) and relatively educated women (attaining at least secondary education) and, conditional on wealth and education, by Hindus as compared with Muslims. The much cited differences in "son preference" (or its expression) between the Northwest and the South of India and between high and low caste groups (see section 5) are apparent in the raw data but are insignificant conditional upon controls for the wealth, education and religion composition of these groups. This is the first result in the literature that shows that these entrenched differences often bundled into the residual we call culture may be explained by the demographic composition of these groups; although a role for culture remains via religion. The finding that educated women are more actively eliminating unborn girls is striking and discussed further in section 5. The finding that missing girls are increasingly concentrated in relatively prosperous households challenges the popular notion that the exercise of son preference is a marker of economic backwardness and ignorance (e.g. The Economist magazine, March 2010), as does the prevalence of sex selection amongst relatively wealthy Indian immigrants in North America and Britain (next section). It stands in (apparent) contrast to economic models of son preference that describe the exercise of son preference as a function of liquidity constraints, which are more likely to bind amongst the poor (Behrman and Deolalikar 1989, Rose 1999). Importantly, it implies that sex selection is distributed such that girls are disproportionately being born into poorer households, so that even if investments in sisters and brothers are equal, the average girl will tend to fare worse in the longer term. This has not been previously recognized. ${ }^{3}$

3 What has been previously recognized, pre-ultrasound, is that fertility stopping rules result in households that initially have girls growing larger. To the extent that larger households are poorer, girls will then 
The following section provides an overview of the related literature, delineating our contributions. Relevant economic, legal and technological developments are detailed in the Appendix. The methodology is described in section 2 and the data in section 3. The results are presented in section 4. Section 5 investigates robustness and extensions, discusses identifying assumptions and explores the potential hold of alternative hypotheses. Section 6 concludes and discusses some of the implications of the findings.

\section{Related Literature}

This section first reviews related studies for India, arguing that there are no previous causal estimates of the impact of availability of prenatal sex detection on the sex ratio at birth. It then delineates the methodological contributions that this paper makes in the wider domain.

While awareness of sex selection in India is now widespread (The Economist, March 2010), even fairly recent studies of gender-biased investments in Indian children make no adjustment for it (e.g. Barcellos et al. 2010), possibly because its scale is under-estimated (e.g. Oster 2009: pp.15-16). For example, the latter study argues that "families may not have strong enough preferences to move to sex selective abortion but may still engage in less immediately obvious forms of discrimination such as lack of vaccination". This underlines the importance of estimating the scale of female foeticide. This is difficult. Some recent studies for India use information on self-reported use of ultrasound scans or abortion (Arnold et al. 2002, Arnold and Parsuranam 2009) but, for the reasons stated in section 1, their estimates are inaccurate (which they recognise). In possibly the most cited study for India, Jha et al. (2006) analyse the conditional sex ratio using a cross sectional survey conducted in 1998. Since the phenomenon of interest is a trend in the sex ratio cross-sectional data for a single post-ultrasound year present a major limitation. Moreover, their data appear to be flawed and the authors' estimation of the number of missing girls has been passionately debated. ${ }^{4}$ Retherford and Roy (2003) compare the

come from poorer households on average (Ahmad and Morduch 1993). Post-ultrasound, sex selective abortion substitutes for continuation of fertility. We show that it more directly produces a similar outcome.

4 Jha et al. use the (one-off) Special Fertility and Mortality Survey of $0.133 \mathrm{~m}$ births. The average ratio of boys to girls at birth in their survey is much higher than in administrative data (Bhat 2006). Further, analysis of these data by Jha et al. indicates an implausibly large scale of (a) abortion of boys at second birth and of (b) abortion of girls at first birth, both of which are at odds with administrative data and with the survey data we analyse. Amongst critiques of the Lancet paper are Bhat 2006, George 2006, Grover and Vijayvergiya 2006, Bardia and Anand 2006, Bhopal 2006, Sheth 2006, Bhalotra and Cochrane (in progress). We come up with a very similar number of abortions ( $\sim 0.5$ million p.a.) in 1995-2005 as they estimate for 1997. However in a paper that concentrates on simulation issues (Bhalotra and Cochrane, in progress) we show that this is a coincidence flowing from a chance cancelling of two sorts of errors (data and simulation) in the Lancet paper. In particular, we demonstrate that applying our method to the estimated coefficients in Jha et al. doubles the estimated number of missing girls in 1997 (section 6 below and appendix Table 4b). 
average sex ratio in 1978-92 and 1984-98 showing a rise between the periods. However their data contain no pre-ultrasound regime and there is an overlap of several years in the two periods that are compared. These are the few microdata analyses. O verall, while aggregate trends in the sex ratio in India have been vastly documented (Bhat 2002, Das G upta 2005, Visaria 2005, Guilmoto 2008), no previous study attempts to estimate the causal impact of PSDT in India and there are no reliable estimates of the scale and distribution of "missing girls" at birth.

In the wider domain are a number of studies of sex ratio trends in China, Korea, Taiwan and amongst Asian immigrants in the UK, US and Canada. These studies indicate sex selection based either upon coss-sectional conditional sex ratios at birth (Almond and Edlund 2008, Abrevaya 2009, Almond et al. 2009) or upon differences in average sex ratio trends by birth order (D ubuc and Coleman 2007, Lin et al. 2008, Abrevaya 20095). Authors of both approaches analyse samples that contain no pre-ultrasound cohorts. The one other study we are aware of that uses pre and post ultrasound cohorts to achieve causal effects is Chen et al. (2010). They use county-level information from China on ultrasound availability in interaction with either birth order or an indicator for whether the family has any boys. The evidence suggests sex selection in China at second and third birth and in the US, UK and Taiwan at third birth.

This paper makes the following contributions. As indicated above, this paper provides the only causal estimates of the impact of ultrasound on the sex ratio at birth in India. This is important in understanding the process driving recent trends and in estimation of the scale of the problem. India contrasts with China in having had no regulation of fertility by the state. It contrasts with all previous studies in the wider literature in invoking a treatment effects framework and scrutinizing identifying assumptions and alternative hypotheses. It is the first to employ a triple difference, which permits a more decisive elimination of alternative processes. It investigates unobserved heterogeneity and state dependence in child sex and allows for heterogeneous treatment effects consistent with, for example, a distribution of son preference in the population. This is not only of statistical but also of substantive relevance as response heterogeneity reveals in which socioeconomic and religious groups the preponderance of boys is. Given limited intergenerational mobility, this has implications for the resources with which the average live girl is being raised and for labour and marriage market consequences of the girl deficit. Estimates of the distribution of sex selection across identifiable social groups is helpful for policies targeting elimination of this problem. This paper further differs from any previous in exploring the impact of adjusting previous sibling sex composition for survival up until

${ }^{5}$ A brevaya (2009) analyses birth order trends for the US. He uses an alternative data set for California to analyse cross-sectional conditional sex ratios. Both samples contain cohorts that are all born after the arrival of ultrasound. 
conception of the index child. Also, while earlier work tends to use summary indicators of previous sibling sex such as the sex of the first child or an indicator for not having had at least one son, we use a comprehensive specification. This allows estimation of the role of birth order independently of the role of previous sex composition, relevant to testing the hypothesis that sex selection intensifies at the parity that corresponds to target fertility (eg. Ebenstein 2010). It improves identification by exploiting differences in sex selection across birth order amongst treated families, analogous to a measure of treatment intensity. It allows us to detect the sibling sex composition at which boy abortion may occur, if at all, which is relevant to accurate simulation of the number (and the distribution across birth order) of girl abortions. It also provides insight into the extent to which families will perform sex selection to achieve two boys rather than just one (as typically assumed), and this implicitly indicates the average desired family size and composition in India. Our methodological contributions are made clearer in the following section.

\section{Methodology}

The empirical phenomenon that motivates this work is the consistently increasing maleness of the sex ratio at birth in India since 1980. The sex ratio at birth can rise either because there is a trend in the sex ratio at conception or because there is a trend in the ratio of male to female foetal survival. The latter can, in turn, arise either because improvements in foetal survival favour males or because improvements in technology facilitate female foeticide. This paper tests the latter hypothesis using a triple difference estimator. As discussed in section 1, the former is controlled for by the main effects in the model. The manner in which the individual decision to use prenatal sex diagnosis and then abort births of the unwanted sex creates systematic variation in the observed sex ratio is formalised in the Appendix. We first detail the structure of the empirical model (sections 2.1-2.4) and then explain how we model the arrival and diffusion of ultrasound (section 2.5). We discuss double difference specifications before developing the triple difference specification. This helps make precise our contributions relative to previous studies. We use the linear probability estimator. The mean of the dependent variable is close to 0.5 , there are no predictions outside the [0,1] interval and probit marginal effects are almost identical. Standard errors are robust to arbitrary forms of heteroskedasticity and adjusted for serial correlation and non-independence at the state level (see Hansen 2007). This is more general than clustering at the mother or village level.

\subsection{Two double differences}

We are interested in modelling $y_{i j t}$ the probability that a birth of order $i$ born of mother $j$ in year $t$ is a girl. Let $Y_{j}$ indicate the sex of the first born child of mother $j, 1$ if female and 0 otherwise. 
On the premise that there is no sex selection amongst first births, $Y_{j}$ is a randomly assigned treatment motivating sex-selection in families "treated" with a first born girl. But this can only be realised if there is access to prenatal sex determination. Using information on the arrival of ultrasound, we construct a dummy "post". So as to reflect a further shock to aggregate availability, we divide the post-ultrasound regime into two periods; this is discussed below. The causal effect of ultrasound, $\beta_{0}$, can be obtained from the double difference specification-

(1) $\mathrm{y}_{\mathrm{ijt}}{ }^{*}=\alpha_{0}+\left[\mathrm{Y}_{\mathrm{j}}{ }^{*} \text { post }\right]^{\prime} \beta_{0}+\mathrm{Y}_{\mathrm{j}}^{\prime} \gamma_{0}+?_{0 \mathrm{t}}+\mathrm{f}_{0 \mathrm{~s}} \mathrm{t}+\mathrm{e}_{\mathrm{ojit}} ; \mathrm{y}_{\mathrm{ijt}}=1$ if $\mathrm{y}_{\mathrm{ijt}}{ }^{*}>0$ and 0 otherwise

The hypothesis predicts $\beta_{0}<0$ or that post-ultrasound and only post-ultrasound, parents who are assigned a girl at first birth are more likely to abort subsequent female conceptions with the consequence that the probability of a girl following a girl is significantly smaller than the probability of a boy following a girl. We control for the main effects of first born sex $\left(\mathrm{Y}_{\mathrm{j}}\right)$ and post $_{t}$ generalised as year dummies $\left(?_{0 t}\right)$ and state specific trends $\left(f_{0 .} . t\right) . \alpha_{0}$ is the proportion of females amongst first births. Discussion of alternative processes that may be at play, motivating the main effects, is in the next section. Previous studies of the conditional sex ratio have tended to regress $\mathrm{y}_{\mathrm{ijt}}$ on $\mathrm{Y}_{\mathrm{j}}$, implicitly invoking the restriction $\gamma_{0}=0$ (Jha et al. 2006, Almond and Edlund 2008, Abrevaya 2009). We are able to test this restriction by introducing ultrasound as a further treatment that changes the relationship between $y_{\mathrm{jit}}$ and $Y_{\mathrm{j}}$. We estimate an alternative specification in which the difference is across time and birth order rather than time and first born sex. D enoting birth order $\mathrm{d}_{\mathrm{i}}$,

(1a) $\mathrm{y}_{\mathrm{ijt}}^{*}=\alpha_{1}+\left[\mathrm{d}_{\mathrm{i}}^{*} \text { post }_{\mathrm{t}}\right]^{\prime} \beta_{1}+\mathrm{d}_{\mathrm{i}}^{\prime} \gamma_{1}+?_{1 \mathrm{t}}+\mathrm{f}_{\mathrm{s} .} \mathrm{t}+\mathrm{e}_{\mathrm{ij \textrm {t }}} \quad ; \mathrm{y}_{\mathrm{ijt}}=1$ if $\mathrm{y}_{\mathrm{ijt}}{ }^{\prime}>0$ and 0 otherwise

As first births are captured by the equation constant, we expect $\beta_{1}<0$ or that second and higher order births conceived post-ultrasound are less likely to be female on average. Previous studies have studied trends in the average sex ratio by birth order but for samples that contain no preultrasound cohorts (D ubuc and Coleman 2007, Abrevaya 2009). Their specifications effectively contain "time" where we have "post" and so are unable to conclusively tie trends in birth order to sex selection. We argue that birth order trends may be driven by variables other than ultrasound access and account for this in controlling for the main effect of time (using a flexible specification of year fixed effects and state trends in place of the dummy post t). $^{\text {. }}$

\subsection{Triple differences}


Specifying $Y_{j}$ as the sex of the first born child of mother $j$ provides a clean estimate of sex selection at birth order two. However for higher birth orders, it omits sibling sex composition between the first and the index child. We therefore generalise the specification to a vector $Y_{i j}$ which comprehensively represents the sex composition of births of mother $j$ born prior to the index birth i. For second order births, $Y_{\mathrm{ij}}$ is either "girl" (g) or "boy" (b). For third order births, it is two girls (gg), a girl and a boy (gb) or two boys (bb) and, similarly, for fourth order births, it is ggg, ggb, gbb or bbb. ${ }^{6}$ Every child in the sample appears as an independent observation, so a family with three births will contribute three rows. ${ }^{7}$ Sibling sex composition is now defined jointly with birth order. In order to make birth order explicit, we shall write $Y_{i j}=Y_{j}^{*} d_{i}$ where $d_{i}$ is a dummy for birth order i. Then the estimated equation is

(2) $\mathrm{y}_{\mathrm{ijt}}{ }^{*}=\alpha+\left[\mathrm{Y}_{\mathrm{j}}{ }^{*} \mathrm{~d}_{\mathrm{i}}^{*} \text { post }_{\mathrm{j}}\right]^{\prime} \beta+\left[\mathrm{Y}_{\mathrm{j}}{ }^{*} \mathrm{~d}_{\mathrm{i}}\right]^{\prime} \gamma+\left[\mathrm{d}_{\mathrm{i}}\right.$ post $_{\mathrm{j}} \mathrm{p}^{\prime} \mathrm{p}+\mathrm{d}_{\mathrm{i}}^{\prime} \mu+?_{t}+\mathrm{f}_{\mathrm{s}} \mathrm{t}+\mathrm{e}_{\mathrm{jit}}$

We are now exploiting a triple difference. Both ultrasound availability and the sex of previous births act as treatments and it is convenient to think of birth order as capturing treatment intensity. As long as there is a positive cost to having an additional birth, the incentive to engage in sex selective abortion will tend to increase with parity in families that have not yet had a son. The treatment variable, $Y_{j}{ }^{*} d_{i}^{*}{ }^{*}$ post, is a vector because $Y_{j}{ }^{*} d_{i}$ is a vector of mutually exclusive binary treatment indicators. Each index birth is subject to one and only one treatment. There are three control groups- first order births, births that occurred before ultrasound became available and families that have had their desired sex mix of births.

The model includes controls for all two-way interactions and main effects. Mechanically, we may expect to see in equation (2) two further terms, the two-way interaction, $Y_{j}^{*} *(t)$ and the main effect, $Y_{j}$ but these are in fact identical to $Y_{j}{ }^{*} d_{i}{ }^{*} f(t)$ and $Y_{j}{ }^{*} d_{i}$ which are included. This is because $Y$ is inherently inseparable from $d$. Even if $Y$ cannot be detached from $d, d$ can be defined independently of $Y$. The main effect of birth order, $\mu$, allows for a systematic variation of index gender with order. Birth order specific trends $\mathrm{d}_{\mathrm{i}} \mathrm{f}(\mathrm{t})$ can be accommodated by dropping one element of $Y_{j}$ at every order but their only impact is to reconfigure the coefficients $\beta$. As

\footnotetext{
6 These variables are set to zero for birth orders to which they do not apply. For example, one of gg, go and bb is "activated" when the index birth is the third in the family and they are all set to zero when the index birth is the first, second or fourth in the family.

${ }_{7}$ Consider a family $\mathrm{j}$ in which the first birth is a girl, Rhea, born in 1995. She will appear as $\mathrm{y}_{1 j(1995)}=\alpha+$ $u_{1(1995)}$. Two years later, she is followed by a boy, Anav. Anav's sex is allowed to depend upon the sex of

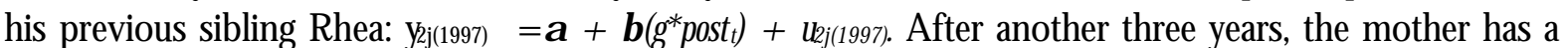
third birth, a boy, Hari, whose sex is modelled as a function of the sex of his siblings, Rhea and Anav: $y_{3 j(2000)}=\alpha+\beta\left(g^{*} p_{0 s t_{t}}\right)+u_{3 j(2000)}$.
} 
before, $Y_{j}$ is set to zero for first births. Previous studies have used summary indicators for first borm sex or for the families having had no boys before the index birth. But the chances that the family has had no boy clearly decline with birth order. Also, as we shall see, families may have had one boy but still sex select in the hope of having two.

We expect the vector of coefficients $\beta$ to show that the probability of a female child at birth orders two and above declines post-ultrasound, this decline is only evident if the family has not realized its desired sex mix of births and the difference in trend between families with and without their desired sex mix is increasing in birth order. The identifying assumption is that the difference in the trend in the sex ratio for families without their ideal sex composition of births relative to families with and relative to families of first birth order is on account of sex selective abortion. In section 5 we extend to a fourth difference in allowing heterogeneous treatment effects.

\subsection{Unobserved heterogeneity and state dependence}

The assumption that the sex of the first born child is randomly assigned defends consistency of the estimates for index births of order two. However unobserved heterogeneity has the potential to bias the estimates for birth orders three and upwards. Heterogeneity in child sex across families is held constant (see the following section). The likely unobserved heterogeneity is in son preference and attitudes to abortion. For instance, amongst families "treated" by the assignment of a first-born girl, families with relatively positive tastes for sons and abortion are more likely to conduct sex selection for their second birth. The proclivity to select is then a persistent omitted variable that may be correlated with regressors describing the sex of second or higher order births. ${ }^{8}$ We investigate this. We further allow unobserved heterogeneity to interact with the treatment. If there is a distribution of son preference (or attitudes to abortion) in the population then it seems plausible that this will create heterogeneous responses, $\beta_{\mathrm{j}}$ across mothers. However, as long as the treatment variable, $Y_{j}{ }^{*} d_{i}^{*}{ }^{*}$ post is orthogonal to preferences, $\beta$ are the average treatment effects (e.g. Wooldridge 2002: 68). We also investigate this. Results are presented in section 5, where we also show estimates that allow for state dependence in sex within family and discuss a number of other robustness checks and extensions. O ur concerns apply equally to previous studies that estimate conditional sex ratios. $\mathrm{O}$ ur checks provide insight into the empirical relevance of previous neglect of these concerns.

8 For example, amongst families having their third birth, those with previous sex composition go may be more likely to have conducted sex selection in the post-ultrasound period than those with previous sex composition gg. 


\subsection{Alternative hypotheses and the main effects}

To motivate the triple difference estimator, consider processes other than sex selective abortion that are absorbed by the main effects and secondary interactions. If there were an innate tendency for gender to cluster within families, that is, if some mothers had a proclivity to bear sons and others to bear daughters, then the sex of the first child would have some predictive power for the sex of the index child irrespective of sex-selection. There is limited evidence of within-family clustering in child sex; see, e.g., Edwards 1970, Clutton-Brock and Iason 1986, and Rodgers and D oughty 2001, who analyse data on white families in the USA, amongst whom sexselection is likely to be limited. However if there were any correlation in our data it would be captured by the main effect $Y_{j}$. Just as previous sibling sex may have a direct effect on index gender, so might birth order $\left(d_{i}\right)$; this is again allowed for. ${ }^{9}$ The reason it is important to control for the main effect of post $t_{t}$ is that the growing availability of ultrasound may have a direct effect on $\mathrm{j}_{\mathrm{jit}}$ because it helps detect pregnancy problems, to which the male foetus is more likely to succumb (see section 1). Controlling for the main effect of ultrasound also removes the concern that its diffusion reflects not only supply but also demand factors. The post-ultrasound period was one of momentous change in India. Education and income registered sharp growth and fertility declined (see the Appendix). So as to capture all relevant secular changes including trends in maternal health and income, we have generalised the functional form of the main effect of time by replacing post $t_{t}$ with cohort fixed effects ${ }_{t}$ and state specific trends, $\mathrm{f}_{\mathrm{s}}$.

\subsection{Timing}

The onset of economic liberalization in India is dated at or around 1981 (Virmani 2004). This has involved progressive relaxation of restrictions on imports and foreign investment and the dismantling of the industrial licensing regime. There was a sharp acceleration of these reforms in 1991 and again in 1993/ 4 (Basu and Maertens 2007, and references therein). The first private clinic offering sex determination is thought to have appeared in 1982-83 (Sudha and Rajan 1999). After that supply increased at an increasing rate, fuelled by imports and the growth of local production. In the mid-1990s large scale local production of ultrasound scanners was initiated by

\footnotetext{
9 This can arise because birth order is correlated with mother's age at birth which in turn reflects her physiological fitness for child bearing (e.g. Lazarus 2002, Almond and Edlund 2007) or, conditional on her age at birth, depletion of the mother from having had many births is likely to be a function of birth order. In both cases, if males are more resource-sensitive than females (e.g. Waldron 1983) then higher order births may be less likely to be male, other things equal. This goes against the prediction of the sex selection hypothesis that maleness of the sex ratio is increasing in birth order (driven by families with zero or one previous boy). What matters for identification is that if birth order does have a direct effect (of whatever sign) it is held constant. There are myriad other biological and evolutionary influences on the sex ratio but these tend to create changes of relatively small magnitude.
} 
$G$ eneral Electric and other multinational firms in joint ventures with Indian firms (G rover and Vijayvergiya 2006, Mahal et al. 2006, Miller 2001, Murthy et al. 2006). Government data show that the number of ultrasound machines manufactured in India increased 15-fold between 1988 and 2003 with especially marked increases after 1994 (G rover and Vijayvergiya 2006, Murthy et al. 2006, G eorge 2006). ${ }^{10}$ Ultrasound scans dominate prenatal sex determination as they are relatively cheap and non-invasive. The technology is continuously improving, providing finer resolution of the foetal image earlier in pregnancy, and the scanners are growing smaller and more mobile.

Nonparametric plots and flexible parametric specifications identify 1985 as a break point in the trend of the average sex ratio at birth. We therefore define pre-ultrasound as 1972-1984 and post-ultrasound as 1985-2005. Consistent with the evidence of sharp increases in supply following the acceleration of economic reform in the early and mid-90s, the data suggest a further break point in 1995. So as to model the process of diffusion, we divide the post-

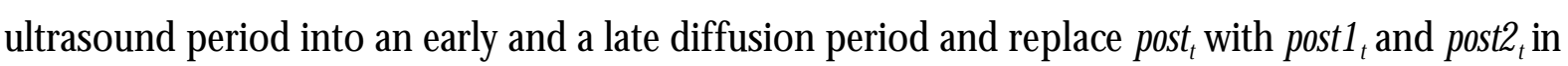
equation (2). Small variations in the thresholds of the three periods create small changes in the coefficients in a direction that is consistent with increasing sex selection over time but the overall findings are not sensitive to the definition of periods. The period indicators are effectively clubbed time dummies, and the wide intervals for each period help minimize measurement error and sampling variation in the data. This specification delivers tests of the significance of differences in the conditional sex ratio across periods. We expect no divergence of the sex ratio by previous sibling sex or birth order pre-ultrasound, and we expect increasing divergence between the early and late diffusion periods. To allow for underlying trends within each period (and in a later specification that includes covariates, for the coefficients on covariates to change by period), we estimate the model by period -

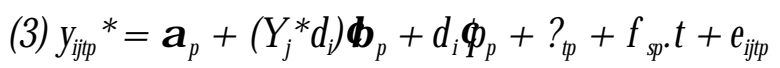

\footnotetext{
10 Aggregate data on the total number of scanners in India show that production increased fivefold in the early 1990s and then almost doubled every three years. Between 1991-94 and 2000-03, the number of scanners imported and the value of these imports both increased 6.4-fold. The numbers increased from 742 to 4733 and the value increased from Rs 388.6 million to Rs 2477.5 million (Mahal et. al. 2006). Local production also grew sharply in the mid-90s after General Electric Healthcare (headquartered in the UK) initiated a joint venture with the Indian multinational Wipro Ltd. Foreign multinationals have competed for space in India's growing market for ultrasound. Important suppliers include Toshiba, Siemens, Philips and Mindray International Medical, a Chinese company.
} 
The triple difference estimator is the difference in $\beta_{\mathrm{p}}$ across periods. ${ }^{11}$ In a further specification, we introduce a vector of other covariates $c_{i j}$, each defined as an exhaustive and mutually exclusive set of indicators for state of residence, rural/ urban location, caste, religion, mother's age cohort, the educational level of the mother and father, a measure of household wealth and the age of the mother at the birth of the index child (section 5).

\section{Data}

Our research strategy requires data that meet the following requirements. First, the data must include pre and post ultrasound cohorts. Second, they must contain the complete birth histories of mothers so that we can model previous sex composition at each birth order. Using birth histories also avoids the common problem that households may include children living with nonbiological parents and siblings; we are able to link all biological children of each mother. Previous studies tend to use data that meet one or the other of these requirements (section 1.1, 2). Third, we shall show that it is useful if the data contain information on individual characteristics correlated with preferences for prenatal sex determination and abortion. Fourth, we need large samples to identify the treatment effects with any precision. What may in biological terms be large deviations of the sex ratio from its expected value of about 0.51 are often still small. The comprehensive specification of previous sibling sex composition that we employ raises sample size requirements. We use the Indian National Family Health Survey (NFHS) data as they satisfy these requirements. ${ }^{12}$ Most previous studies of sex ratios in India use aggregate data from the Census and the Sample Registration System and depict average trends. The census data have the further weakness of being decadal and reporting not the sex ratio at birth but the sex ratio age 0-6. Analysis of the latter is unhelpful because the sex ratio at birth and the gender gap in post-birth mortality have trended in opposite directions (Visaria 2005, Bhalotra 2010). Limitations of the two previous studies that use micro data were discussed in section 1.1.

We pool three rounds of the National Family Health Survey of India (NFHS) conducted in 1992/ 3, 1998/ 9 and 2005/6. The estimated equations include year dummies which naturally nest within them a set of survey round dummies. Women aged 15-49 at the time of the survey (age 13-49 in the first round) record complete fertility histories including the date and gender of their births. An upper limit on the age of women at interview implies that as we go further back

\footnotetext{
11 The differencing across birth order and across families that do and do not have boys is always explicit. The differencing across periods is explicit in equations 2 and 2a but implicit in equation 3.

12 The NFHS is the Indian D emographic and Health Survey, one of a family of comparable D HS surveys conducted across some 70 developing and transition countries; see www.measuredhs.com. Enormous investment has been made into ensuring that these data are of good quality.
} 
in time, births recorded in the sample are increasingly from mothers who were relatively young at birth (Bumpass et. al. 1982). This is addressed by conditioning upon the age of mother at birth (which we find does not alter the coefficients of interest). A common concern with data from retrospective histories is that they may be marked by inaccuracy in recall, anticipating which the D HS contain numerous probes designed to encourage recall accuracy. Inaccuracy need not imply bias and any bias in levels is likely to be differenced out in our specification. Nevertheless, we follow a vast demographic literature in left-truncating the data to limit this problem. ${ }^{13}$ The unrestricted period is as long as 38 years. Having investigated that the results are similar with a 15 and a 20 year window, we retain index births that occur up to 20 years before each survey date. For each index birth, the history of previous births is preserved, even if that history extends across longer than 20 years. We are careful to construct the sex composition of previous births using the complete fertility histories and to then apply the 20 year restriction in selecting the year of birth of the index child. After dropping births of order five or higher, the estimation sample contains $0.528 \mathrm{~m}$ births of order one to four of $0.223 \mathrm{~m}$ mothers that occur across 1972-2005. ${ }^{14}$ The mean share of boys in this sample is 0.5193 , somewhat larger than the biologically normal share of $0.512 .{ }^{15}$ As we shall see, this is an average across births that are and are not born following sex selection; the share is much more skewed in the sub-groups (higher order births occurring in relatively rich and educated Hindu families that have had less than two boys) that conduct selection. Summary statistics for all variables used in the analysis are in Appendix Table 5 .

For a sub-sample of recent births, the data include self-reports of ultrasound scans and abortions. Comparison between rounds confirms an increase in ultrasound use from $4.3 \%$ of women to $17.2 \%$ in an (average) interval of seven years (e.g. Arnold et al. 2002). Even if selfreported data under-estimate usage, as long as under-reporting is constant over time, these data indicate a substantial trend in availability of ultrasound. Ultrasound scans are used not only for sex diagnosis but also for medical purposes and, similarly, abortions occur for purposes other than eliminating unwanted girl conceptions. Moreover, these data do not satisfy the requirements of our research strategy- they do not include a pre-ultrasound period, they are not available for

\footnotetext{
${ }^{13}$ References to the demographic literature are in Arulampalam and Bhalotra (2006: section 4).

14 The potential sample contains $0.734 \mathrm{~m}$ children born of $0.223 \mathrm{~m}$ mothers during $1956-2006.14 .7 \%$ of births are of order greater than five and $22.1 \%$ of mothers have more than four births. The 20 year restriction on the retrospective window results in a loss of $13.8 \%$ observations.

15 The literature expresses the sex ratio in alternative but equivalent ways. Here 0.512 is males/ (males+females) which is the same as saying that $48.8 \%$ of births are naturally female or that, absent intervention, the average is about 960 girls per 1000 boys.
} 
the full birth history of each mother and the sub-samples are small. For these reasons, we do not rely upon these data but instead use them to conduct a robustness check (section 5).

\section{Results}

\subsection{N onparametric trends}

Ours is a story that is well told in pictures (Figures 1-4; also se the appendix figures). The probability that third and fourth order births are girls in families that have not yet had a son declines sharply after the mid-80s. By the mid-90s, second order births similarly start to exhibit an increasing deficit of girls. The control groups in the analysis do not exhibit this negative trend. These are index births that occur before about 1985, first births and families that have had a boy. The divergence between "treated" (post-ultrasound conception of birth order two or more in a family that has not yet had its desired sex mix of births) and control families is seen to increase in both time and birth order, consistent with declining costs of prenatal sex selection and positive costs of fertility.

\subsection{Regression estimates}

The dependent variable in all reported equations is the probability of a female birth. The dummy variable for female birth is multiplied by 100 , so all estimates are in percentage points (henceforth, ppt). Recall that pre is 1972-1984, post1 is 1985-1994 and post2 is 1995-2005.

\section{Double difference: birth order* post-ultrasound}

Table 1 provides estimates of pre and post ultrasound trends in the probability that the index birth is a girl by birth order, allowing birth order specific intercepts; equation (1a) above. On average, there is no significant trend (col. 1), but there are significant trends by birth order (col. 2). Relative to the probability pre-ultrasound, the post2 probability that the index birth is a girl at first order is 0.94 percentage points p.a. (henceforth ppt p.a.) higher while, for higher orders, this probability is significantly lower by between 1.5 and 2 ppt. The main effects of time in the model control for the trend in the sex ratio at first birth, further discussion of which is in section 5 .

\section{D ouble difference: previous sibling sex* post-ultrasound}

Table 2 presents estimates of equation (1). Comparison with insights gained from the more general equations (2) and (3) indicates the empirical importance of one of the innovations in this paper. With $Y_{j}$ defined as an indicator for whether the firstborn is a girl, estimates of index sex show no dependence on firstborn sex in 1972-1985. After 1985, a female deficit emerges in families with a first born girl. In 1985-1994, it is 0.7\% points, rising more than threefold to $2.4 \%$ points in 1995-2005. Estimates with the alternative measure of $Y_{j}$, an indicator for no sons before the index birth, show a stronger divergence of the post from the pre-ultrasound sex ratio. This is consistent with sex selection increasing in birth order if the family has not had a boy- we 
take explicit account of this in the next step. For second births, "first born is a girl" is identical to "no previous son". For third order births, no-son adds to first-girl, information on the sex of the second born, and similarly for fourth births. The alternative summary indicator "at least two sons" is used in Abrevaya (2009) and Chen at al. (2010) for example. This naturally invokes birth order but it lumps together families that have no sons with families that have one son. Using a more general specification (below), we find that these families behave differently.

\section{Triple difference: previous sibling sex*birth order*post-ultrasound}

Estimates of equations (2) are in Appendix Table A1. They are useful in directly delivering tests of the significance of the difference in the post-ultrasound period coefficients from those for the pre-ultrasound period. ${ }^{16}$ The more general period-specific estimates of equation (3) are in Table 3 , where estimates with and without covariates $c_{j t}$ are shown. Consider the estimates conditional on covariates. Pre-ultrasound, there is no significant variation in the probability that the index birth is a girl by birth order or family sex history. In the early diffusion period, the chances of a girl being born at third and fourth order in families with two girls is significantly lower than for the control groups- first births, pre-ultrasound births and births in families with sons. In the late diffusion period, (a) the girl deficit intensifies where it was previously apparent and (b) spreads to second order births and to third births in families that have had one son. For example, the probability of the third birth being a girl in families with two previous girls (gg) shows a 1.84\% point deficit in 1984-1995 (post1) which is enlarged to 4.13\% points in 1995-2005 (post2); this illustrates the rapid diffusion of ultrasound availability. Families with one previous girl (g) that are having their second birth show an insignificant deviation in the sex ratio in post1 which rises to a significant $3.1 \%$ points in post2. Comparing this with the $4.13 \%$ point deviation at order three is consistent with the tension to sex select increasing as fertility approaches its target. Fertility fell significantly between the pre and post-ultrasound periods, from a mean (median) of 4.35 (4) births per mother in 1972-84 to 3.5 (3) in 1984-95 and 2.81 in 1995-2005. As discussed in the Introduction, the documented reasons for son preference are served by having one son and Indian families are often characterized as acting to ensure that they have one son. We find that they act as if they want two. Amongst third births, the girl deficit is $1.52 \%$ points in families with one son (bg), compared with $4.13 \%$ points in families with no son $(\operatorname{lgg}) .^{17}$

16 We also show in Appendix Tables 1 and 2 that including birth-order trends, which forces us to omit one of the sex composition outcomes at each birth order, merely reconfigures the coefficients on $Y j^{*} d^{*}$ t. Here we discuss the (equivalent) specification that retains all possible configurations of previous sex at each order; refer the discussion in section 2.2.

${ }^{17}$ In the Introduction we argued that families may want two sons to cover the risk of one dying (or migrating away). The survival adjustment we make (below) does not necessarily reflect this risk- we adjust 
The year dummies, state-specific trends and state dummies are each jointly significant at the $1 \%$ level. The covariates are mostly insignificant (remember that the coefficients $B$ are picking up deviations in the sex ratio from that of first births) and conditioning upon them makes only small and statistically insignificant differences to the estimated $B$ (Table 3). This suggests it is unlikely that there is any substantial unobserved heterogeneity and that previous sex composition does indeed behave like an exogenously determined treatment (Wooldridge 2002: p.605, Altonji et al. 2005); also see section 5.1. 0 verall, trends in the sex ratio in the postultrasound period are significantly different than in the pre-ultrasound period, showing a striking divergence across and within families by previous sibling sex and birth order. These patterns emerge conditional upon controls for the direct effects of previous sibling sex and birth order, omitted regional trends, aggregate shocks, state-level time-invariant heterogeneity and individual covariates that are plausibly correlated with preferences for sex selection and access to the relevant facilities. The girl deficit evolves dramatically over the sample period, consistent with the explosive spread of ultrasound. The pattern of coefficients is consistent with a desired family of 2 boys and 1 girl.

\section{Specification Checks and Further Analysis}

\subsection{Specification Checks}

\section{Randomness of the sex of first births}

We assumed that families do not sex select at first birth. If they do then we under-estimate sex selective abortion at higher birth orders by the difference between the sex ratio at first birth and the "normal" sex ratio. O ur assumption is supported by the following. (a) The sex ratio for first births lies within the normal range. (b) It shows no tendency to have become more male over time. (c) In contrast to the sex ratio for higher birth orders where sex selection is indicated, it shows no significant interaction with indicators of son preference (below). (d) In focus group discussions in G ujarat and Haryana families report that they do not attempt sex selection for first births (Visaria 2005). (e) This is consistent with families being happy to have one girl, field evidence for which is cited in Das Gupta (1987) and Visaria (2005) and representative survey evidence of which is evident in response to questions concerning the desired number of boys and girls in the NFHS data that we analyse (Table 9). (f) First births exhibit stable and normal sex ratios in other regions, for example, see the studies of Taiwan and of Asian immigrants referred to in section 1.1. O ur expectation was that the sex ratio of first onder births would show no trend but we find it is becoming increasingly female even as the sex ratio of higher order

for survival until conception of the index child but the family may want to cover for the risk that their one son dies after the birth of the index child. 
births is becoming increasingly male (see Figure 1). O ur estimates account for the trend in first births. We nevertheless discuss this in the Appendix, showing that other countries exhibit a similar trend.

\section{Unobserved heterogeneity in son preference and attitudes to abortion}

Even if the sex of the first birth is randomly assigned, a possible concern is that the history captured in $\mathrm{Y}_{\mathrm{ij}}$ may be correlated with (unobservable) preference heterogeneity in equations for third and fourth births. This potentially challenges theidentifying assumption that conditional on sibling sex history, families with history go (for example) are not different from families with history bb or gg in any unobservable way that is correlated with index gender. A related concern is that there are unobservables correlated with fertility choices. It is well established that fertility stopping responds to the sex composition of previous births, especially after two births (Arnold 1985, Angrist and Evans 1997, Bhalotra and van Soest 2008). O ur assumption is that, conditional upon previous sex composition, the decision to have another child does not on its own influence the gender of that child. ${ }^{18}$ This section describes how we investigate these assumptions.

We have investigated sensitivity of the key parameters $\S$ to conditioning upon a vector of covariates $c_{\mathrm{j}}$ that are correlated with the likely omitted heterogeneity in son preference and in attitudes to abortion. Adding $c_{i j}$ results in insignificantly small changes to the coefficients of interest (Table 3; also appendix table 1). ${ }^{19}$ If the amount of selection on observed explanatory variables provides a guide to the amount of selection on unobservables, then this suggests limited selection on unobservables (Altonji et al. 2005). ${ }^{20}$

It seems plausible that if there is a distribution of son preference in the population this will influence the response to the treatment. We therefore investigate a more general random coefficients type model in which mother-level unobserved heterogeneity, $\mathrm{v}_{\mathrm{j} j}$ is allowed to interact with the treatment. Let us define $\mathrm{X}_{\mathrm{it},}$ as a shorthand for the treatment variables $\mathrm{Y}_{\mathrm{j}}{ }^{*} \mathrm{~d}_{\mathrm{i}}^{*}$ post $_{\mathrm{r}}$ Suppressing the underlying two-way interactions and main effects, the conditional expectation function in the linear model is

(4) $E\left(y_{i j t} \mid x_{i j t}, v_{j}\right)=\eta+\beta x_{i j t}+v_{j}+? x_{i j t} \cdot v_{j}$

18 Stopping rules probably complement the use of sex-selective abortion in the post-ultrasound regime. Stopping rules themselves leave the overall sex ratio within the normal biological range since each birth is an independent event with a fixed probability of being a daughter or a son (Arnold et al. 2002). Deviations from the normal range can therefore be attributed to sex-selective abortion.

19 The covariates are insignificant in period 1. In periods 2 and 3, they are jointly significant but this is on account of one coefficient, on wealth, being significant at the 5\% level. When the model is generalised (below) to allow slope heterogeneity then the intercept effect of wealth becomes insignificant, suggesting that the model is mis-specified when heterogeneity is restricted to intercepts.

${ }^{20}$ Recall that the equation intercept reflects the proportion of girls at first birth, so the covariates effects capture heterogeneity in this proportion. 
To identify $ß$, we assume that $\mathrm{v}_{\mathrm{j}}$ is independent of $\mathrm{x}_{\mathrm{ijt}}$ conditional upon the vector of observables $\mathrm{G}\left(\mathrm{G}_{\mathrm{j}}\right.$ averaged to the mother level) that proxy $v_{j}$ or $E\left(v_{j} \mid x_{i j t} G\right)=E\left(v_{j} \mid q_{)}\right)$; this is the commonly invoked ignorability assumption and it is considerably weaker than the assumption that $v_{j}$ is independent of $x_{\mathrm{ijt}}$ in the unconditional model. We can then write

(4a) $E\left(y_{i j t} \mid x_{i j t} g_{j}\right)=a+\beta x_{i j t}+E\left(v_{j} \mid g_{j}\right)+? x_{i j t} E\left(v_{j} \mid g_{j}\right)$

In the linear case, $E\left(v_{j} \mid c\right)=\left(c_{j}-c\right) \delta$, where $c=E\left(c_{g}\right)$ and this is proxied by the sample means of $c_{\text {. }}$ So we effectively extend the baseline model to include a vector of mother-level covariates and interactions of mean-deviations of each covariate with the treatment variable. The more comprehensive a proxy for likely unobservables are the elements of $c_{i j}$, the more plausible is the ignorability assumption. We use a rich set of covariates, detailed in section 2 and the Table notes. Here we indicate their likely correlation with son preference and attitudes to abortion. There are entrenched differences in son preference across the Indian regions and castes with the northwest (Miller 1981, Dyson and Moore 1983, Agnihotri 1996) and high caste groups (Tambiah 1973, Dickenmann 1979, Oldenburg 1992) exhibiting the strongest tradition. Muslims report lower son preference (Bhat and Zavier 2004, Grover and Vijayvergiya 2006) and exhibit smaller gender gaps in education and mortality (Bhalotra et. al. 2009). The Muslim religion is both more averse to use of contraception (D harmalingam and Morgan 2004) and more abhorrent of abortion than the Hindu religion (Almond et al. 2009). Self-reported son preference shows a steep negative gradient in women's education and a shallow negative gradient in wealth (Bhat and Zavier 2004). Although there is some evidence that high SES groups have more male-biased sex ratios in the absence of sex selection (Sen 1985, Murthi, Guio, and Dreze 1995, Edlund 1999), this may arise from compositional effects associated with, for example, region or caste. Older cohorts of mothers may have stronger son preference if, as subjective reports in recent survey data indicate (D as G upta et. al. 2009), son preference is declining with modernization (even as opportunities for exerting son preference through prenatal sex selection are increasing). Estimates are in Table 4a. The population averaged coefficients ( 3 ) are larger than in the baseline case, significantly larger in post1 (when certain families initiate sex selection earlier than others) and insignificantly larger in post2 (when access is much more widespread). This suggests that the baseline coefficients are conservative estimates of the extent of female foeticide but our simulations use the post2 coefficients. In this regard, it seems fair to conclude that while there is striking evidence of heterogeneity in the treatment effects, the heterogeneity appears to be uncorrelated with the (post2) treatment (in deviations from the mean), indicating that the simple linear model delivers 
a consistent asymptotically normal estimator of the average treatment effect (Wooldridge 2002, pp. 68, 613).

\section{Treatment response heterogeneity}

It is of substantive interest to consider the identified heterogeneity in responses. For a given sex history of births, significantly more sex selection is conducted in 1995-2005 by women with at least secondary education and wealth in the top quintile of the distribution and significantly less by Muslim families (Table 4b). ${ }^{21}$ In addition, highly educated women started sex selection earlier, in 1985-1994. This may appear to be at odds with previous findings that improvements in women's education raise investments in child health and survival (Glewwe 1999, Currie and Moretti 2003). ${ }^{22}$ In fact the self-reported son preference of educated women is lower (Bhat and Zavier 2004). O ne explanation of the education gradient in sex selection is that educated women are more receptive to new technologies because they have lower search costs or are better placed to assess the risks of new procedures (e.g. G lewwe 1999 or Lleras Muney and Lichtenberg 2005, in a different context). Another is that they have lower desired fertility; achieving the desired sex mix of births by extending fertility is relatively costly for them. Averaging over the period, median [mean] fertility in the top quantile of the wealth distribution is 3[2.9] compared with 4 [4] in the bottom quantile. The gradient is steeper for education. Median [mean] fertility of women with secondary or higher education is 2 [2.3] and of women with no education is 4 [4]. The education and wealth differentials have narrowed over time but each is still the equivalent of one child: in the late-diffusion period, high status families have about 2 births and low status families about $3{ }^{23} \mathrm{~A}$ third explanation of the status gradient is that high status families have better access to ultrasound and safe abortion facilities. Self-reported use of ultrasound scans is increasing in both education and wealth (Arnold and Parasuranam 2009). The cost of an ultrasound scan is in the region of $\$ 12$ which is about $1 \%$ of per capita income. Although this may not seem large, the income distribution is highly skewed so a scan will make a bigger dent in a poor family's income,

\footnotetext{
21 These effects are conditional upon one another. Conditional on education and wealth, there is no significant slope heterogeneity by the education of men, northwest location or caste.

${ }_{22}$ Previous studies set in India and China respectively show that improvements in women's earnings share raise investments in children (Rosenzweig and Schultz 1982, Qian 2008). These studies analyse changes in earnings conditional upon education. The relevance of these results to the current discussion is further limited by the fact that labour market participation in India tends to take an inverted-J shape in education (D as and D esai 2003).

23 It is also relevant to consider pre/ post ultrasound changes in SES-gradients in fertility. Consider education. Fertility decline was in fact greater for uneducated women but they nevertheless exhibit higher fertility in both periods. In 1972-84, mean (median) fertility of mothers with no education was 4.8 (5) and this fell to 3.3 (3) in 1995-2005. The corresponding decline for mothers with secondary or higher education was from 2.8 (3) to 2 (2).
} 
the cost of safe abortion is much larger (see the Appendix) and families may need more than one round of scans and abortions to achieve the birth of a son.

The persistence of a religion slope differential conditional upon wealth and education isolates a role for culture in motivating sex selective abortion. We adduced evidence above that Muslims have lower son preference and a stronger abhorrence of abortion. The latter suggests that, for a given level of son preference, Muslims will tend to use continuation of fertility more than sex selective abortion. ${ }^{24}$ Our findings ties in with evidence that, in contrast to Indian immigrants in the UK and Canada, immigrants from Bangladesh and Pakistan do not conduct sex selective abortion (D ubuc and Coleman 2007, Almond et al. 2009). Also, the sex ratio at birth in India's neighbours has remained relatively stable in the last few decades while that in India has exhibited a trend (author's estimates).

The differences in slope are large. For example, in the late diffusion period, the percentage point (negative) difference in the probability that the index birth is a girl is $4 \%$ points larger in relatively wealthy households (top $20 \% \mathrm{v}$ the rest). The corresponding education and religion differentials are 2.4 and $3.4 \%$ points respectively.

\section{Unobserved heterogeneity in child sex}

A potential source of unobserved heterogeneity at the mother level lies in the proclivity to give birth to children of a certain gender. We can (a) appeal to the heuristic argument that allowing for a natural clustering of gender within family would only strengthen our findings since it implies, for example, that $\operatorname{pr}(g \mid g)>\operatorname{pr}(g \mid b)$, which directly contrasts with the prediction of the sex selection hypothesis that a girl is more likely to follow a boy than a girl. However, as argued in section 2, (b) there is no evidence in the wider literature that such proclivity prevails and (c) if it does, it is captured by the main effect of $Y_{j}$ in the model. ${ }^{25}$

\section{State dependence in gender}

A challenge to identification arises when, even if there is no unobserved heterogeneity, the sex of previous births influences the sex of the index birth for a reason other than sex selection. An asymmetric form of (first Markov) state dependence in sex may arise if (a) carrying a male foetus

\footnotetext{
24 The average number of births to Muslim women over the sample period has a median [mean] of 4[4] compared with 3[3.4] for Hindu women. Interestingly, this gap is almost closed in the late diffusion period when the median is the same and the mean is only 0.4 births larger amongst Muslims.

25 The estimated model is analogous to a dynamic model. The data may be construed as a panel of births within mother that are naturally sequenced in time. The equation models the sex of the index child as a function of the sex of the history of births in the family (interacted with indicators for birth order and the post-ultrasound regime). The assumption that gender at conception is random within mother (and gender at birth is random for the first borm) releases us from the potential of an initial conditions problem in the estimation (Heckman 1981).
} 
depletes the mother more than carrying a female foetus ${ }^{26}$ and (b) the subsequent birth of a depleted mother is more likely to be female because male conceptions are less likely to survive in a depleted environment (Stinson 1985). This elevates the relative probability of a girl birth after a boy birth (bg) compared to the alternative sequences, bb or gb. As the sex selection hypothesis implies $b g>g g$, it is conceivable that ignoring this form of state dependence would bias us in favour of our hypothesis. We therefore create a dummy indicating whether the birth preceding the index birth is a boy and include it as an additional regressor to the model. It is insignificant (Tables 8a,b: col.2).

We further estimated the more general model that, for all previous siblings, distinguishes sequence for a given sex composition. For example, it distinguishes bg from gb and bgg from gbg. In the forgoing analysis, these are combined into single variables consistent with the hypothesis that parents respond to the realized sex-mix of their births but not to the order in which the sexes arrive. Previous studies, most of which use indicators for having had at least one boy naturally also assume irrelevance of sequence. While the coefficients on variables indicating a given sex mix, like gb and bg are not identical, they are not statistically significantly different from each other (Appendix Table 3). The only plausible reason we can think of for why sequence may interfere with identification is state dependence in gender, for which we have introduced the simple test above.

\subsection{Extensions}

\section{Placebo test}

We create a placebo test that rests upon the fact that the process of manipulating foetal gender takes time. To create deviations of the sex ratio from the normal, parents must conceive a child of the undesired sex, identify its sex and abort it, and then re-conceive, repeating as necessary to produce the desired outcome. The absolute minimum time required from the preceding live birth is a year although the process will often take much longer. (a) It is estimated that it takes three months to conceive after a birth, longer if breastfeeding. We take the minimum of this duration which is zero months. (b) The earliest opportunity for prenatal sex detection is in the third month of pregnancy. This is being shrunk with more recent high resolution technologies but these are not available to most people. (c) Recovery from abortion tends to lengthen the time to the next conception by as long as three months but we also set this to the biologically feasible minimum which is zero. (d) The next conception then takes nine months to delivery. Adding up, the very minimum interval is a year. If the new conception is of the undesired sex

26 The higher average birth weight of males is possibly one indication of the male foetus being more demanding of matemal resources. Matemal depletion is more likely in settings where maternal health is poorer or birth intervals are shorter. 
again then the family goes through a further cycle of at least a year. If estimates of our model were to indicate a skewed sex ratio following birth intervals as short as a year then this would suggest that some other process is at play. In our sample, only about $4 \%$ of births in the postultrasound era are after an interval of less than a year. We therefore compare estimates from this sample with estimates from a sample of identical size generated by randomly dropping observations stratified by birth order. D espite the smaller sample, the estimates on the simulated sample are consistent with selective abortion (Table 5). To allay the concern that they are consistent by chance, we loop through seeds of 1-100 and take the simple average of coefficients and standard errors. In the sample of births with short preceding intervals, as predicted, there is no evidence of selective abortion.

A short preceding interval may directly influence the sex of the index birth. After a birth, the mother needs to replenish her stocks of vital nutrients such as calcium and iron that are needed to support foetal development (e.g. DaVanzo and Pebley (1993)). If she has not had the time to do this, the index child may be less well nourished in utero and, for the reasons set out earlier, be more likely to be male. This is unlikely to matter to this test as it will apply to all births in this sample and we are looking for a divergence in the sex ratio of index births relative to first births and relative to families that have already achieved their desired sex mix of births.

\section{Availability of ultrasound}

It may seem that the more natural specification would be one that directly includes data on availability of facilities for ultrasound scans and sex-selective abortions, say, $U_{j \mathrm{t}}$ where $j$, t may indicate region and year of birth -

(5) $\mathrm{y}_{\mathrm{itt}} * \alpha+\beta_{\mathrm{jt}}+\eta_{\mathrm{j}}+\mu_{\mathrm{t}}+\mathrm{e}_{\mathrm{ijt}}$

But measures of availability such as the number of scanners sold or the number of scans had per mother of reproductive age are unlikely to be exogenous measures of supply. We have therefore replaced $U_{j t}$ with $Y_{j \mathrm{jt}} \mathrm{d}_{\mathrm{i}}$ post $t_{\text {, }}$ where post $t_{\mathrm{t}}$ captures the exogenously determined arrival of ultrasound in India. We investigate division of the post-ultrasound period into sub-periods identified by exogenous increases in supply flowing from deregulation of trade and industry. This is similar, for example, to the identification strategy in Jayachandran et al. (2010). ${ }^{27}$ We complement our approach with an alternative specification that brings availability into the picture more directly

\footnotetext{
${ }^{27}$ Jayachandran et al. (2010) analyse the impact of the arrival of sulfa drugs on disease-specific mortality risk in 1930s America. Their strategy is similar in that it relies upon the aggregate timing of the innovation rather than on individual or regional indicators of availability or use. They interact timing with an indicator for diseases treatable with sulfa. Analogously, we interact timing with indicators for "treatable" families.
} 
using data available for a sub-sample of mothers on (endogenous) self-reported usage of ultrasound. Births in the potential sample occur during 1992-2005 but for comparability with the baseline estimates, we isolate 1995-2005 (see notes to Table 6). The vector of previous sibling sex dummies is interacted with an indicator for whether the mother reported a scan and we allow for a direct effect of scan-usage. The interaction terms are consistently negative for families with girl-rich histories (Table 6). Note that the sex selective abortion hypothesis predicts that if a mother reports a scan, (i) it is more likely that preceding births were girls and (ii) the index birth is a boy. We have conditioned upon the sex of previous births and presented evidence of (ii). Arnold et al. (2002) present evidence of (i).

\section{Adjusting for mortality of previous siblings}

Like previous studies in this domain, we have so far conditioned upon the sex of previous births without accounting for whether or not they survive. We re-estimate the model defining $Y_{j}^{*} d_{i}$ as the sex composition of siblings that survive up until conception of the index birth. ${ }^{28}$ This also results in index births moving up the birth order in families where previous siblings have died. No coefficient is significantly different but the point estimates change, implying more selective abortions of third and fourth births, but slightly fewer of second births. The changes vary across periods, consistent with the birth years of previous siblings in the sample spanning the pre and post ultrasound regimes (Table 7).

\section{Other robustness checks and extensions}

International comparisons- We compared estimates for India with a sample of ten other developing countries including her neighbours (Appendix). India is unique in that sample in showing a divergence of the sex ratio for second and higher order from that of first births. This makes it unlikely that our estimates of birth order differences in the sex ratio trend reflect a natural process of some sort. Since the data for the ten countries are from the same source, it also allays the concern that our estimates are, in some way, an artifact of retrospective survey data.

Specification of the treatment variable: We have shown that models using summary indicators common in previous research such as "first born girl" or "no previous boy" tell the story but fail to capture the distribution of foetcide and the fact that families with one boy were also conducting sex selection. The estimates are robust to changing the thresholds for post ${ }_{\mathrm{t}}$ and post 2 t The coefficients change in a manner consistent with the nonparametric plots but the overall

${ }^{28}$ The date of conception is taken to be the date of birth less nine months. The average birth interval between successive siblings is 34 months, so for second order births, previous sex composition is adjusted by gender-specific mortality rates that, on average are in the range 0.34 months; though our adjustment is on a case by case basis that uses the case-specific birth interval and the sex-specific mortality rate specific to these intervals. Mortality is reported in months up until one year of age and in years thereafter. In total, $14.5 \%$ of observations in the sample are affected by the adjustment. 
story is unchanged. Specifications with linear trends produce biased estimates, failing to capture the fact that the girl deficit has been increasing at an increasing rate, consistent with the exploding path of ultrasound diffusion (results available on request).

L ocal area fix ed effects: We investigated a specification that includes fixed effects for the sampling cluster, which approximates the community (village, town). This controls for all common local cultural differences. The coefficients tend to rise but are not significantly different (Tables 8a,b). Survey design issues: In the data section we explained the trade-off arising in the choice of length of the retrospective window within each survey round. We investigated replacing the 20 year with a 15 year window; our findings are robust to this (Tables 8a,b) and also to going in the other direction, using dl of the available data, stretching back to 1956 (available on request). The coefficients are insignificantly different if we use sample weights in the regression (Tables 8a,b).

Recent trends- The 2001 census recorded a further worsening of the juvenile sex ratio. This stimulated a new range of protests from civil society organizations and a tightening of the 1994 Constitutional Act outlawing prenatal sex diagnosis (Appendix). We re-estimated the model for 2001-05. Rather than slowdown, the trend in sex selection appears to have intensified. The coefficients indicating girl foeticide are larger by between 0.5 and $1.5 \%$ points though they are not significantly different from the baseline coefficients (Tables 8a,b).

\section{Simulation and comparison with other estimates}

We simulated the number of selective abortions in 1995-2005 (Appendix Table 4a). O ur approach is anchored on the observed number of male births which our estimates suggest is unaffected by selective abortion. Assuming, a natural sex ratio of 0.512 , we can predict the natural proportion of female births. The regression coefficients identify significant deviations from this proportion, which we argue can only be explained by selective abortions. We estimate $0.48 \mathrm{~m}$ selective abortions of females p.a. during $1995-2005$. This represents $2.1 \%$ of all potential births and $6.2 \%$ of female foetuses among potential second-fourth births. Previous headline estimates for India in 1998 (Jha et al. 2006) are, as it happens, of a similar order of magnitude but this is the result of a per chance cancelling of errors. Their survey data appear unreliable (section 1.1 above) and their estimate is anchored on the observed total number of births which is itself deflated by selective abortion of females. ${ }^{29}$ Further detail is provided in Bhalotra and Cochrane (in progress). Using the structure set out in the Appendix, we estimate that about $11.6 \%$ of

29 Suppose we observe 100 male and 90 female births. For ease, suppose that the natural sex ratio is 0.50 . Then the natural number of female births is 100 and observing 90 we estimate that 10 females were selectively aborted. Jha's approach is to assume that given a total of 190 births, 95 should have been female and therefore 5 were selectively aborted. This underestimates the actual number of selective abortions by (1-p), where $p$ represents the natural proportion of fem ale births. Lin et al. 2008 appear to make the same mistake in their simulation of the number of sex selective abortions of girls in Taiwan. 
second and $15.3 \%$ of third births are subject to prenatal sex diagnosis for the purpose of sex selection. This broadly matches up with the self-reported use of ultrasound scans in this periodwhich may be expected to be higher as scans are used for purposes other than sex selection, but lower because of under-reporting of use. The trend is not slackening; the equivalent estimate for 2001-5 is $0.62 \mathrm{~m}$ p.a. or $2.7 \%$ of would-be births.

Prevalence rates amongst families in the top quantile of the wealth distribution and amongst mothers with secondary or higher education are about $50 \%$ larger than on average, at $3.7 \%$ and $3.1 \%$ of potential births. Comparisons with rates of female foeticide in other parts of the world need to be done by birth order, and matched on socioeconomic status. Using results for Indian immigrants in the US and the UK presented in Abrevaya (2009) and D ubuc \& Coleman (2007), we estimate that, amongst third and fourth order births, $5.0 \%$ and $5.3 \%$ respectively were selectively aborted. This is higher than the proportion of third and fourth births in all-India (3.5\%), but lower than the proportions for families with high wealth and high levels of women's education (9-11\%). Additionally, Indians in India practice sex selective abortion for second births, which the immigrant populations don't. Studies of China indicate sex selection starts at second order, as in India (Chen et al. 2010). Using results in Ebenstein (2010) for 1982-2000, we estimate that $3.6 \%$ of all potential births were selectively aborted in this period in China, which is similar to the figure for the wealthiest $20 \%$ of families in India.

\section{Conclusions}

We have conducted a triple difference analysis that identifies structural breaks in the sex ratio of second and higher order births conditional upon the sex of previous siblings, the timing of which reflects the arrival (and diffusion) of ultrasound. Ultrasound scans and related prenatal procedures are often used to detect genetic abnormalities or track the health of the mother and child during pregnancy. This is therefore the story of a medical innovation that has had the unintended consequence of resulting in elimination of millions of unborn girls each year for some twenty years. Indeed, our estimates are of the number of girl abortions. The "death toll" associated with ultrasound scans is larger to the extent that families that cannot or do not want to access abortion differentiate prenatal investments in favour of boys (Lhila and Simon 2008, Bharadwaj and Nelson 2010).

Prior to the advent of prenatal sex determination, families attempted to achieve the desired sex mix of children by a combination of selective continuation of fertility (Sloane and Lee 1983, Bhat and Zavier 2003, Bhalotra and van Soest 2008) and relative neglect of girls (Klasen 1994). So, amongst the positive unintended consequences of the increasing availability of prenatal sex diagnostic tools is that they will tend to induce reductions in fertility and 
improved postnatal investments in girls (Almond et al. 2010, Kumar 1983, Lin et al. 2008, Goodkind 1999). However, our preliminary calculations suggest that the increase in the postbirth survival chances of girls is overwhelmed by the current scale of excess pre-birth morality amongst gins (Bhalotra 2010). One reason for this is that prenatal selection incurs lower psychic costs than neglect or infanticide of a born child. Another is that the historical neglect of girls by families did not generate profits for a third party. Prenatal sex selection is profitable for suppliers of ultrasound scanners and private medical practitioners (G eorge 2010). A largely illegal industry is burgeoning, advertisements encouraging sex detection and abortion are proliferating and, as the practice spreads, stigma and the fear of medical procedures are probably being eroded. Many of the dilemmas of modern times are at play here, relating to gender inequality, human rights and freedom of choice.

The dilemmas concerning sex selection are of wider scope. There is some evidence of parental preferences in the USA, for example, being biased in favour of sons (D ahl and Moretti 2008). Even where preferences over child sex are relatively balanced so that the demographic consequences are limited and equality issues do not arise, the ethical issues are live. For example, the Human Fertilisation and Embryology Authority of the UK has banned sex selection for primarily moral reasons (e.g. The Guardian, A pril 2010).

Analyses of similar trends in the sex ratio at birth in China have underlined the importance of the One Child Policy effective since 1979 (Hesketh et al. 2006, Chen et al. 2010, Ebenstein 2010). Korea, which also displayed a rising trend in the sex ratio at birth, similarly regulated fertility. ${ }^{30}$ Fertility regulation raises the cost of adjusting sex composition through fertility (e.g. Ebenstein 2010). What is striking about the case of India is that widespread sex selection has occurred in the absence of fertility regulation. Although fertility has declined, it was as high as three births per mother in the post-ultrasound period.

It may be argued that the imbalance in the sex ratio, once the affected cohorts have matured on to a marriage market, will lead to price adjustments that feedback to lower son preference. But this rests on the untenable assumptions that the only cause of son preference is dowry and that marriage markets are Walrasian (Edlund 1999, Bhaskar forthcoming). The prognosis is however not entirely negative. As noted in the Introduction, the all age sex ratio has stabilised in the post-ultrasound period, having drifted upwards in earlier decades (Bhat 2002). The implied difference in difference in the sex ratio by age and time suggests that overall trends

30 From 1983, the Korean government denied medical insurance benefits and tax deductions for education expenses to parents with at least three and at least two children respectively. This was followed by further incentive schemes appear, for example, the granting of low-interest housing loans to parents who agreed to undergo sterilization (Wikipedia). 
are favourable to women, consistent with declines in reported son preference (authors' estimates, NFHS data). Women's education (Bhalotra 2009) and autonomy have been increasing (Jensen and Oster 2009) and investments in daughters are expected to respond to their improved economic opportunities (Jensen 2010). Central and state governments have initiated a number of programs designed to accelerate normative change to reduce son preference (Chung and D asgupta 2009). Normative change is key since our findings suggest that even if improvements in, for example, women's education lower son preference, they may at the same time encourage sex selection if they also raise the opportunity cost of women's time in childbearing and make women more amenable to the use of modern technologies.

There is also some evidence that legal change is working towards bucking the trend. The popular perception is that the introduction of the Prenatal Sex Diagnostic Techniques (Regulation and Prevention of Misuse) Act (PNDT) in 1994 (effective 1996) and its subsequent tightening in 2002 have had no impact because both ultrasound and abortion providers often work "underground". The law is difficult to enforce when families and private clinics collude to transact outside its reach. However, popular perception tends to ignore the fact that the deepening penetration of ultrasound in the Indian market, its falling costs and continuous improvements in the technology (offering clearer detection earlier in pregnancy) through the period predict a positive (rather than constant) trend in sex selection. A more careful analysis suggests that if not for legal interventions, the sex ratio trend will have been steeper than it was (D eolalikar and Nandi 2010). To the extent that the legal interventions in turn are a response to considerable pressure from human and women rights groups in India (G eorge 2010), normative change remains central.

\section{References}

Abrevaya J (2009), 'Are There Missing Girls in the United States? Evidence from Birth Data'. A merican E conomic Journal: A pplied E conomics Vol. 1, No. 2: 1-34.

Ahmad, A and Morduch J. (1993), 'Identifying sex-bias in the allocation of household resources:

Evidence from linked household surveys from Bangladesh', $\mathrm{H}$ arvard

Institute of E conomic Research D iscussion Paper 1636. Cambridge: Harvard University

Almond D (2006), 'Is the 1918 Influenza Pandemic Over? Long Term Effects of in Utero Influenza Exposure in the Post 1940 USPopulation'. Journal of Political E conomy Vol. 114, No. 4.

Almond D , Edlund L (2007), 'Trivers-Willard at Birth and One Year: Evidence from Us Natality Data 1983-2001'. Procedings of the Royal Society B: Biological Scienoes Vol. 274, No. 1624: 2491-2496.

Almond D , Edlund L (2008), 'Son-Biased Sex Ratios in the 2000 United States Census'. Procedings of the N ational A cademy of Scienoes Vol. 105, No. 15: 5681-5682.

Almond D, Edlund L, Li H, ZhangJ (2007), 'Long-Term Effects of the 1959-1961 China Famine: 
Mainland China and Hong Kong'. N BE R W orking paper.

Almond Jr D , Edlund L, Milligan K (2009), 'Son Preference and the Persistence of Culture: Evidence from Asian Immigrants to Canada'. N BE R W orking paper 15391.

Almond D , Li H, Meng L (2010), 'Son Preference and Early Childhood'. Mimeograph. June, 2010

Anderson S (2003), 'Why D owry Payments D eclined with Modemization in Europe but Are Rising in India'. Journal of Political E conomy Vol. 111, No. 2.

Angrist J (2002), 'How D o Sex Ratios Affect Marriage and Labor Markets? Evidence from America's Second G eneration*'. Q uarterly Journal of E conomics Vol. 117, No. 3: 997-1038.

Angrist J, Evans W (1998), 'Children and Their Parents' Labor Supply: Evidence from Exogenous Variation in Family Size'. A merican E conomic Review Vol. 88, No. 3: 450-477.

Arnold F (1985), 'Measuring the Effect of Sex Preference on Fertility: The Case of Korea'. D emography Vol. 22, No. 2: 280-288.

Arnold F, Kishor S, Roy T (2002), 'Sex-Selective Abortions in India'. Population and D evelopment Review Vol. 28, No. 4: 759-785.

Arnold F and Parsuranam (2009). 'The Effect of Ultrasound Testing during Pregnancy on Pregnancy Termination and the Sex Ratio at Birth in India'. Paper presented at the XXVI International Population Conference, International Union for the Scientific Study of Population, Marrakech, Morocco, 27 Sep. - 2 Oct., 2009

Barcellos S, Carvalho L, Lleras-Muney A (2010), 'Child G ender and Parental Investments in India: Are Boys and Girls Treated Differently?'. Mimeo. UCLA

Bardia A, Anand K (2006), 'Sex Ratio in India'. L anœt Vol. 367, No. 9524: 1727-1727.

Basu K. and Annemarie M. 2007 The pattern and causes of economic growth in India. Oxford Review of Economic Policy, Volume 23, Number 2, 2007, pp.143-167

Behrman, J. and D eolalikar A.. (1989). Seasonal Demands for Nutrient Intakes and Health Status in Rural South India, in D avid Sahn, ed., Seasonal V ariability in Third W orld A griculture: Consequenoes for F ood Security, Baltimore: Johns Hopkins University Press.

Bhalotra, S. (2009) Educational Deficits and Social Identity in India.' Background paper for the Education for All Global Monitoring Report 2010: Reaching the marginalized, Working Paper 2010/ ED/ EFA/ MRT/ PI/ 22, UNESCO, Paris.

Bhalotra S, Valente C and Van Soest, A (2009), 'The Puzzle of Muslim Advantage in Child Survival in India'. Journal of $\mathrm{H}$ ealth $\mathrm{E}$ conomics, online in November.

Bhalotra S, van Soest A (2008), 'Birth-Spacing, Fertility and Neonatal Mortality in India: Dynamics, Frailty, and Fecundity'. Journal of E conometrics Vol. 143, No. 2: 274-290.

Bhalotra, S. and Rawlings S. (2009). G radients of the intergenerational transmission of health in developing countries. Bonn: IZA Discussion Paper 4353. Updated version at:

http:/ / www.efm.bris.ac.uk/ ecsrb/ bhalotra.htm

Bhalotra, S and Cochrane T (in progress). On estimating the number of girl abortions. University of Bristol. 
Bhalotra S (2010). Unintended consequences of sex selective abortion. Mimeograph. University of Bristol. Bharadwaj P, Nelson L (2010), 'D iscrimination Begins in the Womb: Evidence of Sex-Selective Prenatal Investments'. M imeograph. University of San Diego

Bhaskar V. 'Sex Selection and G ender Balance'. , A merican E onomic Journal: Microeconomics, forthcoming..

Bhaskar V, Gupta B (2007), 'India's Missing Girls: Biology, Customs, and Economic D evelopment'. Ox ford Review of E conomic Policy Vol. 23, No. 2: 221.

Bhat PNM (2006), 'Sex Ratio in India. Response to Jha, Prabhat, Rajest Kumar, Neeraj D hingira'. The L anot Vol. 367, No. 9524: 1725.

Bhat P. Mari N. 2002 Matemal Mortality in India: An Update, Studies in Family Planning, Vol. 33, No. 3 (Sep., 2002), pp. 227-236

Bhat PNM, Navaneetham K, Irudaya Rajan S (1992). Maternal Mortality in India: Estimates from an Econometric Model', Population Research Centre. W ork ing Paper 24 (January). D harwad.

Bhat PNM, Zavier A (2003), 'Fertility D ecline and Gender Bias in Northem India'. D emography Vol. 40, No. 4: 637-657.

Bhat PNM (2003), On the trail of missing Indian females. Illusion and reality, Economic and Political Weekly, Vol. 37, No. 52 (D ec. 28, 2002 - Jan. 3, 2003), pp. 5244-5263

Bhopal R.(2006) . 'Sex Ratio in India' L anot, May 2006, Vol. 367 Issue 9524, p1728-1729

Black S, D evereux P, Salvanes K (2007), 'From the Cradle to the Labor Market? The Effect of Birth Weight on Adult Outcomes*'. The Q uarterly Journal of E conomics Vol. 122, No. 1: 409-439.

Bumpass, L., Rindfuss, R. R., Janosik, R., (1978). 'Age and marital status at first birth and the pace of subsequent fertility.' D emography 15 (1), 75-86.

Chen, Y uyu, H. Li and L. Meng (2010), Prenatal Sex Selection and Missing Girls in China: Evidence from the Diffusion of Diagnostic Ultrasound. Mimeograph, Tsinghua University.

Chowdhury M, Bairagi R (1990), 'Son Preference and Fertility in Bangladesh'. Population and D evelopment Review Vol. 16, No. 4: 749-757.

Chung W (2007), 'The Relation of Son Preference and Religion to Induced Abortion: The Case of South Korea'. Journal of Biosodal ScienceVol. 39, No. 05: 707-719.

Chung W, D as G upta M (2007), 'Why Is Son Preference D eclining in South Korea? The Role of Development and Public Policy, and the Implications for China and India'. Policy Research W orking Paper Series 4373The World Bank.

Clutton-Brock T, Iason G (1986), 'Sex Ratio Variation in Mammals'. Q uarterly Review of Biology Vol. 61, No. 3: 339-374.

Currie J, Moretti E (2003), 'Mother's Education and the Intergenerational Transmission of Human Capital: Evidence from College O penings*'. Q uarterly Journal of E conomics Vol. 118, No. 4: 1495-1532.

Dahl G , Moretti E (2008), 'The Demand for Sons'. Review of E conomic Studies Vol. 75, No. 4: 1085-1120.

Das G upta M (1987), 'Selective Discrimination against Female Children in Rural Punjab, India'. Population and D evelopment Review Vol. 13, No. 1: 77-100. 
Das G upta M, Bhat P (1997), 'Fertility D ecline and Increased Manifestation of Sex Bias in India'. Population Studies Vol. 51, No. 3: 307-315.

Das G upta M, Ebenstein A, Jennings E (In Progress), 'The Socio-Economic Implications of Son Preference and Fertility D ecline in China'.

Das M and D esai S (2003), 'Why Are Educated Women Less Likely to Be Employed in India? Testing Competing Hypotheses'. W orld Bank Social Protection D iscussion Paper Vol. 313, No.

Das G upta, M. (2005) 'Explaining A sia's "Missing Women": A New Look at the D ata', Population and D evelopment Review, Vol. 31, Issue 3: 529-535, September 2005

Das Gupta, M. \& Chung, W. \& , Li S., (2009). 'Is there an incipient turnaround in Asia's"missing girls"phenomenon ?' Policy Research W orking Paper Series 4846, The World Bank.

Das Gupta, Monica and PN Mari Bhat 1997. Fertility decline and increased manifestation of sex bias in India. Population Studies, 51(3), November, 307-315.

DaVanzo J, Pebley A (1993), 'Maternal D epletion and Child Survival in Guatemala and Malaysia'. L abor and Population Program W orking Paper 93-18. RAND.

Deaton A (2008), 'Height, Health, and Inequality: The Distribution of Adult Heights in India'. The A merican E wnomic Review P\& P Vol. 98, No. 2: 468.

Deaton A and J D reze 2002. Poverty and Inequality in India: A Re-Examination. E conomic and Political W ekly, Vol. 37, No. 36, Sep. 7-13, pp. 3729-3748.

Deolalikar, A and Nandi, A (in progress). Did the ban on sex-selective abortions improve the juvenile sex ratio in India? UC Riverside. M imeograph.

Dharmalingam A, Morgan S (2004), 'Pervasive Muslim-Hindu Fertility Differences in India'. D emography Vol. 41, No. 3: 529-545.

Dickemann M (1979), 'Female Infanticide, Reproductive Strategies, and Social Stratification: A

Preliminary Model' in N.A. Chagnon and W.G. Irons, ed. E volutionary Biology and H uman Social Behavior. North Scituate, MA: D uxbury Press: 321-367.

Dubuc S, Coleman D (2007), 'An Increase in the Sex Ratio of Births to India-Born Mothers in England and Wales: Evidence for Sex-Selective Abortion'. Population and D evelopment Review Vol. 33, No. 2: 383-400.

Dyson T, Moore M (1983), 'On Kinship Structure, Female Autonomy, and D emographic Behavior in India'. Population and D evelopment Review Vol. 9, No. 1: 35-60.

Ebenstein A (2010), 'The 'Missing Girls' of China and the Unintended Consequences of the One Child Policy'. Journal of H uman Resouroes Vol. 45, No. 1: 87-115.

Ebenstein A, Sharygin E (2009), 'The Consequences of The" Missing Girls" Of China'. The W orld Bank E conomic Review Vol. 23, No. 3: 399-425.

Edlund L (1999), 'Son Preference, Sex Ratios, and Marriage Patterns'. Journal of Political E conomy Vol. 107, No. 6: 1275-1304.

Edlund L, Lee C (2009), 'Son Preference, Sex Selection and Economic Development: Theory and Evidence from South Korea'. M imeo. Columbia University 
Edlund L, Yi J and Li H et al. (2007) 'Sex Ratios and Crime: Evidence from China' IZA Discussion Paper no. 3214

Foster DA, Rosenzweig RM 'D oes Economic Growth Reduce Fertility? Rural India 1971-1999'. Paper Prepared for the N CA E R India Policy F orum 31 Jul -1 Aug 2006. D elhi, India.

George SM (2006), 'Sex Ratio in India. Response to Jha Et Al.'. TheL anœt 27 May 2006. Vol. 367, No. 9524: 1725.

George, SM (2010), 'Sex selection as genocide'. Paper presented at the University of Bristol, 31 March 2010. Mimeo. Intercultural Resources, New D elhi

Glewwe P (1999), 'Why D oes Mother's Schooling Raise Child Health in D eveloping Countries? Evidence from Morocco'. Journal of H uman Resources Vol. 34, No. 1: 124-159.

Goodkind D (1999), On Substituting Sex Preference Strategies in East Asia: Does Prenatal Sex Selection ReducePostnatal Discrimination? Population and D evelopment Review, Vol. 22, No. 1 (Mar., 1996), pp. 111-125

Grover A, Vijayvergiya R (2006), 'Sex Ratio in India. Response to Jha, Prabhat, Rajesh Kumar, Neeraj D hingira'. The L anoet 27 May-2 June 2006 Vol. 367, No. 9524: 1726.

Guilmoto C Z. 2008. "Economic, Social and Spatial Dimensions of India's Excess Child Masculinity" Population, 63 (1), 2008, 93-122.

Hansen C (2007), 'Asymptotic Properties of a Robust Variance Matrix Estimator for Panel Data When T Is Large'. Journal of $\mathrm{E}$ conometrics Vol. 141, No. 2: 597-620.

Heckman J (1981), The Incidental Parameters Problem and the Problem of Initial Conditions in Estimating a Discrete Time-Discrete D ata Stochastic Process' in C.F. Manski and D .L. McFadden, ed. Structural A nalysis of D iscrete D ata with E onometric A pplications. London: MIT Press: 179-195.

Hesketh T, Xing Z (2006), 'Abnormal Sex Ratios in Human Populations: Causes and Consequences'. Proceedings of the N ational A cademy of Sciences of the U nited States of A merica Vol. 103, No. 36: 13271-13275.

Jayaraj D, Subramanian S (2004), 'Women S Wellbeing and the Sex Ratio at Birth: Some Suggestive Evidence from India'. Journal of D evelopment Studies Vol. 40, No. 5: 91-119.

Jayachandran S., Lleras-Muney A. and Smith, Kimberly V.(2010), 'Modem Medicine and the 20th Century Decline in Mortality: Evidence on the Impact of Sulfa Drugs' . American Economic Journal: Applied Economics 2, April: 118-146

Jensen R and Oster E (2009), 'The Power of Tv: Cable Television and Women's Status in India*'. Q uarterly Journal of E conomics Vol. 124, No. 3: 1057-1094.

Jha P, Kumar R, Vasa P, D hingra N, Thiruchelvam D, Moineddin R (2006), 'Low Male-to-Female Sex Ratio of Children Bom in India: National Survey of 1. 1 Million Households'. The L anot Vol. 367, No. 9506: 211-218.

Kim J (2005), 'Sex Selection and Fertility in a Dynamic Model of Conception and Abortion'. Journal of Population E conomics Vol. 18, No. 1: 41-67.

Klasen, S. 1994. "Missing women reconsidered," W orld D evelopment 22: 1061- 1071.

Klasen S, Wink C (2002), 'A Turming Point in Gender Bias in Mortality? An Update on the Number of Missing Women'. Population and D evelopment Review Vol. 28, No. 2: 285-312. 
Kumar D . (1983), Male Utopias or Nightmares, Economic and Political Weekly, January 15, 61-64.

Kumm J, Laland K, Feldman M (1994), 'Gene-Culture Coevolution and Sex-Ratios: The Effects of Infanticide, Sex-Selective Abortion, Sex Selection, and Sex-Biased Parental Investment on the Evolution of Sex Ratios'. Theoretical Population Biology Vol. 46, No. 3: 249-278.

Lazarus J (2002), 'Human Sex Ratios: Adaptations and Mechanisms, Problems and Prospects. Chapter 14' in Ian C. and W. Hardy, ed. Sex Ratios: C oncepts and Research Methods: 287-311.

Lhila A, Simon K (2008), 'Prenatal Health Investment Decisions: D oes the Child's Sex Matter?'. D emography Vol. 45, No. 4: 885-905.

Lichtenberg F, Lleras-Muney A (2005). The Effect of Education on Medical Technology Adoption: Are the More Educated More Likely to Use New D rugs. Special issue of the A nnales d'E conomie et Statistique in memory of Zvi G riliches. 79/ 80.

Lin M, Qian N, Liu J (2008), 'More Women Missing, Fewer Girls Dying: The Impact of Abortion on Sex Ratios at Birth and Excess Female Mortality in Taiwan'. CE PR D isaussion paper 6667.

Low B (2001), W hy Sex Matters: A D arwinian L ook at H uman Behavior, Princeton University Press.

Mahal A, Varshney A, Taman S (2006), 'D iffusion of Diagnostic Medical D evices and Policy Implications for India'. International journal of technology assessment in health careVol. 22, No. 02: 184-190.

Mazumder B, Almond D , Park K, Crimmins E, Finch C (2009), 'Lingering Prenatal Effects of the 1918 Influenza Pandemic on Cardiovascular Disease'. Journal of developmental origins of health and disease Vol. 1, No. 01: 26-34.

Miller B (1981), The E ndangered Sex: N eglect of F emale Children in Rural N orth India, Comell University Press, Ithaca.

Mishra V, Roy T, Retherford R (2004), 'Sex Differentials in Childhood Feeding, Health Care, and Nutritional Status in India'. Population and D evelopment Review Vol. 30, No. 2: 269-295.

Murthi M, Guio A, Dreze J (1995), 'Mortality, Fertility, and Gender Bias in India: A District-Level Analysis'. Population and D evelopment Review Vol. 21, No. 4: 745-782.

Murthy L, Bal V, Sharma D, al. e (2006), 'The Business of Sex Selection: The Ultrasonography Boom. Presented at the Nehru Memorial Museum \& Library Workshop on D eclining Child Sex Ratio'. Presented at the N ehru M emorial M useum \& L ibrary W ork shop on dedining child sex ratio, Jan 23-24 2006 New Delhi, India.

Oldenburg P (1992), 'Sex Ratio, Son Preference and Violence in India: A Research Note'. E onomic and Political W ekly Vol. 27, No. 49: 2657-2662.

O ster E (2005), 'Hepatitis B and the Case of the Missing Women'. Journal of Political E conomy Vol. 113, No. 6.

O ster E (2009), 'Proximate Sources of Population Sex Imbalance in India'. D emography May 2009, Vol. 46, No. 325-339.

O ster E, Chen G, Yu X, Lin W 'Hepatitis B Does Not Explain Male-Biased Sex Ratios in China'. E conomics L etters. Forthcoming

Park C, Cho N (1995), 'Consequences of Son Preference in a Low-Fertility Society: Imbalance of the Sex 
Ratio at Birth in Korea'. Population and D evelopment Review Vol. 21, No. 1: 59-84.

Potts M (1997), 'Sex and the Birth Rate: Human Biology, Demographic Change, and Access to FertilityRegulation Methods'. Population and D evelopment Review Vol. 23, No. 1: 1-39.

Qian N (2008), 'Missing Women and the Price of Tea in China: The Effect of Sex-Specific Earnings on Sex Imbalance*'. Q uarterly Journal of E conomics Vol. 123, No. 3: 1251-1285.

Rajan SI, US. Mishra, K Navaneetham. 1992. D ecline in Sex Ratio: Alternative Explanation Revisited Source: Economic and Political Weekly, Vol. 27, No. 46 (Nov. 14, 1992), pp. 2505-2508

Rao V (1993), 'The Rising Price of Husbands: A Hedonic Analysis of D owry Increases in Rural India'. Journal of Political E onomy Vol. 101, No. 4: 666-677.

Retherford R, Roy T (2003). Factors Affecting Sex-Selective Abortion in India and 17 Major States. $\mathrm{N}$ ational Family H ealth Survey Subject Reports N 0. 21. Mumbai, International Institute for Popoulation Sciences and Honolulu: East-West Center.

Rodgers J, D oughty D (2001), 'D oes Having Boys or Girls Run in the Family?'. Chanœ Vol. No. 14(4): 813.

Rose, E. (1999), Consumption smoothing and excess female mortality in rural India, Review of E conomics and Statistics, 81(1), February, 41-49.

Rosenzweig M, Schultz T (1982), 'Market Opportunities, Genetic Endowments, and Intrafamily Resource Distribution: Child Survival in Rural India'. The A merican economic review Vol. 72, No. 4: 803-815.

Samuelson PA (1985), 'Modes of Thought in Economics and Biology'. The A merican economic review Papers and Proc. Vol. 75, No. 2: 166-172.

Sen A (1990), 'More Than 100 Million Women Are Missing'. N ew Y ork Review of Books Vol. 37, No. 20: 6166.

Sen A (1992), 'Missing Women'. British Medical Journal Vol. 304, No. 6827: 587.

Sheth SS (2006). 'Missing female births in India. ' L anœt 2006; 367: 185

Sinha N. \& Yoong J., 2009. "Long-term financial incentives and investment in daughters : evidence from conditional cash transfers in north India," Policy Research Working Paper Series 4860, The World Bank

Stinson S (1985), 'Sex Differences in Environmental Sensitivity D uring G rowth and D evelopment'. A merican Journal of Physical A nthropology Vol. 28, No. S6: 123-147.

Sudha, S and S Irudaya Rajan, "Female Demographic Disadvantage in India 1981-1991: Sex

Selective Abortions and Female Infanticide," D evelopment and Change, 1999, 30 (3), 585-618

Tambiah S (1973), 'D owry, Bridewealth and Women's Property Rights' in Jack R. G oody and Stanley J. Tambiah, ed. Bridewealth and D owry. Cambridge Papers in Social A nthropology Cambridge University Press. 7: 59-169.

Teitelbaum MS, Mantel N (1971), 'Socio-Economic Factors and the Sex Ratio at Birth'. Journal of biosocial science Vol. 3, No. 01: 23-42.

The Economist (1993). The Lost Girls. (Male Births O utnumber Female Births in Asian Countries) 18 September 1993. 
The Economist (2010). G endercide (Killed, Aborted or Neglected, at Least 100m Girls Have Disappeared - and the Number Is Rising). 4 March 2010.

Trivers R, Willard D (1973), 'Natural Selection of Parental Ability to Vary the Sex Ratio of Offspring'. Scienc Vol. 179, No. 4068: 90.

Tuljapurkar S, Li N, Feldman M (1995), 'High Sex Ratios in China's Future'. ScienœV Vol. 267, No. 5199: 874-876.

Virmani A (2004), 'India's Economic G rowth: From Socialist Rate of G rowth to Bharatiya Rate of Growth'. W orking Paper N 0. 122, New Delhi: Indian Council for Research on Internatioinal Relations (ICRIER)

Visaria L (2005), 'Female D eficit in India: Role of Prevention of Sex Selective Abortion Act'.

Visaria PM (1967), 'The Sex Ratio of the Population of India and Pakistan and Regional Variations During 1901-61' in A. Bose, ed. Patterns of Population Change in India 1951-61. Bombay: Allied Publishers. 61: 334-71.

Waldron I (1983), 'The Role of G enetic and Biological Factors in Sex Differences in Mortality' in A.D. Lopez and L.T. Ruzicka, ed. Sex D ifferentials in M ortality: Trends, D eterminants and Consequences. New York, NT: Dept. of Demography: 141-64.

Wooldridge J (2002), E onometric A nalysis of Cross Section and Panel D ata, The MIT press.

Wooldridge J (2005), 'Fixed-Effects and Related Estimators for Correlated Random-Coefficient and Treatment-Effect Panel D ata Models'. Review of E conomics and Statistics Vol. 87, No. 2: 385-390.

Wooldridge JM (2005a). Unobserved heterogeneity and estimation of average partial effects, in Donald Andrews and James Stock (eds.). Identification and Inference for E conometric Models: A Festschritt in $\mathrm{H}$ onor of Thomas J Rothenberg, Cambridge: Cambridge University Press.

Yi Z, Ping T, Baochang G, Yi X, Bohua L, Yongpïng L (1993), 'Causes and Implications of the Recent Increase in the Reported Sex Ratio at Birth in China'. Population and Development Review Vol. 19, No. 2: 283302.

Zhu W, Lu L, Hesketh T (2009), 'China's Excess Males, Sex Selective Abortion, and One Child Policy: Analysis of Data from 2005 National Intercensus Survey'. British M edical Journal Apr09 Vol. 338, No. 2. 
Figures: N on-parametric trend in proportion of females at birth by birth order and previous sex composition

Figure 1: Control groups

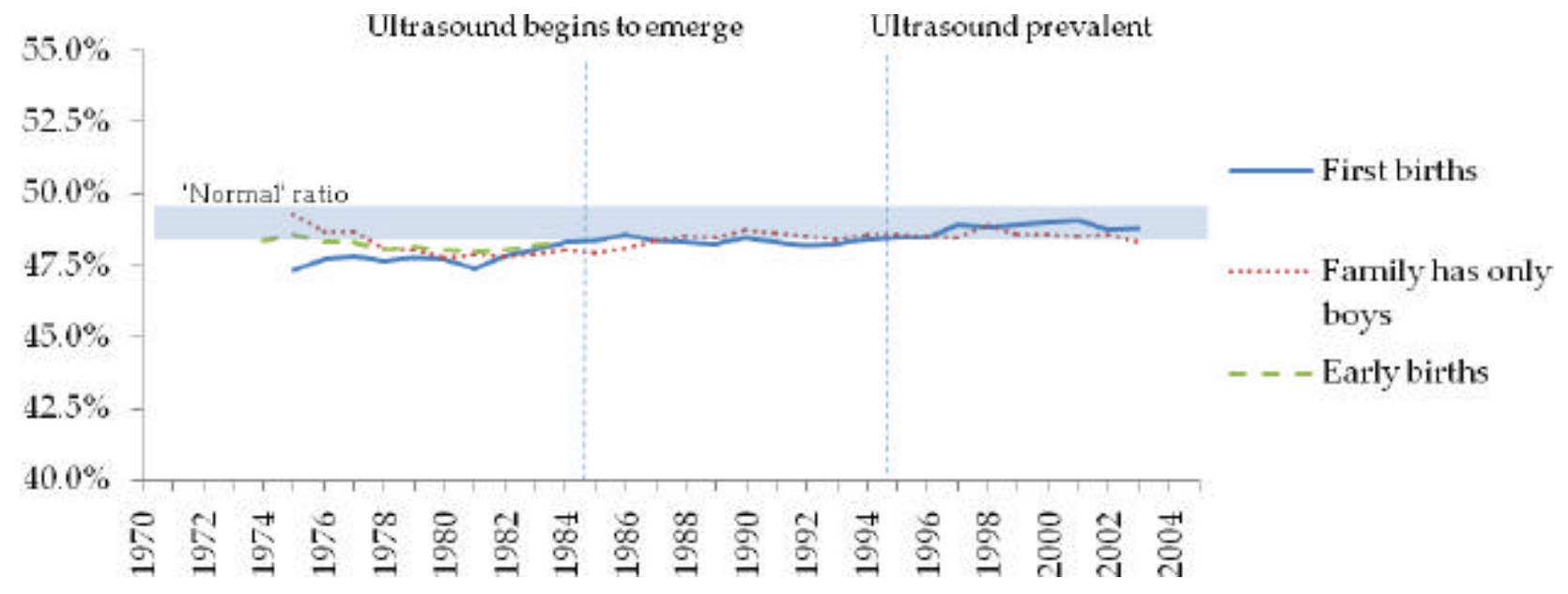

Figure 2: Second births (5-year moving average)

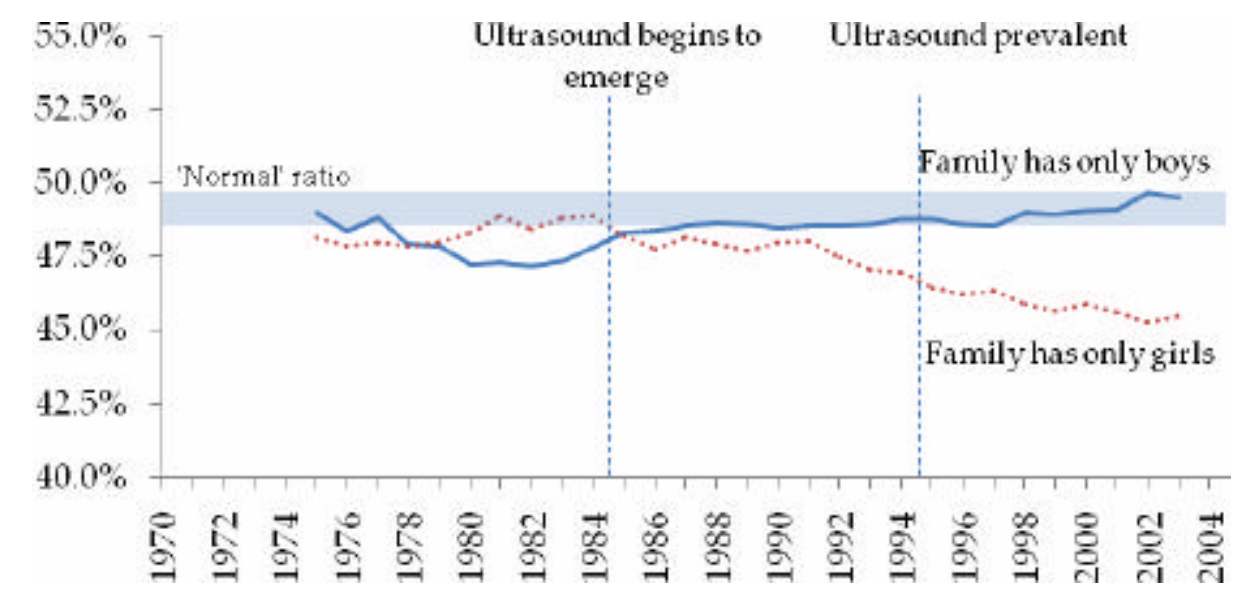


Figure 3: Third births (5-year moving average)

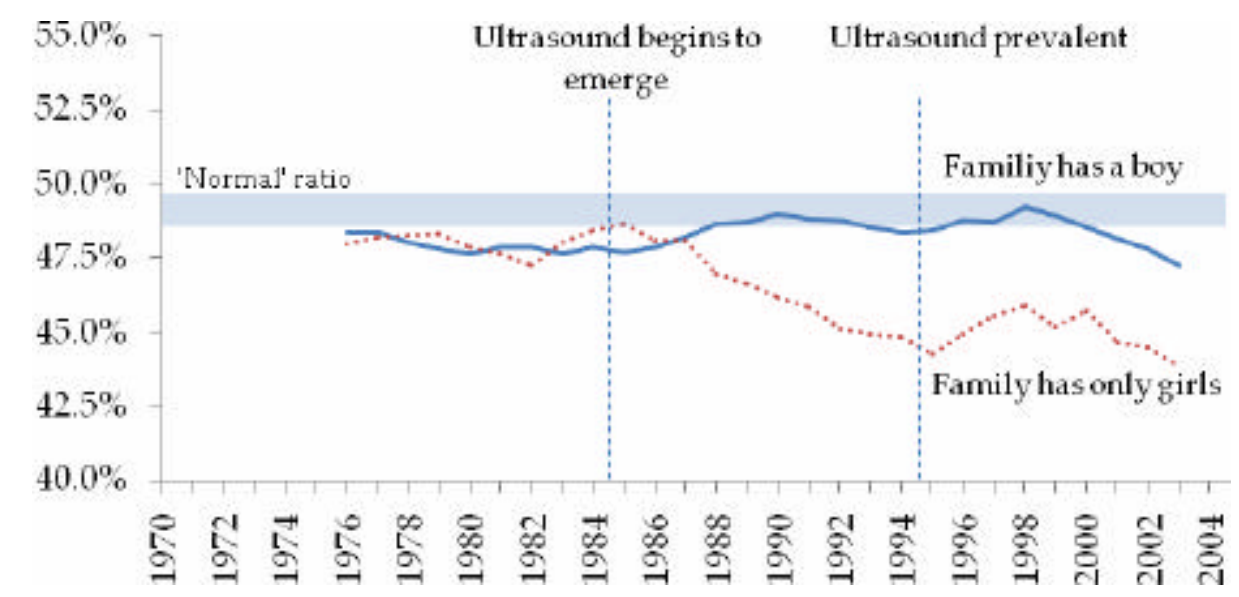

Figure 4: F ourth births (5-year moving average)

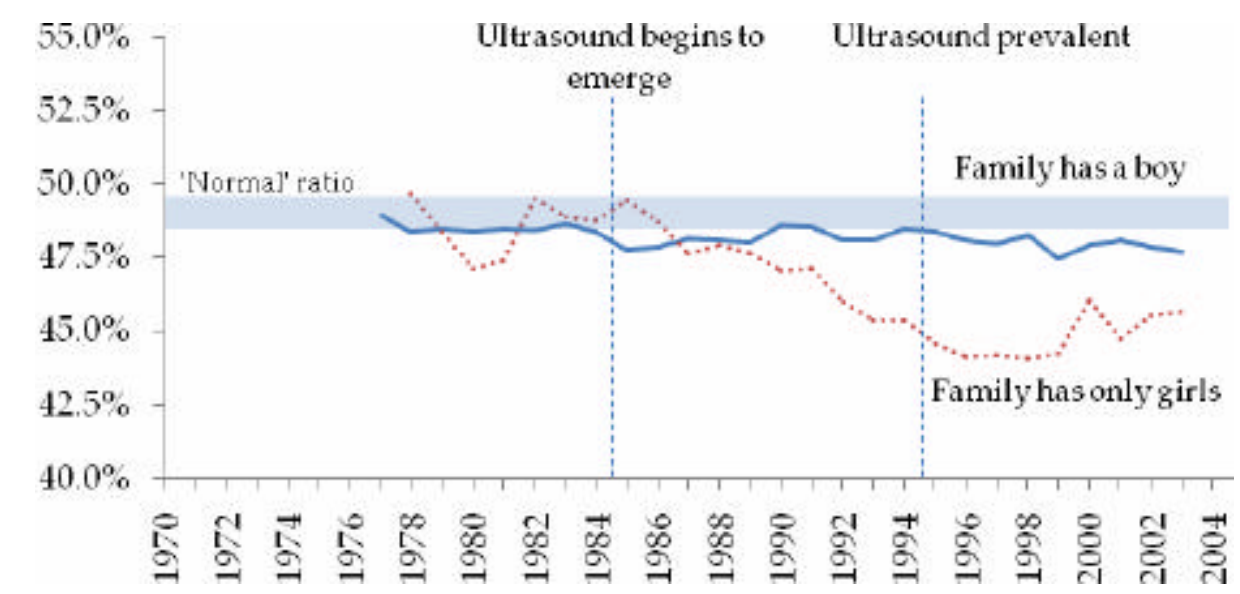




\section{Tables}

Table 1: D ouble difference: Birth order* post-ultrasound

\begin{tabular}{lcc}
\hline & $(1)$ & $(2)$ \\
\hline Constant & $48.05^{* * *}$ & $47.84^{* * *}$ \\
& $(0.200)$ & $(0.192)$ \\
\hline Post1 & 0.11 & $0.46^{* *}$ \\
Post2 & 0.172 & $(0.220)$ \\
& -0.13 & $0.94^{* * *}$ \\
\hline Post1 * Second birth & 0.249 & $(0.245)$ \\
Post1 * Third birth & & -0.21 \\
& & $(0.328)$ \\
Post1 * Fourth birth & & -0.5 \\
& & $(0.388)$ \\
Post2 * Second birth & & $-1.11^{* * *}$ \\
& & $(0.396)$ \\
Post2 * Third birth & & $-1.47 * * *$ \\
& & $(0.319)$ \\
Post2 * Fourth birth & & $-1.53^{* *}$ \\
& & $(0.622)$ \\
Second birth & & $-2.08^{* * *}$ \\
Third birth & & $(0.469)$ \\
Fourth birth & & 0.13 \\
& & $(0.275)$ \\
Year dummies & & 0.22 \\
Covariates & No & $(0.317)$ \\
Observations & No & $0.79 * *$ \\
\end{tabular}

Notes: Dependent variable is 100 if index birth is female, 0 otherwise. Standard errors clustered by state are in parentheses, $* \mathrm{p}<0.10, * * \mathrm{p}<0.05,{ }^{* * *} \mathrm{p}<0.01$. Postt is 0 for $1972-84$ and 1 for $1985-2005$. The post-period is divided into two periods, post1 (1985-94) and post2 (1995-2005). Refer equation (1a) in the text. The regressors of interest are the interaction terms between birth order and the post dummy. The sample includes first births. The trend for first births is reflected in the uninteracted post dummies. The interacted dummies indicate the deviation of the trend for higher order births from the trend for first births by period. 
Table 2: D ouble difference-sex composition of previous siblings* post-ultrasound

\begin{tabular}{|c|c|c|c|c|}
\hline Constant & $\begin{array}{c}(1) \\
47.83^{* * *} \\
(0.759) \\
\end{array}$ & $\begin{array}{c}(2) \\
46.46^{* * *} \\
(0.720) \\
\end{array}$ & $\begin{array}{c}(3) \\
47.69 * * * \\
(0.778) \\
\end{array}$ & $\begin{array}{c}(4) \\
46.27 * * * \\
(0.729) \\
\end{array}$ \\
\hline \multicolumn{5}{|l|}{ D ouble differeno: $Y^{*}$ post } \\
\hline Post1 * First born in family is a girl & $\begin{array}{c}-0.67 * \\
(0.381)\end{array}$ & $\begin{array}{c}-0.55 \\
(0.357)\end{array}$ & & \\
\hline Post2 * First born in family is a girl & $\begin{array}{c}-2.42 * * * \\
(0.512)\end{array}$ & $\begin{array}{c}-2.24^{* * *} \\
(0.517)\end{array}$ & & \\
\hline Post1 * Family has no son & & & $\begin{array}{c}-1.27 * * * \\
(0.352)\end{array}$ & $\begin{array}{c}-1.20^{* * *} \\
(0.349)\end{array}$ \\
\hline Post2 * Family has no son & & & $\begin{array}{c}-3.47 * * * \\
(0.622) \\
\end{array}$ & $\begin{array}{c}-3.32 * * * \\
(0.617)\end{array}$ \\
\hline \multicolumn{5}{|l|}{ Oneway effects: $Y$ and post } \\
\hline First born in family is a girl & $\begin{array}{c}-0.21 \\
(0.267)\end{array}$ & $\begin{array}{l}-0.45^{*} \\
(0.264)\end{array}$ & & \\
\hline Family has no son & & & $\begin{array}{c}0.35 \\
(0.269)\end{array}$ & $\begin{array}{c}0.23 \\
(0.266)\end{array}$ \\
\hline Post1 & $\begin{array}{c}0.76 \\
(0.769)\end{array}$ & $\begin{array}{c}1.80^{*} \\
(0.877)\end{array}$ & $\begin{array}{c}0.8 \\
(0.772)\end{array}$ & $\begin{array}{c}1.84^{* *} \\
(0.869)\end{array}$ \\
\hline Post2 & $\begin{array}{c}0.78 \\
(0.843) \\
\end{array}$ & $\begin{array}{l}2.30 * * * \\
(0.818)\end{array}$ & $\begin{array}{c}0.74 \\
(0.850) \\
\end{array}$ & $\begin{array}{l}2.23 * * \\
(0.826) \\
\end{array}$ \\
\hline $\begin{array}{l}\text { Year dummies } \\
\text { Covariates (inc. state dummies \& trends) } \\
\text { Observations }\end{array}$ & $\begin{array}{c}\text { Yes } \\
\text { No } \\
528,061\end{array}$ & $\begin{array}{c}\text { Yes } \\
\text { Yes } \\
521,290\end{array}$ & $\begin{array}{c}\text { Yes } \\
\text { No } \\
528,061\end{array}$ & $\begin{array}{c}\text { Yes } \\
\text { Yes } \\
521,290\end{array}$ \\
\hline
\end{tabular}

Notes: $D$ ependent variable is 100 if index birth is female, 0 otherwise. Standard errors clustered by state in parentheses, $* p<0.10, * * p<0.05, * * * p<0.01$. Refer equation (1) in the text. Columns $1-2$ define the "treatment" as first born sex and columns 34 as an indicator for the family having had no son up until the index birth. Estimates with and without covariates are shown. The regressors of interest are the double interaction terms $Y_{j}{ }^{*}$ postt, where post $t_{t}$ is 0 for 1972-84 and 1 for 1985-2005. The post-period is divided into two periods, post1 (1985-94) and post2 (1995-2005). We use two alternative summary indicators of previous sibling sex $\left(Y_{j}\right)$. The uninteracted $Y_{j}$ capture pre ultrasound coefficients and the interacted terms indicate the deviation in the post-ultrasound period. Each column includes year dummies, which are jointly significant at the $1 \%$ level. The covariates $\mathrm{G}_{\mathrm{ij}}$ are as detailed in the text and include dummy variables indicating: the top $20 \%$ of households by wealth, secondary or higher mother's and father's education, urban location, north-western state, Muslim, Christian and high caste Hindu, mother's birth cohort and age of mother at birth. Where included, the state dummies and linear state trends incorporated in Gijt are each jointly significant at the $1 \%$ level. Consider the main effects in the lower panel. Positive coefficients on the "post" terms confirm the positive trend in the first birth sex ratio seen in Table 1. The one positive coefficient on first born sex appears to signal restrictiveness of the parsimonious specification used in previous studies as no previous sex indicator is significant in the more general model corresponding to equation (2) in the text, estimates of which are in Appendix Table 1. 
Table 3: Triple difference - pre and post-ultrasound coefficients on birth order*sex composition of previous siblings

\begin{tabular}{|c|c|c|c|c|c|c|c|}
\hline \multirow[t]{2}{*}{ Birth order } & \multirow[t]{2}{*}{ Previous births } & \multirow{2}{*}{\multicolumn{3}{|c|}{$\begin{array}{ll}1985-94 & 1995-2005 \\
\text { Without covariates }\end{array}$}} & $1972-84$ & $1985-94$ & 1995-2005 \\
\hline & & & & & \multicolumn{3}{|c|}{ With covariates } \\
\hline Constant & - & $\begin{array}{c}47.58^{* * *} \\
(0.774)\end{array}$ & $\begin{array}{c}48.42^{* * *} \\
(0.472)\end{array}$ & $\begin{array}{c}48.57 * * * \\
(0.496)\end{array}$ & $\begin{array}{c}46.86^{* * * *} \\
(0.833)\end{array}$ & $\begin{array}{c}47.41 * * * \\
(0.404)\end{array}$ & $\begin{array}{c}49.64^{* * *} \\
(0.656)\end{array}$ \\
\hline \multicolumn{8}{|c|}{ Triple differenœ: $Y^{*} d^{*}$ post } \\
\hline \multirow[t]{2}{*}{ Second births } & $\mathrm{B}$ & $\begin{array}{c}-0.25 \\
(0.348)\end{array}$ & $\begin{array}{c}0.28 \\
(0.324)\end{array}$ & $\begin{array}{c}0.22 \\
(0.429)\end{array}$ & $\begin{array}{c}-0.45 \\
(0.345)\end{array}$ & $\begin{array}{c}0.18 \\
(0.339)\end{array}$ & $\begin{array}{c}0.08 \\
(0.444)\end{array}$ \\
\hline & G & $\begin{array}{c}0.53 \\
(0.374)\end{array}$ & $\begin{array}{c}-0.46 \\
(0.365)\end{array}$ & $\begin{array}{c}-2.93 * * * \\
(0.449)\end{array}$ & $\begin{array}{c}0.27 \\
(0.387)\end{array}$ & $\begin{array}{c}-0.6 \\
(0.354)\end{array}$ & $\begin{array}{c}-3.06^{* * *} \\
(0.485)\end{array}$ \\
\hline \multirow[t]{3}{*}{ Third births } & BB & $\begin{array}{c}0.84 \\
(0.582)\end{array}$ & $\begin{array}{c}0.93 * \\
(0505)\end{array}$ & $1.30^{*}$ & $\begin{array}{c}0.52 \\
(0578)\end{array}$ & $\begin{array}{c}0.73 \\
(0.507)\end{array}$ & 0.72 \\
\hline & BG & $\begin{array}{l}-0.06 \\
(0.378)\end{array}$ & $\begin{array}{c}-0.2 \\
(0.405)\end{array}$ & $\begin{array}{c}-1.13^{* * *} \\
(0.375)\end{array}$ & $\begin{array}{l}-0.44 \\
(0.427)\end{array}$ & $\begin{array}{l}-0.33 \\
(0.410)\end{array}$ & $\begin{array}{l}-1.52^{* * *} \\
(0.512)\end{array}$ \\
\hline & GG & $\begin{array}{c}0.05 \\
(0.621)\end{array}$ & $\begin{array}{r}-1.64^{* *} \\
(0.755)\end{array}$ & $\begin{array}{c}-3.82 * * * \\
(1.091)\end{array}$ & $\begin{array}{c}-0.39 \\
(0.689)\end{array}$ & $\begin{array}{r}-1.84^{* *} \\
(0.773)\end{array}$ & $\begin{array}{c}-4.13^{* * *} \\
(1.227)\end{array}$ \\
\hline \multirow[t]{4}{*}{ Fourth births } & BBB & $\begin{array}{c}0.9 \\
(0.775)\end{array}$ & $\begin{array}{c}0.59 \\
(0.774)\end{array}$ & $\begin{array}{c}1.04 \\
(0.862)\end{array}$ & $\begin{array}{c}0.53 \\
(0.889)\end{array}$ & $\begin{array}{c}0.58 \\
(0.809)\end{array}$ & $\begin{array}{c}0.38 \\
(1.017)\end{array}$ \\
\hline & BBG & $\begin{array}{l}1.62 * * * \\
(0.477)\end{array}$ & $\begin{array}{c}0.59 \\
(0.489)\end{array}$ & $\begin{array}{c}0.43 \\
(0.912)\end{array}$ & $\begin{array}{l}1.14^{*} \\
(0.595)\end{array}$ & $\begin{array}{c}0.48 \\
(0.428)\end{array}$ & $\begin{array}{l}-0.08 \\
(0.842)\end{array}$ \\
\hline & BG G & $\begin{array}{c}-0.28 \\
(0.542)\end{array}$ & $\begin{array}{l}-1.00^{*} \\
(0.492)\end{array}$ & $\begin{array}{l}-2.20 * * * \\
(0690)\end{array}$ & $\begin{array}{c}-0.8 \\
(0.588)\end{array}$ & $\begin{array}{l}-1.09 * \\
(0.533)\end{array}$ & $\begin{array}{l}-2.76^{* * *} \\
(0.847)\end{array}$ \\
\hline & GGG & $\begin{array}{c}1.35 \\
(0.902)\end{array}$ & $\begin{array}{l}-1.32 \\
(0.847)\end{array}$ & $\begin{array}{l}-4.06^{* * *} \\
(0.986)\end{array}$ & $\begin{array}{c}0.74 \\
(0.939)\end{array}$ & $\begin{array}{l}-1.41 \\
(0.847)\end{array}$ & $\begin{array}{c}-4.39 * * * \\
(1.033)\end{array}$ \\
\hline \multicolumn{2}{|l|}{ Year dummies } & Yes & Yes & Yes & Yes & Yes & Yes \\
\hline \multicolumn{2}{|l|}{ Covariates } & No & No & No & Yes & Yes & Yes \\
\hline \multicolumn{2}{|c|}{ Observations } & 153,588 & 245,524 & 128,949 & 152,181 & 242,431 & 126,678 \\
\hline \multicolumn{2}{|c|}{ p-values of F-tests: } & & & & & & \\
\hline \multicolumn{2}{|c|}{ Year dummies } & 0.05 & 0.02 & 0.14 & 0.22 & 0.00 & 0.06 \\
\hline \multicolumn{2}{|l|}{ State dummies } & & & & 0.00 & 0.00 & 0.00 \\
\hline \multicolumn{2}{|l|}{ State trends } & & & & 0.00 & 0.00 & 0.00 \\
\hline
\end{tabular}

Notes: See Notes to Table 2. These are estimates of equation (3) in the text. Interactions with post are implicit as the model is estimated separately for each period, with the period indicated by the column headings. The positive coefficient on bbg at fourth birth order is an anomaly. Cell sizes for sub-categories of fourth births are relatively small, especially when the composition of births up until the third is boyrich. 
Table 4a: Population-averaged estimates of heterogeneous coefficients models

\begin{tabular}{lccc}
\hline & $(1)$ & $(2)$ & $(3)$ \\
\hline Constant & No controls & With controls & ATE \\
& $47.69^{* * *}$ & $47.08^{* * *}$ & $46.79^{* * *}$ \\
& $(0.778)$ & $(0.759)$ & $(0.751)$ \\
\hline D ouble differenoe: $Y^{*}$ post & & & \\
\hline Post1 * Family has no son & $-1.27^{* * *}$ & $-1.22^{* * *}$ & $-2.98^{* * *}$ \\
& $(0.352)$ & $(0.351)$ & $(0.392)$ \\
Post2 * Family has no son & $-3.47^{* * *}$ & $-3.34^{* * *}$ & $-5.15^{* * *}$ \\
& $(0.622)$ & $(0.614)$ & $(1.380)$ \\
\hline Oneway effects: Y and post & & & \\
\hline Family has no son & 0.35 & 0.25 & -0.19 \\
& $(0.269)$ & $(0.265)$ & $(0.904)$ \\
Post1 & 0.8 & 1.21 & $1.53^{*}$ \\
& $(0.772)$ & $(0.830)$ & $(0.833)$ \\
Post2 & 0.74 & 1.17 & $1.57^{*}$ \\
& $(0.850)$ & $(0.850)$ & $(0.872)$ \\
\hline Year dummies & Yes & Yes & Yes \\
Covariates & Yes & Yes & Yes \\
Observations & 528,061 & 521,290 & 521,290 \\
\hline
\end{tabular}

Notes: See Notes to Table 2. The variables of interest are the interaction terms $Y_{j}{ }^{*}$ post. In col. 3, these terms are interacted with each (mother-level) covariate in mean-deviations and the average treatment effects (ATE) are derived; see equation (4a) in the text. As there are ten covariates, interacting each with the nine element vector $Y_{\mathrm{ij}}$ would produce 90 terms. To avoid this we work with the parsimonious specification of $Y$ used in Table 2. Since it is at the mother level that we want to model heterogeneity and one covariate is defined at the child level (age of the mother at the index birth), this is averaged to the mother level for this exercise. 
Table 4b: $\mathrm{H}$ eterogeneity in the coefficients by mother-level covariates

\begin{tabular}{|c|c|c|c|c|c|c|c|c|}
\hline $\begin{array}{l}\text { M ean deviation interactions: } \\
Y^{*} Z^{*} \text { post and } Y * Z\end{array}$ & W ealth & $\begin{array}{l}\text { Mother's } \\
\text { education }\end{array}$ & $\begin{array}{l}\text { Father's } \\
\text { education }\end{array}$ & U rban & $\begin{array}{l}\text { N orth-west } \\
\text { state }\end{array}$ & $\mathrm{H}$ indu & Muslim & H igh caste \\
\hline \multirow[t]{2}{*}{$\mathrm{Y} * \mathrm{Z}$} & 0.33 & -0.44 & -0.56 & 0.28 & -0.84 & 1.2 & 0.13 & 0.11 \\
\hline & $(0.976)$ & $(0.906)$ & $(0.897)$ & $(0.813)$ & $(0.746)$ & (1.079) & (1.357) & $(0.986)$ \\
\hline \multirow[t]{2}{*}{ Y*Z*P2 } & -1.95 & $-2.24^{*}$ & 0.77 & -0.49 & 0.12 & 0.4 & $2.81 *$ & -0.21 \\
\hline & (1.353) & (1.269) & $(0.957)$ & $(0.873)$ & $(0.683)$ & (1.221) & (1.473) & (1.243) \\
\hline \multirow[t]{2}{*}{ Y*Z*P3 } & $-4.03 * * *$ & $-2.39 *$ & -0.85 & -0.44 & -1.23 & 0.78 & $3.43^{*}$ & -1.62 \\
\hline & $(1.439)$ & $(1.211)$ & (1.744) & (1.132) & $(1.543)$ & $(1.922)$ & $(1.980)$ & $(1.262)$ \\
\hline \multirow{2}{*}{\multicolumn{2}{|c|}{$\begin{array}{l}\text { M ean deviation interactions (cont.): } \\
Y^{*} Z^{*} \text { post and } Y^{*} Z\end{array}$}} & Mother's whort & M other's cohort & M other's age & $\bar{M}$ other's age & M other's age & Mother's age & M other's age \\
\hline & & 1954-79 & 1980-7 & $12-15$ & $16-18$ & 19-24 & $25-30$ & $31-49$ \\
\hline \multirow[t]{2}{*}{$\mathrm{Y} * \mathrm{Z}$} & & $2.70^{* *}$ & -8.19 & $-7.31^{* *}$ & $-7.62^{* *}$ & $-8.50 * * *$ & $-4.81^{*}$ & \\
\hline & & (1.068) & (15.519) & (3.427) & (3.200) & (2.770) & (2.387) & \\
\hline \multirow[t]{2}{*}{$\mathrm{Y} * \mathrm{Z} * \mathrm{P} 2$} & & $10.38 * * *$ & & -2.95 & -1.11 & -2.94 & -0.4 & \\
\hline & & (2.698) & & $(4.366)$ & (3.661) & (2.782) & (3.242) & \\
\hline $\mathrm{Y} * \mathrm{Z} * \mathrm{P} 3$ & & $\begin{array}{c}24.474 \\
(20.572)\end{array}$ & $\begin{array}{l}36.26 \\
(32.070)\end{array}$ & $\begin{array}{c}-4.3 \\
(4.402)\end{array}$ & & $\begin{array}{c}0.08 \\
(1596)\end{array}$ & 1.54 & $\begin{array}{c}1.3 \\
3547)\end{array}$ \\
\hline
\end{tabular}

Notes: See Notes to Tables 2 and 4a. The coefficients presented here are from the model in column 3 of Table 4a. Let Z denote the demeaned mother-level covariates, (Git-c). As before, $\mathrm{Y}$ is previous sex composition and post indicates pre/ post ultrasound periods. These are the coefficients on $\mathrm{Y}_{j}{ }^{*} \mathrm{p}_{\mathrm{t}}{ }^{*} \mathrm{Z}_{\mathrm{j}}$. The column labels indicate the mother-level covariate being interacted; in every case this is a dummy variable. Most headers are self-explanatory; the covariates are described in Notes to Table 3 . Blank cells indicate terms that were dropped due to collinearity. For example, earlier in the sample period when age at birth was lower, older mothers had relatively few births and hence the blank cells. Mother's cohort 1942-52 was similarly dropped on account of small cell sizes. Coefficients for individual states are not displayed. 
Table 5: Placebo test premised on sex selection being impossible with a birth interval of less than a year

\begin{tabular}{lccc}
\hline & $(1)$ & $(2)$ & $(3)$ \\
\hline & Full sample & Random subsample & $\begin{array}{c}\text { Short birth interval } \\
(12 \mathrm{mths})\end{array}$ \\
\hline Constant & $48.43^{* * *}$ & $48.78^{* * *}$ & $48.60^{* * *}$ \\
Family has no boy & $(0.440)$ & $(0.210)$ & $(0.799)$ \\
& $-3.12^{* * *}$ & $-3.00^{* *}$ & -1.29 \\
& $(0.541)$ & $(1.445)$ & $(1.314)$ \\
\hline Year dummies & Yes & Yes & Yes \\
Covariates & No & No & No \\
Observations & 128,949 & 48,053 & 48,053 \\
\hline
\end{tabular}

Notes: See Notes to Table 2. These are estimates for (1995-2005), using the parsimonious specification of previous sibling sex. "Full sample" includes all births up to birth order four as in the baseline model. "Random subsample" includes random subsamples constructed to include the same number and order of births as in col. 3, i.e. 48,053 births (all 44,693 first births, 1,591 second births, 1,053 third births and 716 fourth births). We created 100 distinct such subsamples, and the results presented are simple averages of the coefficients from these subsamples. The third column includes only births following a 12-month or shorter birth interval. 
Table 6: Introducing data on self-reported use of ultrasound

\begin{tabular}{|c|c|c|c|}
\hline Birth order & Previous births & $(\mathrm{A})$ & (B) \\
\hline Constant & - & \multicolumn{2}{|c|}{$\begin{array}{c}49.44^{* * *} \\
(0.669) \\
\end{array}$} \\
\hline \multicolumn{4}{|c|}{ T riple \& quadruple differen $\mathrm{Y} \mathrm{Y}^{*} \mathrm{~d}^{*}$ post $\& \mathrm{Y}^{*} \mathrm{~d}^{*} \mathrm{U}^{*}$ post } \\
\hline \multirow[t]{2}{*}{ Second births } & $\mathrm{B}$ & $\begin{array}{c}0.18 \\
(0.546)\end{array}$ & $\begin{array}{c}0.12 \\
(1.133)\end{array}$ \\
\hline & G & $\begin{array}{c}-2.89 * * * * \\
(0.588)\end{array}$ & $\begin{array}{c}-0.4 \\
(0.849)\end{array}$ \\
\hline \multirow[t]{4}{*}{ Third births } & BB & $\begin{array}{c}0.85 \\
(0.697)\end{array}$ & $\begin{array}{c}0.75 \\
(1.838)\end{array}$ \\
\hline & BG & $-1.29 * *$ & -0.41 \\
\hline & & $(0.548)$ & (1.674) \\
\hline & G G & $\begin{array}{l}-3.18 * * \\
(1.285)\end{array}$ & $\begin{array}{l}-5.22 * * \\
(1.979)\end{array}$ \\
\hline \multirow[t]{4}{*}{ Fourth births } & $\mathrm{BBB}$ & $\begin{array}{c}0.79 \\
(1.058)\end{array}$ & $\begin{array}{l}-3.13 \\
(5.419)\end{array}$ \\
\hline & BBG & 0.35 & -3.31 \\
\hline & BGG & $\begin{array}{c}(0.894) \\
-2.30 * * \\
(0.861)\end{array}$ & $\begin{array}{c}(2.814) \\
-3.36^{*} \\
(1.823)\end{array}$ \\
\hline & GGG & $\begin{array}{c}-3.22 * * * \\
(0.980)\end{array}$ & $\begin{array}{c}-7.52^{* * * *} \\
(2.549)\end{array}$ \\
\hline \multicolumn{4}{|c|}{ T wo-way effects: U*post } \\
\hline \multicolumn{2}{|c|}{ Mother had recent scan } & \multicolumn{2}{|c|}{$\begin{array}{l}1.61^{* * *} \\
(0.564)\end{array}$} \\
\hline \multicolumn{2}{|l|}{ Year dummies } & \multicolumn{2}{|c|}{ Yes } \\
\hline \multicolumn{2}{|l|}{ Covariates } & \multicolumn{2}{|c|}{ Yes } \\
\hline \multicolumn{2}{|l|}{ Observations } & \multicolumn{2}{|c|}{126,678} \\
\hline \multicolumn{2}{|c|}{ p-values of F-tests: } & \\
\hline \multicolumn{2}{|c|}{ Year dummies } & \multicolumn{2}{|c|}{0.07} \\
\hline \multicolumn{2}{|l|}{ State dummies } & \multicolumn{2}{|c|}{0.00} \\
\hline \multicolumn{2}{|l|}{ State trends } & \multicolumn{2}{|c|}{0.00} \\
\hline
\end{tabular}

Notes: See Notes to Table 2. These are estimates of equation (5) in the text for the period 1995-2005. The interaction with post is implicit - see notes to Table 3 . There are no individual data on self-reported ultrasound use for the pre-ultrasound period. The indicator of ultrasound use (U) is 1 if the mother reported ultrasound use in the six years preceding the survey (and the index birth fell in that period), and 0 otherwise (see text). The model includes year dummies and the full set of covariates, Gijt. 
Table 7: A djusting for mortality of previous siblings

\begin{tabular}{|c|c|c|c|c|}
\hline \multirow{2}{*}{$\begin{array}{l}\text { Birth order } \\
\text { Constant }\end{array}$} & Previous births & $1972-84$ & $1985-94$ & 1995-2005 \\
\hline & - & $\begin{array}{l}46.96^{* * *} \\
(0.816)\end{array}$ & $\begin{array}{l}47.17 * * * \\
(0.418)\end{array}$ & $\begin{array}{c}49.64^{* * *} \\
(0.660)\end{array}$ \\
\hline \multicolumn{5}{|c|}{ Triple difference: $Y^{*} d^{*}$ post } \\
\hline \multirow[t]{2}{*}{ Second births } & $\mathrm{B}$ & $\begin{array}{c}-0.26 \\
(0.339)\end{array}$ & $\begin{array}{c}-0.08 \\
(0.329)\end{array}$ & $\begin{array}{c}-0.24 \\
(0.414)\end{array}$ \\
\hline & G & $\begin{array}{c}0.18 \\
(0.325)\end{array}$ & $\begin{array}{c}-0.45 \\
(0.316)\end{array}$ & $\begin{array}{l}-2.89 * * * \\
(0.457)\end{array}$ \\
\hline \multirow[t]{3}{*}{ Third births } & BB & $\begin{array}{c}0.7 \\
(0.481)\end{array}$ & $\begin{array}{c}0.87^{*} \\
(0.490)\end{array}$ & $\begin{array}{c}0.59 \\
(0801)\end{array}$ \\
\hline & BG & $\begin{array}{l}-0.2 \\
(0.378)\end{array}$ & $\begin{array}{l}-0.3 \\
(0.432)\end{array}$ & $\begin{array}{c}-1.77 * * * \\
(0.555)\end{array}$ \\
\hline & GG & $\begin{array}{c}-0.62 \\
(0.744)\end{array}$ & $\begin{array}{l}-1.78^{* *} \\
(0.752)\end{array}$ & $\begin{array}{l}-4.50^{* * *} \\
(1.149)\end{array}$ \\
\hline \multirow[t]{4}{*}{ Fourth births } & BBB & $\begin{array}{l}1.92 * * \\
(0857)\end{array}$ & $\begin{array}{c}0.18 \\
(1.039)\end{array}$ & $\begin{array}{c}1.07 \\
(1.380)\end{array}$ \\
\hline & BBG & $\begin{array}{l}0.99 * * \\
(0.467)\end{array}$ & $\begin{array}{c}0.73 \\
(0.457)\end{array}$ & $\begin{array}{c}0.19 \\
(0.927)\end{array}$ \\
\hline & BG G & $\begin{array}{c}0 \\
(0.590)\end{array}$ & $\begin{array}{c}-0.93 * * \\
(0.426)\end{array}$ & $\begin{array}{c}-2.32 * * * \\
(0720)\end{array}$ \\
\hline & GGG & $\begin{array}{c}0.01 \\
(0.848)\end{array}$ & $\begin{array}{r}-1.84 * * \\
(0.756)\end{array}$ & $\begin{array}{c}-4.46^{* * *} \\
(0.791)\end{array}$ \\
\hline \multirow{3}{*}{\multicolumn{2}{|c|}{$\begin{array}{l}\text { Y ear dummies } \\
\text { Covariates } \\
\text { Observations }\end{array}$}} & Yes & Yes & Yes \\
\hline & & Yes & Yes & Yes \\
\hline & & 156,994 & 249,031 & 129,722 \\
\hline \multirow{2}{*}{\multicolumn{2}{|c|}{$\begin{array}{l}\text { p-values of F-tests: } \\
\text { Year dummies }\end{array}$}} & & & \\
\hline & & 0.19 & 0.00 & 0.00 \\
\hline \multicolumn{2}{|l|}{ State dummies } & 0.00 & 0.00 & 0.00 \\
\hline \multicolumn{2}{|l|}{ State trends } & 0.00 & 0.00 & 0.00 \\
\hline
\end{tabular}

$\mathrm{N}$ otes: See $\mathrm{N}$ otes to $\mathrm{T}$ able 2 . The interactions with post are implicit - see notes to Table 3. Previous sibling sex composition is adjusted for survival of previous births up until the time of conception of the index birth. W hen we allow for some earlier birth order births to have died, the adjusted fourth order births may be in fact be fifth order births (etc.). For this reason, sample size increases relative to Table 3. 
Table 8a: Robustness checks using a parsimonious indicator of previous sibling sex composition

\begin{tabular}{|c|c|c|c|c|c|c|}
\hline & $(1)$ & $(2)$ & (3) & $(4)$ & (5) & (6) \\
\hline & Baseline & $\begin{array}{l}\text { Preceding } \\
\text { boy }\end{array}$ & Sample weights & $\begin{array}{l}\text { Cluster fixed } \\
\text { effects }\end{array}$ & 15 year window & $\begin{array}{c}2001-5 \\
\text { ("modern times") }\end{array}$ \\
\hline Constant & $\begin{array}{l}46.27 * * * \\
(0.729)\end{array}$ & $\begin{array}{c}47.64^{* * *} \\
(0.771)\end{array}$ & $\begin{array}{c}46.29 * * * \\
(0.988)\end{array}$ & $\begin{array}{c}46.27 * * * \\
(0.827)\end{array}$ & $\begin{array}{c}46.28^{* * * *} \\
(0.618)\end{array}$ & $\begin{array}{c}46.27 * * * \\
(0.729)\end{array}$ \\
\hline \multicolumn{7}{|l|}{ D ouble difference: $Y^{*}$ post } \\
\hline Post1 * Family has no son & $\begin{array}{l}-1.20 * * * \\
(0.349)\end{array}$ & $\begin{array}{c}-1.27^{* * *} \\
(0.353)\end{array}$ & $\begin{array}{l}-1.11^{* *} \\
(0.446)\end{array}$ & $\begin{array}{l}-1.19 * * * \\
(0.398)\end{array}$ & $\begin{array}{l}-1.58^{* * *} \\
(0.476)\end{array}$ & $\begin{array}{l}-1.20^{* * *} \\
(0.349)\end{array}$ \\
\hline Post2 * Family has no son & $\begin{array}{c}-3.32 * * * \\
(0.617)\end{array}$ & $\begin{array}{c}-3.48^{* * *} \\
(0.623)\end{array}$ & $\begin{array}{c}-3.25 * * * \\
(0.692)\end{array}$ & $\begin{array}{c}-3.32 * * * \\
(0.458)\end{array}$ & $\begin{array}{c}-3.59 * * * \\
(0.658)\end{array}$ & \\
\hline Post2a* Family has no son & & & & & & $\begin{array}{c}-3.24^{* * *} \\
(0.677)\end{array}$ \\
\hline Post2b * Family has no son & & & & & & $\begin{array}{c}-3.48 * * * \\
0.8 \\
\end{array}$ \\
\hline \multicolumn{7}{|l|}{ Oneway effects: $Y$ and post } \\
\hline Family has no son & $\begin{array}{c}0.23 \\
0.266\end{array}$ & $\begin{array}{l}0.41 \\
0.29\end{array}$ & $\begin{array}{c}0.22 \\
0.339\end{array}$ & $\begin{array}{c}0.17 \\
0.315\end{array}$ & $\begin{array}{c}0.52 \\
0.388\end{array}$ & $\begin{array}{c}0.23 \\
0.266\end{array}$ \\
\hline Post1 & $\begin{array}{c}1.84^{* *} \\
0.869\end{array}$ & $\begin{array}{c}0.8 \\
0.772\end{array}$ & $\begin{array}{c}1.64 \\
1.132\end{array}$ & $\begin{array}{l}1.88 * * \\
0.809\end{array}$ & $\begin{array}{c}2.00^{* * *} \\
0.504\end{array}$ & $\begin{array}{l}1.84^{* *} \\
0.869\end{array}$ \\
\hline Post2 & $\begin{array}{c}2.23 * * \\
0.826\end{array}$ & $\begin{array}{c}0.74 \\
0.849\end{array}$ & $\begin{array}{c}2.01^{* *} \\
0.889\end{array}$ & $\begin{array}{c}2.33 * * \\
0.951\end{array}$ & $\begin{array}{l}2.19 * * \\
0.847\end{array}$ & \\
\hline Post2a & & & & & & $\begin{array}{c}2.21 * * \\
0.831\end{array}$ \\
\hline Post2b & & & & & & $\begin{array}{l}1.97 * * \\
0.882\end{array}$ \\
\hline \multicolumn{7}{|l|}{0 ther covariates } \\
\hline Preceding boy & & $\begin{array}{c}0.14 \\
0.191\end{array}$ & & & & \\
\hline Observations & 521,290 & 528,061 & 521,290 & 521,290 & 417,599 & 521,290 \\
\hline
\end{tabular}

$\mathrm{N}$ otes: Se $\mathrm{N}$ otes to Table 2. The baseline is olumn 4 in Table 2. Col. 2: additional regressor denoting whether the birth preeeding the index birth was a boy. Col. 3: sample weights used as regression weights. C ol. 4: onditional upon duster fix ed effects. C ol. 5: Sample restricted to births in 15 year window preeeding the date of each survey, rather than 20 as in the baseline. Col. 6: D istinguishes post2a (1995-2000) and post2b (2001-5). 
Table 8b: Robustness checks using the comprehensive specification of previous sibling sex composition

\begin{tabular}{|c|c|c|c|c|c|c|c|}
\hline Birth order & $\begin{array}{l}\text { Previous } \\
\text { births }\end{array}$ & Baseline & Preceding boy & Sample weights & $\begin{array}{c}\text { Cluster fixed } \\
\text { effects }\end{array}$ & 15 year window & $\begin{array}{c}2001-5 \\
\text { ("modern times") }\end{array}$ \\
\hline Constant & - & $\begin{array}{l}49.64^{* * *} \\
(0.656)\end{array}$ & $\begin{array}{c}49.64^{* * * *} \\
(0.657)\end{array}$ & $\begin{array}{c}49.20 * * * \\
(0.807)\end{array}$ & $\begin{array}{c}49.86^{* * * *} \\
(0.814)\end{array}$ & $\begin{array}{l}49.64 * * * \\
(0.656)\end{array}$ & $\begin{array}{c}50.04^{* * *} \\
(0.844)\end{array}$ \\
\hline \multicolumn{8}{|c|}{ Triple differenœ: $Y^{*} d^{*}$ post } \\
\hline \multirow[t]{4}{*}{ Second births } & $\mathrm{B}$ & 0.08 & 0.01 & 0.58 & 0.18 & 0.08 & 0.56 \\
\hline & & 0.444 & 0.898 & 0.641 & 0.438 & 0.444 & 0.636 \\
\hline & G & $-3.06^{* * *}$ & $-3.06 * * *$ & $-3.00^{* * *}$ & $-3.13^{* * *}$ & $-3.06^{* * *}$ & $-3.38 * * *$ \\
\hline & & 0.485 & 0.485 & 0.589 & 0.44 & 0.485 & 0.86 \\
\hline \multirow[t]{6}{*}{ Third births } & BB & 0.72 & 0.65 & 0.07 & 0.84 & 0.72 & -1.79 \\
\hline & & 0.662 & 0.966 & 0.823 & 0.712 & 0.662 & 1.271 \\
\hline & BG & $-1.52^{* * *}$ & $-1.56^{* *}$ & $-1.45^{* *}$ & $-1.51^{* * *}$ & $-1.52^{* * *}$ & $-2.92 * * *$ \\
\hline & & 0.512 & 0.647 & 0.567 & 0.535 & 0.512 & 0.883 \\
\hline & GG & $-4.13^{* * *}$ & $-4.13^{* * *}$ & $-3.49 * *$ & $-4.26^{* * *}$ & $-4.13^{* * *}$ & $-5.35 * * *$ \\
\hline & & 1.227 & 1.227 & 1.349 & 0.656 & 1.227 & 1.318 \\
\hline \multirow[t]{8}{*}{ Fourth births } & BBB & 0.38 & 0.31 & 0.88 & 0.53 & 0.38 & 3.04 \\
\hline & & 1.017 & 1.312 & 1.389 & 1.215 & 1.017 & 1.876 \\
\hline & BBG & -0.08 & -0.13 & -0.67 & -0.03 & -0.08 & -2.02 \\
\hline & & 0.842 & 0.854 & 0.9 & 0.781 & 0.842 & 1.459 \\
\hline & BG G & $-2.76 * * *$ & $-2.78 * *$ & -1.14 & $-2.82 * * *$ & $-2.76^{* * *}$ & $-4.02 * * *$ \\
\hline & & 0.847 & 1.003 & 1.098 & 0.713 & 0.847 & 1.347 \\
\hline & GGG & $-4.39 * * *$ & $-4.39 * * *$ & $-4.00^{* * *}$ & $-4.55^{* * *}$ & $-4.39 * * *$ & $-4.15^{* *}$ \\
\hline & & 1.033 & 1.033 & 1.161 & 1.032 & 1.033 & 1.639 \\
\hline \multicolumn{8}{|l|}{ 0 ther covariates } \\
\hline \multirow{2}{*}{\multicolumn{2}{|c|}{ Preceding boy }} & & $\begin{array}{c}0.07 \\
0.567\end{array}$ & & & & \\
\hline & & 126,678 & 126,678 & 126,678 & 126,678 & 126,678 & 39,260 \\
\hline
\end{tabular}

N otes: See N otes to Table 8a. The baseline model is now ol. 6 in Table 3. C ol 6: Sample restricted to post2b (2001-5). 


\begin{tabular}{|c|c|c|c|}
\hline & $\begin{array}{c}\text { Ideal no. of } \\
\text { boys }\end{array}$ & $\begin{array}{l}\text { Ideal no. of } \\
\text { girls }\end{array}$ & $\begin{array}{c}\text { Ratio - } \\
\text { boys:girls }\end{array}$ \\
\hline \multicolumn{4}{|l|}{ By period } \\
\hline Period 1 & $\begin{array}{c}1.76 \\
(0.83)\end{array}$ & $\begin{array}{c}1.25 \\
(0.67)\end{array}$ & 1.41 \\
\hline Period 2 & $\begin{array}{c}1.66 \\
(0.78)\end{array}$ & $\begin{array}{c}1.20 \\
(0.62)\end{array}$ & 1.38 \\
\hline Period 3 & $\begin{array}{c}1.52 \\
(0.72)\end{array}$ & $\begin{array}{c}1.16 \\
(0.58)\end{array}$ & 1.31 \\
\hline \multicolumn{4}{|l|}{ By religion } \\
\hline Hindu & $\begin{array}{c}1.44 \\
(0.65)\end{array}$ & $\begin{array}{c}1.07 \\
(0.48)\end{array}$ & 1.35 \\
\hline Muslim & $\begin{array}{c}1.69 \\
(0.86)\end{array}$ & $\begin{array}{c}1.26 \\
(0.60)\end{array}$ & 1.35 \\
\hline \multicolumn{4}{|l|}{ By wealth } \\
\hline Low wealth & $\begin{array}{c}1.59 \\
(0.75)\end{array}$ & $\begin{array}{c}1.19 \\
(0.60)\end{array}$ & 1.34 \\
\hline High wealth & $\begin{array}{c}1.19 \\
(0.50)\end{array}$ & $\begin{array}{l}1.03 \\
(0.45)\end{array}$ & 1.16 \\
\hline \multicolumn{4}{|l|}{ By education } \\
\hline Low education & $\begin{array}{c}1.57 \\
(0.74)\end{array}$ & $\begin{array}{c}1.18 \\
(0.59)\end{array}$ & 1.33 \\
\hline High education & $\begin{array}{c}1.13 \\
(0.46)\end{array}$ & $\begin{array}{c}1.01 \\
(0.44)\end{array}$ & 1.13 \\
\hline
\end{tabular}

N otes: Statistics presented are sample means (first aggreegated across mothers) ex duding parents who state a preference for no dildren. Standard deviations presented below in parentheses. Figures for each period are averages for all mothers who gave birth to a child in that period. F or ex ample, if a mother has two dhildren in Period 1 and two in Period 2, her preference is induded as one observation in Period 1 and one observation in Period 2. 


\section{Appendix Figures}

A ppendix Figure 1: Third births (5-year moving average)
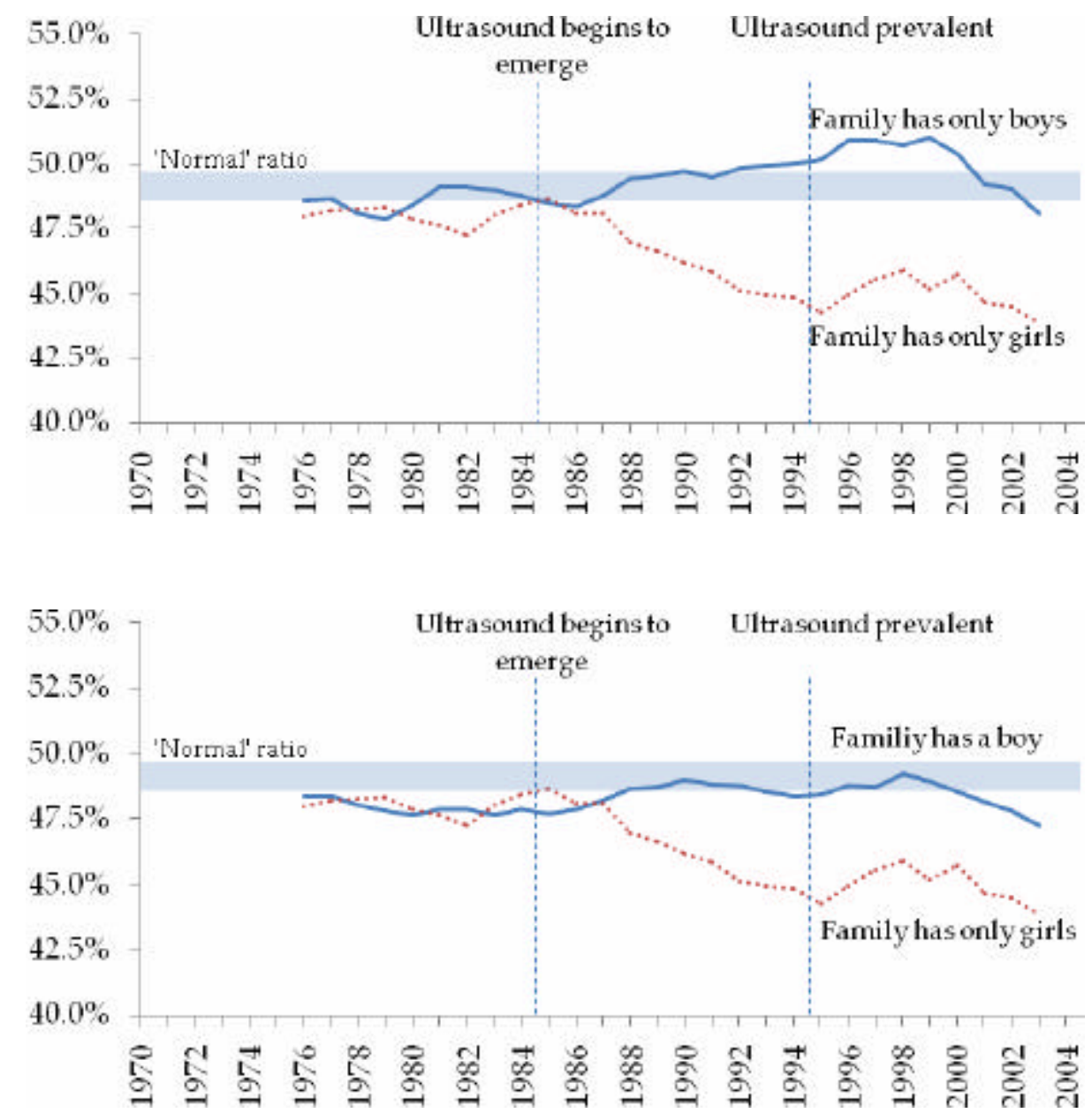
A ppendix Figure 2: F ourth births (5-year moving average)
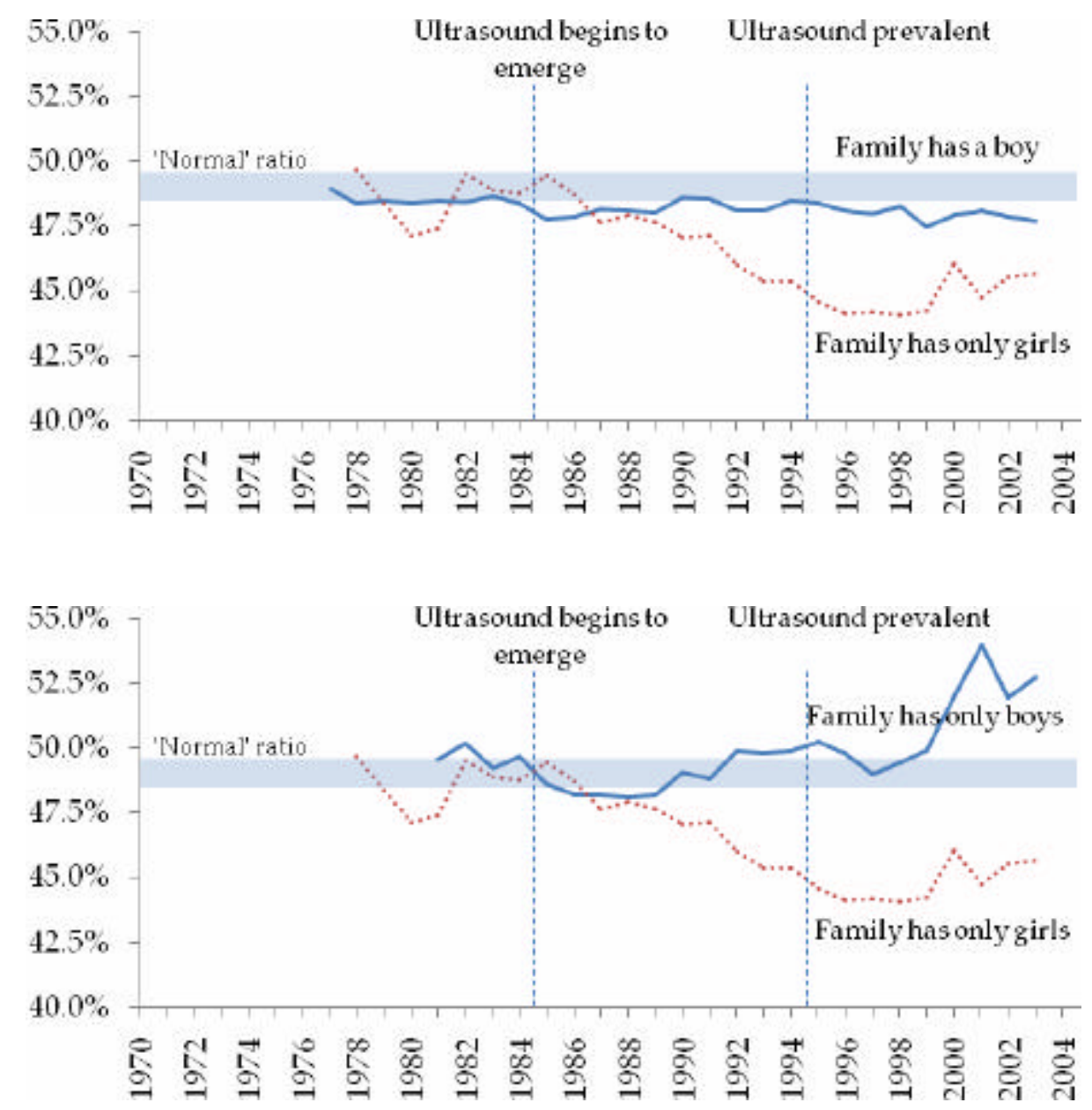


\section{Appendix Tables}

A ppendix Table 1: Triple difference model - birth order*sex composition of previous sibling** post-ultrasound

\begin{tabular}{|c|c|c|c|c|c|}
\hline \multirow{2}{*}{ Birth order } & \multirow{2}{*}{$\begin{array}{l}\text { Previous } \\
\text { births }\end{array}$} & \multicolumn{2}{|c|}{ Birth order explicit } & \multicolumn{2}{|c|}{ Birth order implicit } \\
\hline & & (1) & (2) & (3) & (4) \\
\hline Constant & - & $\begin{array}{c}47.58^{* * *} \\
(0.774)\end{array}$ & $\begin{array}{c}46.42^{* * *} \\
(0.769)\end{array}$ & $\begin{array}{c}47.58 * * * \\
(0.774)\end{array}$ & $\begin{array}{c}46.42^{* * *} \\
(0.769)\end{array}$ \\
\hline \multirow{2}{*}{\multicolumn{6}{|c|}{$\begin{array}{l}\text { Triple differeno: } Y^{*} d^{*} \text { post } \\
\text { Interadions with post1 (1985-1994) }\end{array}$}} \\
\hline & & & & & \\
\hline \multirow[t]{2}{*}{ Second births } & B & & & $\begin{array}{c}0.54 \\
(0.488)\end{array}$ & $\begin{array}{c}0.65 \\
(0.495)\end{array}$ \\
\hline & G & $\begin{array}{l}-1.52^{* *} \\
(0.600)\end{array}$ & $\begin{array}{l}-1.52^{* *} \\
(0.607)\end{array}$ & $\begin{array}{r}-0.99 * * \\
(0.394)\end{array}$ & $\begin{array}{c}-0.87 * * \\
(0.386)\end{array}$ \\
\hline \multirow[t]{3}{*}{ Third births } & BB & & & $\begin{array}{c}0.09 \\
(0.563)\end{array}$ & $\begin{array}{c}0.17 \\
(0.528)\end{array}$ \\
\hline & BG & $\begin{array}{c}-0.23 \\
(0.701)\end{array}$ & $\begin{array}{c}-0.08 \\
(0.698)\end{array}$ & $\begin{array}{c}-0.14 \\
(0.522)\end{array}$ & $\begin{array}{c}0.08 \\
(0.500)\end{array}$ \\
\hline & GG & $\begin{array}{l}-1.78^{*} \\
(0.987)\end{array}$ & $\begin{array}{l}-1.65 \\
(0.999)\end{array}$ & $\begin{array}{l}-1.69 * * \\
(0.734)\end{array}$ & $\begin{array}{l}-1.48^{*} \\
(0.746)\end{array}$ \\
\hline \multirow[t]{5}{*}{ Fourth births } & BBB & & & $\begin{array}{c}-0.31 \\
(1.125)\end{array}$ & $\begin{array}{c}-0.14 \\
(1.189)\end{array}$ \\
\hline & BBG & $\begin{array}{c}-0.72 \\
(1.486)\end{array}$ & $\begin{array}{c}-0.7 \\
(1.490)\end{array}$ & $\begin{array}{l}-1.03 \\
(0.730)\end{array}$ & $\begin{array}{c}-0.85 \\
(0.745)\end{array}$ \\
\hline & $\mathrm{BGG}$ & $\begin{array}{c}-0.4 \\
(1.274)\end{array}$ & $\begin{array}{c}-0.31 \\
(1.260)\end{array}$ & $\begin{array}{l}-0.71 \\
(0.699)\end{array}$ & $\begin{array}{l}-0.46 \\
(0.701)\end{array}$ \\
\hline & GGG & $\begin{array}{c}-2.37 \\
(1.579)\end{array}$ & $\begin{array}{c}-2.22 \\
(1.607)\end{array}$ & $\begin{array}{l}-2.67 * * \\
(1.034)\end{array}$ & $\begin{array}{l}-2.36 * * \\
(0.992)\end{array}$ \\
\hline & ost2 (1995-2 & & & & \\
\hline \multirow[t]{2}{*}{ Second births } & B & & & $\begin{array}{c}0.47 \\
(0.534)\end{array}$ & $\begin{array}{c}0.64 \\
(0.545)\end{array}$ \\
\hline & G & $\begin{array}{c}-3.93^{* * *} \\
(0.906)\end{array}$ & $\begin{array}{c}-3.89 * * * \\
(0.897)\end{array}$ & $\begin{array}{c}-3.46 * * * \\
(0.571)\end{array}$ & $\begin{array}{c}-3.25 * * * \\
(0.587)\end{array}$ \\
\hline \multirow[t]{3}{*}{ Third births } & BB & & & $\begin{array}{c}0.46 \\
(0.768)\end{array}$ & $\begin{array}{c}0.47 \\
(0.782)\end{array}$ \\
\hline & BG & $\begin{array}{l}-1.53^{*} \\
(0.846)\end{array}$ & $\begin{array}{c}-1.3 \\
(0.853)\end{array}$ & $\begin{array}{l}-1.07 * \\
(0.602)\end{array}$ & $\begin{array}{l}-0.83 \\
(0.600)\end{array}$ \\
\hline & GG & $\begin{array}{c}-4.33^{* * *} \\
(1.282)\end{array}$ & $\begin{array}{c}-4.05^{* * *} \\
(1.304)\end{array}$ & $\begin{array}{c}-3.86 * * * \\
(1.199)\end{array}$ & $\begin{array}{c}-3.58 * * * \\
(1.230)\end{array}$ \\
\hline \multirow[t]{4}{*}{ Fourth births } & BBB & & & $\begin{array}{c}0.14 \\
(1.078)\end{array}$ & $\begin{array}{c}0.19 \\
(1.216)\end{array}$ \\
\hline & BBG & $\begin{array}{c}-1.34 \\
(1.314)\end{array}$ & $\begin{array}{c}-1.09 \\
(1.383)\end{array}$ & $\begin{array}{l}-1.2 \\
(0.864)\end{array}$ & $\begin{array}{c}-0.9 \\
(0.926)\end{array}$ \\
\hline & $\mathrm{BGG}$ & $\begin{array}{c}-2.06 \\
(1.395)\end{array}$ & $\begin{array}{c}-1.91 \\
(1.393)\end{array}$ & $\begin{array}{l}-1.92^{* *} \\
(0.894)\end{array}$ & $\begin{array}{l}-1.72^{*} \\
(0.850)\end{array}$ \\
\hline & GGG & $\begin{array}{c}-5.55 * * * \\
(1.712)\end{array}$ & $\begin{array}{c}-5.19 * * * \\
(1.729)\end{array}$ & $\begin{array}{c}-5.41^{* * *} \\
(1.068)\end{array}$ & $\begin{array}{c}-5.00^{* * *} \\
(0.975)\end{array}$ \\
\hline
\end{tabular}




\begin{tabular}{|c|c|c|c|c|c|}
\hline \multirow{2}{*}{ Birth order } & \multirow{2}{*}{$\begin{array}{l}\text { Previous } \\
\text { births }\end{array}$} & \multicolumn{2}{|c|}{ Birth order explicit } & \multicolumn{2}{|c|}{ Birth order implicit } \\
\hline & & (1) & (2) & (3) & (4) \\
\hline \multicolumn{6}{|c|}{ T wo-way effects: $d^{*}$ post $\& Y^{*} d$} \\
\hline \multicolumn{2}{|c|}{ Post1 * Second birth } & 0.54 & 0.65 & & \\
\hline \multirow{2}{*}{\multicolumn{2}{|c|}{ Post1 * Third birth }} & 0.09 & 0.17 & & \\
\hline & & $(0.563)$ & $(0.528)$ & & \\
\hline \multirow{2}{*}{\multicolumn{2}{|c|}{ Post1 * Fourth birth }} & -0.31 & -0.14 & & \\
\hline & & (1.125) & (1.189) & & \\
\hline \multirow{2}{*}{\multicolumn{2}{|c|}{ Post2 * Second birth }} & 0.47 & 0.64 & & \\
\hline & & $(0.534)$ & $(0.545)$ & & \\
\hline \multirow{2}{*}{\multicolumn{2}{|c|}{ Post2 * Thind birth }} & 0.46 & 0.47 & & \\
\hline & & $(0.768)$ & $(0.782)$ & & \\
\hline \multirow{2}{*}{\multicolumn{2}{|c|}{ Post2 * Fourth birth }} & 0.14 & 0.19 & & \\
\hline & & (1.078) & $(1.216)$ & & \\
\hline \multirow[t]{4}{*}{ Second births } & B & & & -0.25 & -0.48 \\
\hline & & & & $(0.348)$ & $(0.350)$ \\
\hline & G & 0.78 & 0.74 & 0.53 & 0.26 \\
\hline & & $(0.466)$ & $(0.476)$ & $(0.374)$ & $(0.387)$ \\
\hline \multirow[t]{6}{*}{ Third births } & BB & & & 0.84 & 0.51 \\
\hline & & & & $(0.582)$ & $(0.566)$ \\
\hline & BG & -0.9 & -0.95 & -0.06 & -0.45 \\
\hline & & $(0.627)$ & $(0.629)$ & $(0.378)$ & $(0.394)$ \\
\hline & GG & -0.79 & -0.89 & 0.05 & -0.38 \\
\hline & & $(0.877)$ & $(0.889)$ & $(0.621)$ & $(0.647)$ \\
\hline \multirow[t]{8}{*}{ Fourth births } & $\mathrm{BBB}$ & & & 0.9 & 0.57 \\
\hline & & & & $(0.775)$ & $(0.843)$ \\
\hline & BBG & 0.72 & 0.62 & $1.62^{* * *}$ & $1.19 *$ \\
\hline & & (0.798) & (0.799) & (0.477) & (0.578) \\
\hline & BGG & -1.18 & -1.29 & -0.28 & -0.73 \\
\hline & & $(0.899)$ & $(0.875)$ & $(0.542)$ & $(0.578)$ \\
\hline & $\mathrm{GGG}$ & 0.45 & 0.3 & 1.35 & 0.87 \\
\hline & & $(0.965)$ & (0.969) & $(0.902)$ & $(0.911)$ \\
\hline \multicolumn{6}{|c|}{ One way effects: $d \&$ post } \\
\hline \multirow{2}{*}{\multicolumn{2}{|c|}{ Second birth }} & -0.25 & -0.48 & & \\
\hline & & $(0.348)$ & $(0.350)$ & & \\
\hline \multirow{2}{*}{\multicolumn{2}{|c|}{ Third birth }} & 0.84 & 0.51 & & \\
\hline & & $(0.582)$ & $(0.566)$ & & \\
\hline \multirow{2}{*}{\multicolumn{2}{|c|}{ Fourth birth }} & 0.9 & 0.57 & & \\
\hline & & $(0.775)$ & $(0.843)$ & & \\
\hline \multirow{2}{*}{\multicolumn{2}{|c|}{ Post1 }} & 0.84 & $1.72 *$ & 0.84 & $1.72 *$ \\
\hline & & $(0.784)$ & $(0.908)$ & $(0.784)$ & $(0.908)$ \\
\hline \multirow{2}{*}{\multicolumn{2}{|c|}{ Post2 }} & 0.99 & $2.35^{* *}$ & 0.99 & $2.35^{* *}$ \\
\hline & & $(0.856)$ & $(0.859)$ & $(0.856)$ & $(0.859)$ \\
\hline \multicolumn{2}{|l|}{ Y ear dummies } & Yes & Yes & Yes & Yes \\
\hline \multicolumn{2}{|l|}{ Covariates } & No & Yes & No & Yes \\
\hline \multicolumn{2}{|l|}{ Observations } & 528,061 & 521,290 & 528,061 & 521,290 \\
\hline
\end{tabular}

$\mathrm{N}$ otes: See notes to Table 2. These are estimates of equation (2a) in the text. The cefficients on birth order dummies and their interactions are ex pliait in ol. 1-2 which entails dropping one indicator of previous birth composition per birth order, which we choose to be the indicator denoting no previous female births. Birth order is impliat in ool. 3-4. The specifications with and without the birth order terms are equivalent. The year dummies, state dummies and state specific trends are each jointly significant at the $1 \%$ level. 
A ppendix Table 2: T riple difference model - Period-specific coefficients on birth order and sex composition of previous siblings

\begin{tabular}{|c|c|c|c|c|c|c|c|}
\hline \multirow{2}{*}{ Birth order } & \multirow{2}{*}{ Previous births } & \multicolumn{3}{|c|}{ Birth order explicit } & \multicolumn{3}{|c|}{ Birth order implicit } \\
\hline & & 1972-84 & $1985-94$ & $1995-2005$ & $1972-84$ & $1985-94$ & 1995-2005 \\
\hline Constant & - & $\begin{array}{c}47.58^{* * *} \\
(0.774)\end{array}$ & $\begin{array}{c}48.42^{* * *} \\
(0.472)\end{array}$ & $\begin{array}{c}48.57 * * * \\
(0.496)\end{array}$ & $\begin{array}{c}47.58^{* * *} \\
(0.774)\end{array}$ & $\begin{array}{c}48.42^{* * *} \\
(0.472)\end{array}$ & $\begin{array}{c}48.57^{* * *} \\
(0.496)\end{array}$ \\
\hline \multicolumn{8}{|c|}{ T riple difference: $Y * d^{*}$ post } \\
\hline \multirow[t]{2}{*}{ Second births } & B & & & & $\begin{array}{c}-0.25 \\
(0.348)\end{array}$ & $\begin{array}{c}0.28 \\
(0.324)\end{array}$ & $\begin{array}{c}0.22 \\
(0.429)\end{array}$ \\
\hline & G & $\begin{array}{c}0.78 \\
(0.466)\end{array}$ & $\begin{array}{c}-0.74 \\
(0.454)\end{array}$ & $\begin{array}{c}-3.15^{* * *} \\
(0.744)\end{array}$ & $\begin{array}{c}0.53 \\
(0.374)\end{array}$ & $\begin{array}{c}-0.46 \\
(0.365)\end{array}$ & $\begin{array}{c}-2.93 * * * \\
(0.449)\end{array}$ \\
\hline \multirow[t]{3}{*}{ Third births } & BB & & & & $\begin{array}{c}0.84 \\
(0.582)\end{array}$ & $\begin{array}{c}0.93^{*} \\
(0.505)\end{array}$ & $\begin{array}{c}1.30^{*} \\
(0.660)\end{array}$ \\
\hline & BG & $\begin{array}{c}-0.9 \\
(0.627)\end{array}$ & $\begin{array}{l}-1.13^{*} \\
(0.600)\end{array}$ & $\begin{array}{c}-2.43^{* * *} \\
(0.829)\end{array}$ & $\begin{array}{c}-0.06 \\
(0.378)\end{array}$ & $\begin{array}{c}-0.2 \\
(0.405)\end{array}$ & $\begin{array}{c}-1.13^{* * *} \\
(0.375)\end{array}$ \\
\hline & GG & $\begin{array}{c}-0.79 \\
(0.877)\end{array}$ & $\begin{array}{l}-2.57 * * \\
(0.987)\end{array}$ & $\begin{array}{c}-5.12^{* * *} \\
(1.264)\end{array}$ & $\begin{array}{c}0.05 \\
(0.621)\end{array}$ & $\begin{array}{l}-1.64^{* *} \\
(0.755)\end{array}$ & $\begin{array}{c}-3.82 * * * \\
(1.091)\end{array}$ \\
\hline \multirow[t]{4}{*}{ Fourth births } & BBB & & & & $\begin{array}{c}0.9 \\
(0.775)\end{array}$ & $\begin{array}{c}0.59 \\
(0.774)\end{array}$ & $\begin{array}{c}1.04 \\
(0.862)\end{array}$ \\
\hline & BBG & $\begin{array}{c}0.72 \\
(0.798)\end{array}$ & $\begin{array}{c}0 \\
(1.017)\end{array}$ & $\begin{array}{c}-0.61 \\
(1.168)\end{array}$ & $\begin{array}{c}1.62 * * * \\
(0.477)\end{array}$ & $\begin{array}{c}0.59 \\
(0.489)\end{array}$ & $\begin{array}{c}0.43 \\
(0.912)\end{array}$ \\
\hline & BGG & $\begin{array}{l}-1.18 \\
(0.899)\end{array}$ & $\begin{array}{c}-1.59 \\
(1.002)\end{array}$ & $\begin{array}{c}-3.24 * * * \\
(1.146)\end{array}$ & $\begin{array}{c}-0.28 \\
(0.542)\end{array}$ & $\begin{array}{l}-1.00^{*} \\
(0.492)\end{array}$ & $\begin{array}{c}-2.20 * * * \\
(0.690)\end{array}$ \\
\hline & GGG & $\begin{array}{c}0.45 \\
(0.965) \\
\end{array}$ & $\begin{array}{c}-1.91 \\
(1.235) \\
\end{array}$ & $\begin{array}{c}-5.10 * * * \\
(1.323)\end{array}$ & $\begin{array}{c}1.35 \\
(0.902) \\
\end{array}$ & $\begin{array}{c}-1.32 \\
(0.847)\end{array}$ & $\begin{array}{c}-4.06 * * * \\
(0.986)\end{array}$ \\
\hline \multicolumn{8}{|c|}{ Two-way effects: $d^{*}$ post } \\
\hline \multicolumn{2}{|c|}{ Second birth } & $\begin{array}{c}-0.25 \\
(0.348)\end{array}$ & $\begin{array}{c}0.28 \\
(0.324)\end{array}$ & $\begin{array}{c}0.22 \\
(0.429)\end{array}$ & & & \\
\hline \multicolumn{2}{|l|}{ Third birth } & $\begin{array}{c}0.84 \\
(0.582)\end{array}$ & $\begin{array}{c}0.93^{*} \\
(0.505)\end{array}$ & $\begin{array}{l}1.30 * \\
(0.660)\end{array}$ & & & \\
\hline \multicolumn{2}{|l|}{ Fourth birth } & $\begin{array}{c}0.9 \\
(0.775) \\
\end{array}$ & $\begin{array}{c}0.59 \\
(0.774) \\
\end{array}$ & $\begin{array}{c}1.04 \\
(0.862) \\
\end{array}$ & & & \\
\hline \multirow{3}{*}{\multicolumn{2}{|c|}{$\begin{array}{l}\text { Y ear dummies } \\
\text { Covariates } \\
\text { Observations }\end{array}$}} & Yes & Yes & Yes & Yes & Yes & Yes \\
\hline & & No & No & No & No & No & No \\
\hline & & 153,588 & 245,524 & 128,949 & 153,588 & 245,524 & 128,949 \\
\hline
\end{tabular}

$\mathrm{N}$ otes to A ppendix Table 2: See notes to Table 2. These are estimates of equation (3) in the tex t. The interactions with post are implicit - see notes to Table 3. In the left panel, dummy variables for birth order are ex plicitly incorporated. Since the coeficients are now period specific, these are effectively birth order trends. In the right panel, birth order is implicit. A ll columns indude year dummies, which are jointly significant at the 5\% level in oolumns 1,2, 4 and 5, and not significant at the 10\% level in oolumns 3 and 6 . 
A ppendix T able 3: T riple differenœ model - A llowing sequence of gender for a given sex composition to matter

\begin{tabular}{|c|c|c|c|c|}
\hline Birth order & Previous births & $1972-84$ & $1985-94$ & 1995-2005 \\
\hline First births & - & $\begin{array}{c}46.81 * * * \\
(0.810)\end{array}$ & $\begin{array}{c}47.48^{* * * *} \\
(0.397)\end{array}$ & $\begin{array}{c}49.57 * * * \\
(0.647)\end{array}$ \\
\hline \multicolumn{5}{|c|}{ Triple differenœ: $Y^{*} d^{*}$ post } \\
\hline \multirow[t]{2}{*}{ Second births } & B & $\begin{array}{c}-0.44 \\
(0.344)\end{array}$ & $\begin{array}{c}0.18 \\
(0.338)\end{array}$ & $\begin{array}{c}0.09 \\
(0.445)\end{array}$ \\
\hline & G & $\begin{array}{c}0.28 \\
(0.387)\end{array}$ & $\begin{array}{l}-0.61 * \\
(0.355)\end{array}$ & $\begin{array}{c}-3.05^{* * *} \\
(0.485)\end{array}$ \\
\hline \multirow[t]{5}{*}{ Third births } & BB & $\begin{array}{c}0.54 \\
(0.579)\end{array}$ & $\begin{array}{c}0.72 \\
(0.509)\end{array}$ & $\begin{array}{c}0.73 \\
(0.663)\end{array}$ \\
\hline & BG & 0.5 & -0.13 & $-1.32^{*}$ \\
\hline & & $(0.566)$ & (0.438) & $(0.708)$ \\
\hline & GB & $\begin{array}{r}-1.35^{* *} \\
(0.616)\end{array}$ & $\begin{array}{c}-0.53 \\
(0.559)\end{array}$ & $\begin{array}{c}-1.70^{* *} \\
(0.645)\end{array}$ \\
\hline & G G & $\begin{array}{l}-0.38 \\
(0.685)\end{array}$ & $\begin{array}{l}-1.85^{* *} \\
(0.774)\end{array}$ & $\begin{array}{c}-4.12 * * * \\
(1.227)\end{array}$ \\
\hline \multirow[t]{8}{*}{ Fourth births } & BBB & $\begin{array}{c}0.56 \\
(0.887)\end{array}$ & $\begin{array}{c}0.56 \\
(0.811)\end{array}$ & $\begin{array}{c}0.39 \\
(1.017)\end{array}$ \\
\hline & BBG & $\begin{array}{l}2.06^{* *} \\
(0.925)\end{array}$ & $\begin{array}{c}0.95 \\
(0.853)\end{array}$ & $\begin{array}{c}1.43 \\
(1.205)\end{array}$ \\
\hline & BG B & $\begin{array}{c}1.23 \\
(0.808)\end{array}$ & $\begin{array}{c}0.38 \\
(0.636)\end{array}$ & $\begin{array}{c}-1.63 \\
(1.366)\end{array}$ \\
\hline & GBB & $\begin{array}{c}0.18 \\
(0.778)\end{array}$ & $\begin{array}{c}0.08 \\
(0.785)\end{array}$ & $\begin{array}{c}0 \\
(1.225)\end{array}$ \\
\hline & BGG & $\begin{array}{c}0.86 \\
(0.945)\end{array}$ & $\begin{array}{l}-1.22 \\
(0.949)\end{array}$ & $\begin{array}{c}-4.08^{* * *} \\
(1.319)\end{array}$ \\
\hline & GBG & $\begin{array}{c}-0.75 \\
(0.923)\end{array}$ & $\begin{array}{c}-0.93 \\
(0.801)\end{array}$ & $\begin{array}{l}-3.42^{* *} \\
(1.303)\end{array}$ \\
\hline & G G B & $\begin{array}{c}-2.47^{* *} \\
(1003)\end{array}$ & $\begin{array}{l}-1.15^{*} \\
(0667)\end{array}$ & $\begin{array}{c}-0.88 \\
(1045)\end{array}$ \\
\hline & GGG & $\begin{array}{c}0.76 \\
(0.941)\end{array}$ & $\begin{array}{l}-1.42 \\
(0.846)\end{array}$ & $\begin{array}{c}-4.37 * * * \\
(1.036)\end{array}$ \\
\hline \multicolumn{2}{|l|}{ Year dummies } & Yes & Yes & Yes \\
\hline \multicolumn{2}{|l|}{ Covariates } & Yes & Yes & Yes \\
\hline \multicolumn{2}{|c|}{ Observations } & 152,181 & 242,431 & 126,678 \\
\hline \multicolumn{5}{|c|}{ p-values of F-tests: } \\
\hline \multicolumn{2}{|c|}{ Year dummies } & 0.23 & 0.00 & 0.06 \\
\hline \multicolumn{2}{|l|}{ State dummies } & 0.00 & 0.00 & 0.00 \\
\hline \multicolumn{2}{|l|}{ State trends } & 0.00 & 0.00 & 0.00 \\
\hline
\end{tabular}

$\mathrm{N}$ otes: See $\mathrm{N}$ otes to Table 2. These are estimates of equation (3) in the text. The interactions with post are impliait - see notes to Table 3. The speafication is equivalent to that in the right panel of Table 3, ex pect that within each birth order we distinguish the sequence of births for a given sex composition of births, for ex ample, BG is now distinct from $\mathrm{GB}$. 
A ppendix T able 3: Simulation of the number of sex selective abortions per year (representative year 1995-2005)

Panel A

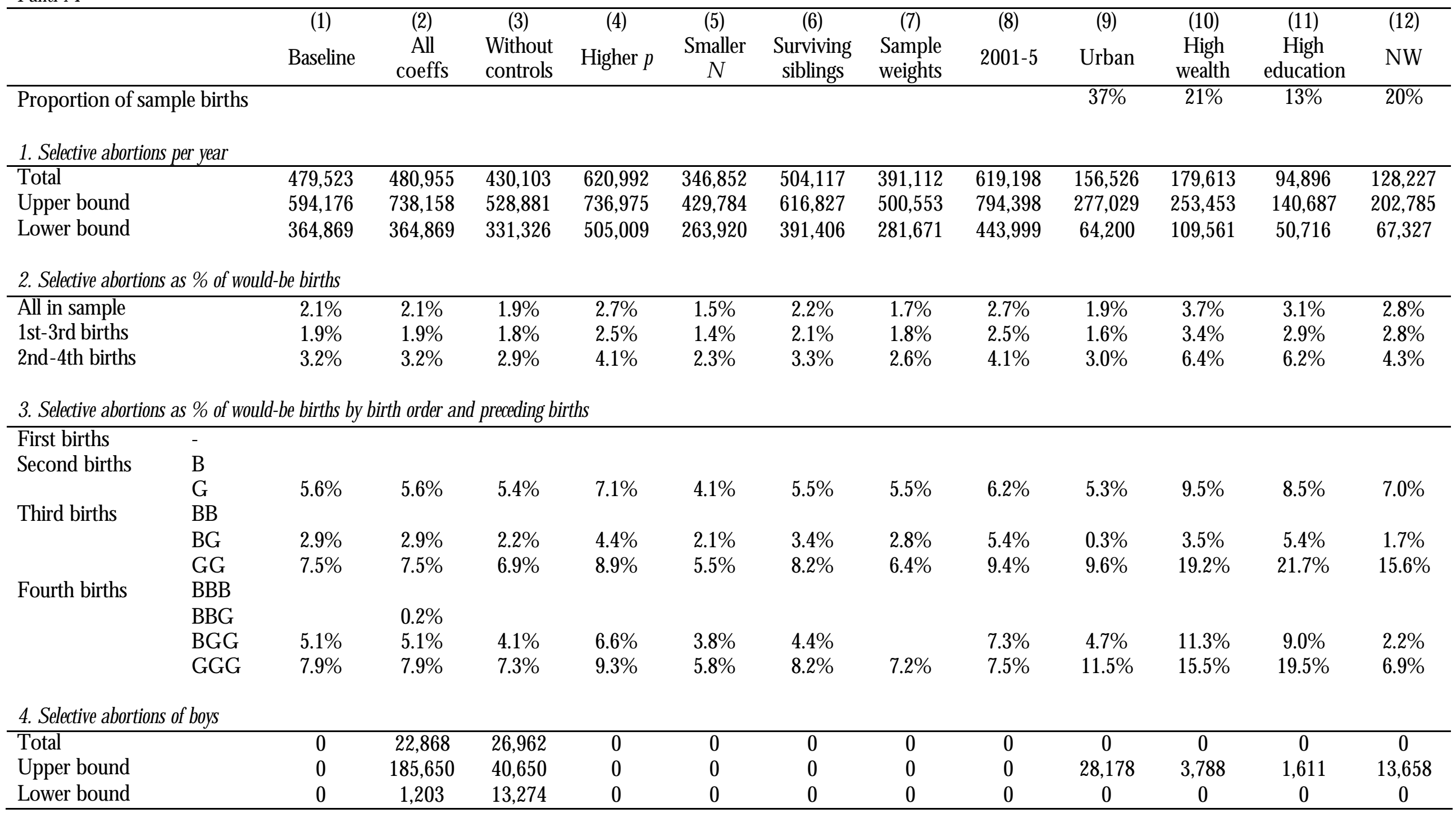


Panel B

\begin{tabular}{|c|c|c|c|c|c|c|c|c|c|c|c|c|c|}
\hline \multicolumn{2}{|c|}{$\begin{array}{l}\text { 1. Break down of selective } \\
\text { abortions by sub-group }\end{array}$} & Baseline & $\begin{array}{c}\text { All } \\
\text { coeffs }\end{array}$ & $\begin{array}{l}\text { Without } \\
\text { controls }\end{array}$ & Higher $\mathrm{p}$ & $\begin{array}{c}\text { Smaller } \\
\mathrm{N}\end{array}$ & $\begin{array}{c}\text { Surviving } \\
\text { siblings }\end{array}$ & $\begin{array}{l}\text { Sample } \\
\text { weights }\end{array}$ & $2001-5$ & Urban & $\begin{array}{c}\text { High } \\
\text { wealth }\end{array}$ & $\begin{array}{c}\text { High } \\
\text { education }\end{array}$ & NW \\
\hline \multirow{3}{*}{$\begin{array}{l}\text { First birtns } \\
\text { Second births }\end{array}$} & & & & & & & & & & & & & \\
\hline & B & & & & & & & & & & & & \\
\hline & G & $43.1 \%$ & $43.0 \%$ & $46.0 \%$ & $42.4 \%$ & $43.1 \%$ & $41.5 \%$ & $51.8 \%$ & $36.8 \%$ & $47.9 \%$ & $48.1 \%$ & $50.7 \%$ & $43.6 \%$ \\
\hline \multirow[t]{3}{*}{ Third births } & $\mathrm{BB}$ & & & & & & & & & & & & \\
\hline & BG & $14.1 \%$ & $14.1 \%$ & $11.7 \%$ & $16.8 \%$ & $14.1 \%$ & $16.1 \%$ & $16.5 \%$ & $21.0 \%$ & $1.4 \%$ & $6.5 \%$ & $7.2 \%$ & $5.9 \%$ \\
\hline & GG & $21.6 \%$ & $21.6 \%$ & $22.3 \%$ & $20.2 \%$ & $21.6 \%$ & $23.9 \%$ & $22.4 \%$ & $21.7 \%$ & $29.3 \%$ & $31.6 \%$ & $33.6 \%$ & $41.2 \%$ \\
\hline \multirow[t]{4}{*}{ Fourth births } & BBB & & & & & & & & & & & & \\
\hline & BBG & & $0.3 \%$ & & & & & & & & & & \\
\hline & BGG & $12.9 \%$ & $12.8 \%$ & $11.4 \%$ & $12.9 \%$ & $12.9 \%$ & $10.2 \%$ & & $14.5 \%$ & $10.3 \%$ & $7.7 \%$ & $3.3 \%$ & $3.5 \%$ \\
\hline & GGG & $8.3 \%$ & $8.3 \%$ & $8.6 \%$ & $7.7 \%$ & $8.3 \%$ & $8.3 \%$ & $9.3 \%$ & $6.1 \%$ & $11.1 \%$ & $6.2 \%$ & $5.2 \%$ & $5.7 \%$ \\
\hline \multicolumn{14}{|c|}{ 2. Births as $\%$ of all births } \\
\hline First births & - & $27.8 \%$ & $27.8 \%$ & $27.8 \%$ & $27.8 \%$ & $27.8 \%$ & $27.7 \%$ & $27.8 \%$ & $27.8 \%$ & $11.5 \%$ & $7.4 \%$ & $5.5 \%$ & $5.9 \%$ \\
\hline \multirow[t]{2}{*}{ Second births } & B & $12.8 \%$ & $12.8 \%$ & $12.8 \%$ & $12.8 \%$ & $12.8 \%$ & $13.5 \%$ & $12.8 \%$ & $12.8 \%$ & $5.0 \%$ & $3.0 \%$ & $1.9 \%$ & $2.7 \%$ \\
\hline & G & $12.5 \%$ & $12.5 \%$ & $12.5 \%$ & $12.5 \%$ & $12.5 \%$ & $13.4 \%$ & $12.5 \%$ & $12.5 \%$ & $4.9 \%$ & $3.0 \%$ & $1.9 \%$ & $2.7 \%$ \\
\hline \multirow[t]{3}{*}{ Third births } & $\mathrm{BB}$ & $3.8 \%$ & $3.8 \%$ & $3.8 \%$ & $3.8 \%$ & $3.8 \%$ & $3.9 \%$ & $3.8 \%$ & $3.8 \%$ & $1.3 \%$ & $0.5 \%$ & $0.2 \%$ & $0.6 \%$ \\
\hline & BG & $8.2 \%$ & $8.2 \%$ & $8.2 \%$ & $8.2 \%$ & $8.2 \%$ & $8.5 \%$ & $8.2 \%$ & $8.2 \%$ & $2.6 \%$ & $1.2 \%$ & $0.4 \%$ & $1.6 \%$ \\
\hline & GG & $4.7 \%$ & $4.7 \%$ & $4.7 \%$ & $4.7 \%$ & $4.7 \%$ & $5.0 \%$ & $4.7 \%$ & $4.7 \%$ & $1.6 \%$ & $0.9 \%$ & $0.4 \%$ & $1.0 \%$ \\
\hline \multirow[t]{4}{*}{ Fourth births } & BBB & $1.2 \%$ & $1.2 \%$ & $1.2 \%$ & $1.2 \%$ & $1.2 \%$ & $1.1 \%$ & $1.2 \%$ & $1.2 \%$ & $0.3 \%$ & $0.1 \%$ & $0.0 \%$ & $0.1 \%$ \\
\hline & BBG & $3.3 \%$ & $3.3 \%$ & $3.3 \%$ & $3.3 \%$ & $3.3 \%$ & $3.0 \%$ & $3.3 \%$ & $3.3 \%$ & $0.9 \%$ & $0.3 \%$ & $0.1 \%$ & $0.4 \%$ \\
\hline & BGG & $4.1 \%$ & $4.1 \%$ & $4.1 \%$ & $4.1 \%$ & $4.1 \%$ & $4.1 \%$ & $4.1 \%$ & $4.1 \%$ & $1.2 \%$ & $0.4 \%$ & $0.1 \%$ & $0.7 \%$ \\
\hline & GGG & $1.7 \%$ & $1.7 \%$ & $1.7 \%$ & $1.7 \%$ & $1.7 \%$ & $1.7 \%$ & $1.7 \%$ & $1.7 \%$ & $0.5 \%$ & $0.2 \%$ & $0.1 \%$ & $0.4 \%$ \\
\hline
\end{tabular}


Notes:

1. Simulation results presented only for sub-groups with consistent evidence of selective abortion. A sub-group is defined by the interaction of birth order and previous birth composition - e.g. "third births following a boy and a girl". Consistent evidence was judged on the basis of significant and robust coefficients, except in the column 'Unadjusted', which simply takes the point estimate for each sub-group at face value, regardless of its significance.

2. Upper and lower bounds calculated using $+/$ - one standard error for each sub-group.

3. Calculation formula defined as follows:

a. The number of selective abortions is calculated as: $\hat{N}\left(\frac{\hat{s} p}{1-\hat{s} p}\right)$, where $\hat{N}$ is the number of actual births, $\hat{s}$ is a parameter denoting the proportion of mothers who wish to selectively abort female foetuses, and p is the assumed 'natural' proportion of females. $p$ is assumed to be 48.8\%, consistent with international norms and evidence from first births, except for: the 'High p' variation, in which it is 49.4 .

b. The term $\hat{s} p$ represents the proportion of would-be births that are selectively aborted (i.e. the propensity to identify and abort female foetuses multiplied by the proportion of foetuses that are female).

c. The parameter $\hat{s}$ is calculated as: $\frac{p-\hat{p}}{p(1-\hat{p})}$, where $\hat{p}$ denotes the estimated proportion of females from the relevant model. The estimated proportion for each sub-group is calculated using coefficients on previous births, which we argue indicate selective abortion.

d. All calculations are carried out initially for each sub-group then aggregated based on the proportion of births in the sample falling in each subgroup.

4. Total number of births assumed to be 27.65m for a representative year from 1995-2005 based on United Nations Population Division estimates. Jha reports $28 \mathrm{~m}$ births in 1997 based on SRS data. All coefficients taken from models estimated over 1995-2005 except the '2001-5' variant, where they are taken from a model estimated over 2001-5.

5. Baseline model uses coefficients from a model with controls. 'All coeffs' variant includes estimates of $\hat{p}$ for each sub-group, including those with insignificant coefficients (i.e. no significant evidence of selective abortion). Estimates from a model without controls are presented in the column 'Without controls'. 'Higher p' variant uses $49.4 \%$ for the 'natural' proportion of females. 'Smaller N' variant uses $20 \mathrm{~m}$ as the number of births, based on the 2001 Census population estimate as reported by Bhaksar \& Gupta. 'Surviving siblings' variant includes composition dummies for previous births, based only on children that survived to the date of conception of the index child. 'Sample weights' variant uses sample weights. 'Urban', 'High wealth', 'High education' and 'NW' use the relevant interaction terms from the appropriate model. E.g. for 'High wealth' the coefficients used are the interactions of previous birth composition with a dummy for the top $20 \%$ of households by wealth.

6. Total number of births of $26.75 \mathrm{~m}$ adjusted down to $22.1 \mathrm{~m}$ (16.0m in the 'Higher N' variant; $22.6 \mathrm{~m}$ in the 'Surviving siblings' variant) to account for sample restrictions, including the exclusion of fifth and higher order births, twin births, etc. 
A ppendix Table 4: Comparison of simulations of the number of sex selective abortions per year

\begin{tabular}{|c|c|c|c|c|c|c|c|c|c|}
\hline & $\begin{array}{c}\text { (1) } \\
\text { Our core } \\
\text { estimate }\end{array}$ & $\begin{array}{c}\text { (2) } \\
\text { Jha (i) }\end{array}$ & $\begin{array}{c}\text { (3) } \\
\text { Jha (ii) }\end{array}$ & $\begin{array}{c}(4) \\
\text { Arnold et } \\
\text { al }\end{array}$ & $\begin{array}{c}\text { (5) } \\
\text { Bhaksar \& } \\
\text { Gupta }\end{array}$ & $\begin{array}{c}\text { (6) } \\
\text { Abrevaya }\end{array}$ & $\begin{array}{c}\text { (7) } \\
\text { Dubuc \& } \\
\text { Coleman }\end{array}$ & $\begin{array}{c}(8) \\
\text { Meng }\end{array}$ & $\begin{array}{c}\text { (9) } \\
\text { Ebenstein }\end{array}$ \\
\hline Population & India & India & India & India & India & US Indians & $\begin{array}{c}\text { UK } \\
\text { Indians }\end{array}$ & China & China \\
\hline $\begin{array}{l}\text { Total births/ year } \\
\text { Selective abortions per year } \\
\text { Selective abortions as \% potential births } \\
\text { Selective abortions of boys } \\
\text { Natural p (assumed) } \\
\text { Actual p }\end{array}$ & $\begin{array}{l}27.7 \mathrm{~m} \\
0.48 \mathrm{~m} \\
2.1 \% \\
0.00 \mathrm{~m} \\
48.8 \% \\
47.9 \%\end{array}$ & $\begin{array}{l}28.0 \mathrm{~m} \\
0.47 \mathrm{~m} \\
2.1 \%\end{array}$ & $\begin{array}{l}27.7 \mathrm{~m} \\
1.00 \mathrm{~m} \\
4.7 \% \\
0.39 \mathrm{~m} \\
48.8 \% \\
46.9 \%\end{array}$ & $\begin{array}{l}25.9 \mathrm{~m} \\
0.11 \mathrm{~m} \\
0.4 \% \\
\\
48.8 \% \\
48.6 \%\end{array}$ & $\begin{array}{l}20.0 \mathrm{~m} \\
0.37 \mathrm{~m} \\
1.8 \% \\
48.6 \% \\
47.6 \%\end{array}$ & $\begin{array}{c}0.256 \mathrm{~m} \\
0.002 \mathrm{~m} \\
0.6 \%\end{array}$ & $\begin{array}{c}0.138 \mathrm{~m} \\
0.001 \mathrm{~m} \\
1.1 \%\end{array}$ & $\begin{array}{l}48.7 \% \\
48.0 \%\end{array}$ & $\begin{array}{l}236.5 \mathrm{~m} \\
8.8 \mathrm{~m} \\
3.6 \% \\
\\
48.6 \% \\
46.7 \%\end{array}$ \\
\hline \multicolumn{10}{|l|}{ Selective abortions as \% potential births } \\
\hline $\begin{array}{l}\text { First births } \\
\text { Second births } \\
\text { Third births } \\
\text { Fourth births }\end{array}$ & $\begin{array}{l}0.0 \% \\
2.9 \% \\
3.6 \% \\
3.4 \%\end{array}$ & $\begin{array}{l}1.0 \% \\
2.7 \% \\
2.5 \% \\
0.5 \%\end{array}$ & $\begin{array}{l}4.2 \% \\
5.2 \% \\
4.8 \%\end{array}$ & & & $\begin{array}{l}0.0 \% \\
0.0 \% \\
5.1 \% \\
3.6 \%\end{array}$ & & $\begin{array}{l}0.0 \% \\
2.5 \% \\
4.5 \%\end{array}$ & \\
\hline
\end{tabular}

$\mathrm{N}$ otes: The number of potential female births is calculated as the number of actual female births plus the estimated number of selective abortions. C olumn 'Jha (i)' displays Jha's reported estimates.

Column 'Jha (ii)' displays the estimates resulting from applying our simulation approach to Jha's statistical results. B hak sar \& G upta's estimate recognised by the authors as a crude calculation based simply on census data. A brevaya's estimates based on significant evidenoe of selective abortion for 3rd and 4th births only. Break down of selective abortions by birth order not available for olumns 4, 5,

7 and 9. Birth figures for olumns 6, 7 and 9 are total births over the period indicated, not births per year. 
A ppendix T able 5: Sample means for all variables used

\begin{tabular}{lcccc}
\hline & $1972-84$ & $1985-94$ & $1995-2005$ & All periods \\
\hline Child is female & 47.9 & 48.2 & 48.0 & 48.0 \\
First born in family is a girl & 33.2 & 36.6 & 36.8 & 34.8 \\
Family has no living son & 18.4 & 19.8 & 20.9 & 19.4 \\
Family has at least two living sons & 21.1 & 22.1 & 20.2 & 20.7 \\
First birth & & & & \\
Second birth & 31.5 & 27.9 & 29.2 & 30.4 \\
B & 25.1 & 25.0 & 26.6 & 25.5 \\
G & 13.2 & 12.9 & 13.4 & 13.2 \\
Third birth & 11.9 & 12.1 & 13.1 & 12.3 \\
BB & 18.0 & 18.6 & 17.6 & 18.0 \\
BG & 4.9 & 4.7 & 4.0 & 4.6 \\
G G & 8.9 & 9.2 & 8.7 & 8.8 \\
Fourth birth & 4.3 & 4.8 & 4.9 & 4.6 \\
BBB & 11.5 & 12.1 & 10.8 & 11.3 \\
BBG & 1.6 & 1.5 & 1.2 & 1.4 \\
BG G & 4.2 & 4.0 & 3.5 & 3.9 \\
GG G & 4.3 & 4.8 & 4.3 & 4.4 \\
Fifth or more birth & 1.5 & 1.8 & 1.8 & 1.6 \\
Top 20\% by wealth & 7.1 & 9.1 & 9.1 & 8.0 \\
Secondary or higher education & 21.9 & 18.7 & 18.6 & 20.0 \\
Secondary or higher education (father) & 4.2 & 6.5 & 11.3 & 6.4 \\
Urban & 15.2 & 16.5 & 17.0 & 15.8 \\
West group of states & 31.1 & 31.0 & 34.9 & 31.7 \\
Hindu & 21.9 & 21.0 & 18.8 & 20.8 \\
High caste Hindu & 77.4 & 74.3 & 70.2 & 74.8 \\
Muslim & 43.7 & 33.5 & 20.6 & 35.5 \\
Other religion & 12.3 & 14.2 & 15.9 & 13.7 \\
Mother had recent u/ sound scan & 10.3 & 11.5 & 13.9 & 11.5 \\
Mothers bom 1942-53 & 0.2 & 2.3 & 18.9 & 7.1 \\
Mothers bom 1954-79 & & & & \\
Mothers bom 1980-87 & 30.8 & 3.4 & 0.1 & 17.1 \\
Mothers aged 12-15 & 69.2 & 96.5 & 79.1 & 78.5 \\
Mothers aged 16-18 & 0.0 & 0.1 & 20.8 & 4.4 \\
Mothers aged 19-24 & 5.1 & 3.5 & 1.9 & 4.2 \\
Mothers aged 25-30 & 17.7 & 14.1 & 11.3 & 15.7 \\
Mothers aged 31-49 & 47.8 & 45.3 & 45.3 & 46.4 \\
& 23.5 & 26.8 & 28.7 & 25.0 \\
& 5.9 & 10.3 & 12.8 & 8.8 \\
\hline
\end{tabular}




\begin{tabular}{lcccc}
\hline & $1972-84$ & $1985-94$ & $1995-2005$ & All periods \\
\hline Andhra Pradesh & 4.6 & 4.2 & 4.2 & 4.5 \\
Assam & 3.6 & 3.6 & 3.3 & 3.5 \\
Bihar & 6.9 & 7.7 & 7.7 & 7.4 \\
G oa & 2.4 & 1.6 & 1.6 & 2.0 \\
Gujarat & 4.3 & 3.7 & 3.2 & 3.8 \\
Haryana & 3.1 & 3.2 & 2.5 & 3.0 \\
Himachal Pradesh & 3.2 & 2.7 & 2.2 & 2.8 \\
Jammu \& Kashmir & 3.0 & 3.1 & 2.7 & 3.0 \\
Karnataka & 4.9 & 4.4 & 4.1 & 4.6 \\
Kerala & 3.5 & 2.4 & 2.0 & 2.8 \\
Madhya Pradesh & 8.1 & 8.4 & 8.9 & 8.3 \\
Maharashtra & 5.2 & 5.3 & 5.8 & 5.4 \\
Manipur & 1.6 & 1.9 & 3.3 & 2.0 \\
Meghalaya & 1.1 & 1.5 & 2.1 & 1.5 \\
Mizoram & 1.1 & 1.3 & 1.7 & 1.3 \\
Nagaland & 1.3 & 1.8 & 3.4 & 1.9 \\
Orissa & 4.6 & 4.5 & 3.8 & 4.4 \\
Punjab & 3.2 & 3.1 & 2.5 & 3.0 \\
Rajasthan & 6.6 & 6.5 & 5.3 & 6.2 \\
Sikkim & 0.5 & 0.9 & 1.4 & 0.8 \\
Tamil Nadu & 4.4 & 3.6 & 3.7 & 4.0 \\
West Bengal & 4.9 & 4.4 & 4.2 & 4.6 \\
Uttar Pradesh & 13.0 & 14.2 & 15.0 & 13.9 \\
New D elhi & 2.9 & 3.0 & 2.5 & 2.8 \\
Arunachal Pradesh & 0.9 & 1.4 & 1.7 & 1.3 \\
Tripura & 1.2 & 1.3 & 1.2 & 1.2 \\
\hline N & & & &
\end{tabular}

$\mathrm{N}$ otes: A ll figures in percentages. 


\section{O nline Appendix: Bhalotra and Cochrane}

\section{The legal, technological and economic setting}

While son preference has characterized parts of Indian society for centuries, the availability of affordable prenatal sex diagnostic techniques combined with legal access to abortion is more recent. The latter was in place by 1972 but the former only really emerged after 1980, becoming evident by 1985 and widespread by 1995. Abortion was legalised in India with the passage of the Medical Termination of Pregnancy Act in 1971, effective in most states in 1972. The Act specifies the reasons for which an abortion can be legally performed and requires that it be performed by a registered medical practitioner in medical facilities approved for the conduct of abortions. Abortion is legal if the pregnancy that it terminates endangers the woman's life, causes grave injury to her physical or mental health, is a result of rape or contraceptive failure (the latter applies only to married women), or is likely to result in the birth of a child suffering from serious physical or mental abnormalities. Approval is required from two medical practitioners for abortions taking place after 12 weeks of gestation (Arnold et al. 2006). The stated purpose of the Act was to provide women with safe medical services for the termination of pregnancy, although it has been argued that the political motivation was population control (Phadke 1998). More illegal than legal abortions are being performed in India, often to avoid the terms of the law or because of a shortage of approved facilities (Jesani and Iyer 1995). Government statistics estimate legal abortions at about 0.6 million p.a. (Ministry of Health and Family Welfare 1996) and illegal abortions are estimated to be 8 to 11 times as high as legal abortions (ICMR 1989, Chhabra 1996, Jesani and Iyer 1995). Using self-reported survey data on abortion from the data source that we analyse in this paper, Arnold et al. (2002) show an increase between the early and the late 1990s in the proportion of pregnancies ending in induced abortion. The problems of self-reporting aside, it is difficult to detect whether induced abortions are being used to limit fertility or to balance the sex composition of births but the trend is consistent with the rapid diffusion of ultrasound in the 1990s.

Sex determination of the foetus first became possible in India with the advent of amniocentesis in the 1970s. This technology was introduced to detect genetic abnormalities but began to be used as a way of determining the sex of a foetus. As early as 1976, the government banned the use of these tests for sex determination in government facilities (Arnold et al. 2006). The private sector remained unregulated but widespread use was limited by the high direct cost and the invasiveness of amniocentesis. In the early 1980s, ultrasound scans emerged and spread rapidly and improvements in technology over the course of the period made it easier to detect sex earlier in pregnancy. D emand proliferated as a result of the technology being non-invasive and widely affordable at about \$10-20 for a scan (Arnold et al. 2002). The cost of an abortion in a private clinic is, in rural Maharashtra, \$10 in the first and \$30 in the second trimester (Ganatra and Hirve 2002; D uggal suggests much higher costs in general). These may be significant costs in a country where many live under the $\$ 1.25$ a day line. The costs cumulate if repeated scans and abortions are needed before a boy is conceived and vary with distance of the household from the clinic and with the safety of the procedures. Clinics and portable facilities have mushroomed, advertising availability of ultrasound with slogans such as that the cost of a scan is much lower than the future costs of dowry. Section 2 of the text documents the time profile of ultrasound arrival and diffusion.

Academic opinion on the emergence of sex selective abortion is mixed. It has been argued that the prenatal elimination of girls is preferable to infanticide or ill treatment after birth (Kumar 1983, Goodkind 1996, 1999). Feminists have been divided by the seeming contradiction of supporting a woman's right to abortion while opposing sex-selective abortion (Kumar 1983, Gangoli 1998). Since the late 1980s, sex-selection has become the dominant concern amongst women's and human rights NGOs. Their campaigns led to the central government passing the 
Prenatal Sex Diagnostic Techniques (Regulation and Prevention of Misuse) Act (PNDT) in 1994. This became fully effective throughout India on 1 January 1996. The PNDT made it illegal to use prenatal sex diagnostic techniques (like ultrasound) to reveal the sex of a foetus. Following the revelation in the 2001 census of a continuing deterioration in the sex ratio, the PNDT was strengthened by a 2002 Amendment (effective 2003) incorporating a ban on advertising prenatal sex determination and increased penalties for violations. More detail on the PNDT is in Retherford and Roy (2003), Visaria (2005). The current consensus is that these regulations have made little difference (Visaria 2005). ${ }^{31}$ They are difficult to enforce because ultrasound scans (or alternatives like amniocentesis) are used for medical purposes and in routine prenatal care, making it easy to cover up sex determination as a motive. There appear to be enough families that seek sex-selection and enough doctors that are willing to cooperate in this for profit. India is witnessing increasing privatisation of health provision. Private medical colleges that award degrees on dubious grounds in exchange for high fees are proliferating, often with investments made by local politicians (G eorge 2010). Activists in India have described the phenomenon as gendercide (genocide of girls; this is also the title of the lead article in the Economist Magazine March 2010) and referred to the ultrasound scanner as a weapon of mass destruction.

\section{Relevant changes in the economy and demography}

The growth in income and the decline in poverty in India since the early 1980s is widely documented (e.g. Basu and Maertens 2007, D eaton and D reze 2002). School enrolment grew and gender and caste inequalities in educational narrowed (Bhalotra 2009). Fertility decline set in from 1981 (Bhalotra and van Soest 2008). Together with declining neonatal mortality rates (authors' estimates), these changes indicate trend improvement in the foetal environment. There are no systematic time series data on maternal health in India and different indicators have probably progressed at different rates over the period. Maternal mortality is estimated to have declined (Rajan et al. 1992, Bhat 2002) and maternal age at birth has risen (author's calculations, NFHS data). The incidence of anemia amongst women increased in the 1990s and average BMI showed a rise, a mixed blessing that represented declining rates of under-nutrition in rural areas and rising rates of obesity in urban areas. (NFHS3 report). Women's height improved for birth cohorts 1950-65 (who were giving birth around 1970-85) but stagnated after (Bhalotra 2007).

\section{N otation and conceptual framework linking sex selective abortion to the sex ratio}

If a woman decides to perform an ultrasound test in order to determine the sex of her foetus, we assume that she will carry the foetus to term if it is male and abort the foetus if the test shows it is female. If we denote the joint probability of these three decisions as $\hat{s}$ and the natural proportion of female births as $p$ then, other things equal, the probability of a live birth is given by:

(1) $\operatorname{Pr}($ livebirth $)=1-\hat{s} \cdot p$

and the probability of a female (live) birth by:

(2) $\operatorname{Pr}($ female $)=p(1-\hat{s})$

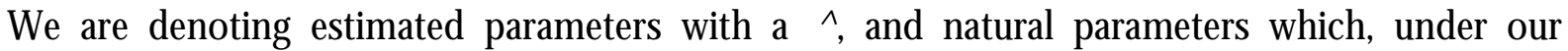
hypothesis, are not directly observed with unadjusted lower case letters. Note that $\hat{s}$ represents the average willingness to conduct selective abortion, and the term $\hat{s} . p$ in (1) represents the

31 The Chinese government has also attempted to regulate prenatal sex selection, see, for example, Greenlaugh and Li (1995). 
proportion of would-be births that are aborted. ${ }^{32}$ We can derive an expression for the observed proportion of female births in all live births as:

$$
\text { (3) } \hat{p}=\frac{\operatorname{Pr}(\text { female })}{\operatorname{Pr}(\text { livebirth })}=\frac{p(1-\hat{s})}{1-\hat{s} \cdot p}
$$

which can also be rearranged to gives as a function of $\mathrm{p}$ and $\hat{p}$ :

(4) $\hat{s}=\frac{p-\hat{p}}{p(1-\hat{p})}$

In the text we elaborate a strategy for identifying the key parameter of interest, $\hat{s}$ by focusing on systematic differences in $\hat{p}$ across cohorts and across families, which we argue represent deviations from $\mathrm{p}$ that can only be accounted for by sex selective abortion.

\section{The trend in the sex ratio of first births}

We investigated the increasing feminization of first births by estimating birth-order specific trends in the sex ratio at birth for seven other arbitrarily picked countries for which surveys of similar design to the Indian survey are available (see www.measuredhs.com). In five of the seven other countries, first births exhibit a positive trend (Pakistan, Bangladesh, Bolivia, Nigeria, E thiopia), in one it is insignificant (Nepal) and in one other it is negative (Mexico). In none of these seven developing countries analysed does the sex ratio at birth orders two to four exhibit a trend. Many richer countries exhibit a positive overall trend in the proportion of females at birth. ${ }^{33}$ Explanations for this include environmental and physiological factors, for example, contaminant exposure or age at birth (James 1998, D avis et al. 1998, Rostron and James 1977, Vartiainen et al. 1999). If these factors are at play in India, they will have created similar downward pressure on the sex ratio $(\mathrm{m} / \mathrm{f})$ for higher order births. This suggests that the aggregate rise in the sex ratio in India is probably under-estimated by the observed trend. The true rise is the sum of the opposing trends for first and higher order births. This is relevant to the popular discussions of the aggregate rise. However, in our analysis, environmental and physiological forces are differenced out in the comparison of families with different sex composition histories. These findings suggest that (a) the feminization of first-order births in India is in line with similar trends in other richer and poorer countries and (b) the increasing maleness of higher order births in India is unique in the set of countries studied and plausibly a function of sex selection.

It is striking that Pakistan and Bangladesh which, until 1947, shared a history with India, show no significantly negative trend in the proportion of females born at any order. The populations of these countries are predominantly Muslim while only about $14 \%$ of India's population is Muslim. The Muslim religion condemns abortion more strongly than the Hindu religion. This is confirmed on the India sample by interacting the treatment variable with religion (see section 5); Muslims in India show no significant tendency to conduct sex selection and the Hindu-Muslim difference in the coefficients $\beta$ is increasing in birth order, consistent with the stronger preference for lower fertility amongst Hindus.

We investigated whether the positive trend in first births in India might be an artefact of the data structure. It has been argued that female births are under-reported relative to male births in son preferring societies (Bhat 2006). If the relative under-reporting of females is increasing in

\footnotetext{
32 We use the term 'would-be births' to denote the number of births that would have been observed had there been no selective abortions, other influences on foetal mortality being constant.

33 For e.g. England and Wales (D ubuc and Coleman 2007), the USA (Norberg 2007), Canada (Allan et al. 1997), D enmark (Møller 1996) and the Netherlands (van der Pal-de Bruin et al. 1997).
} 
the retrospective window this could show as a (spurious) trend in the share of female births. In principle this applies to all births not just first births but for higher order births it may be overwhelmed by an opposing trend created by sex selection. This explanation is undermined by the appearance of positive first-birth trends in African and Latin American countries which are not son preferring societies.

\section{References}

Allan, BB., Rollin B, Judy ES., and John FJ. (1997). Declining Sex Ratios in

Canada.' Canadian M edication A ssodiation Journal, Vol. 156 Issue. 1: 37- 41.

D avis, Devra Lee, Michelle B. Gottlieb, and Julie R. Stampnitzky. (1998). "Reduced Ratio of Male to Female Births in Several Industrial Countries: A Sentinel Health Indicator?" Journal of the A merican M edical A ssociation, Vol. 279, Issue 13: 1018- 23.

Møller H. (1996). 'Change in Male:Female Ratio am ong Newborn Infants in D enmark.' L anœt, Vol. 348, Issue 9030: 828- 29.

van der Pal-de Bruin, K. M., S. P. Verloove-Vanhorick, and N. Roeleveld. (1997). 'Change in Male:Female Ratio among Newborn Babies in Netherlands.' L ancet, Vol. 349, Issue 9044: 62. 